\title{
Investigations on cytosolic nucleic acid fragment induced innate immune functions of keratinocytes
}

\author{
Judit Danis
}

$\mathrm{PhD}$ Thesis

Supervisor:

Prof. Dr. Márta Széll

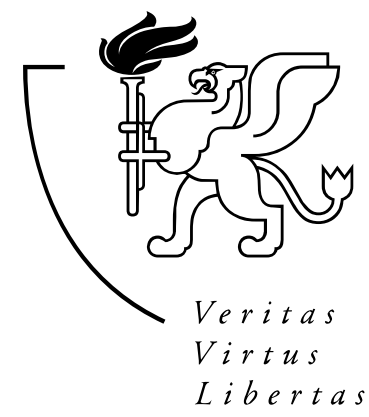

University of Szeged

Faculty of Medicine

Department of Dermatology and Allergology

Doctoral School of Clinical Medicine

Szeged

2018 


\section{List of publications}

\section{Scientific papers included in this thesis}

I. J. Danis, L. Janovák, B. Gubán, A. Göblös, K. Szabó, L. Kemény, Z. Bata-Csörgő, M. Széll: Differential Inflammatory-Response Kinetics of Human Keratinocytes upon Cytosolic RNA- and DNA-Fragment Induction, Int J Mol Sci 19(3):774 (2018)

IF:3.226*

II. J. Danis, A. Göblös, Z. Bata-Csörgő, L. Kemény, M. Széll: PRINS Non-Coding RNA Regulates Nucleic Acid-Induced Innate Immune Responses of Human Keratinocytes, Front Immunol 8:1053 (2017)

\section{IF:6.429*}

(Independent citation: 0 Self citation: 1 Cumulative: 1)

III. M. Széll, J. Danis, Z. Bata-Csörgő, L. Kemény: PRINS, a primate-specific long noncoding RNA, plays a role in the keratinocyte stress response and psoriasis pathogenesis, Pflug Arch Eur J Phys 468(6), p. 935-943 (2016) [Invited Review]

\section{IF:3.156}

(Independent citation: 6 Self citation: 1 Cumulative: 7)

\section{Publications not directly related to the thesis}

IV. J. Danis, M. Széll: Functional relevance of pyknons in tumor formation, Non-coding RNA Investig 2:3 (2018) [Invited Editorial]

V. J. Danis, M. Széll: VELUCT, a long non-coding RNA with an important cellular function despite low abundance, J Thorac Dis 9(10):3638-3640 (2017) [Invited Editorial]

VI. A. Göblös, J. Danis, K. Vas, Z. Bata-Csörgő, L. Kemény, M. Széll: Keratinocytes express functional CARD18, a negative regulator of inflammasome activation, and its altered expression in psoriasis may contribute to disease pathogenesis, Mol Immunol 73, p. 10-18. (2016)

\section{IF:3.236}

(Independent citation: 3 Self citation: 2 Cumulative: 5)

VII. Danis J., Forczek E., Bari F.: A telemedicina alkalmazása a bőrgyógyászatban: a teledermatológia [Telemedicine in dermatological practice: teledermatology] Orv Hetil 157:(10) pp. 363-369. (2016)

\section{IF:0.349}

(Independent citation: 0 Self citation: 1 Cumulative: 1)

VIII. J. Danis, T. Turányi: Sensitivity Analysis of Bacterial Chemotaxis Models, Procedia Computer Science 7 p.233-234. (2011)

(Independent citation: 1 Self citation: 1 Cumulative: 2) 


\section{Tartalomjegyzék}

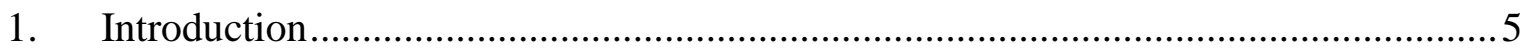

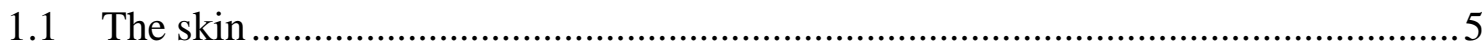

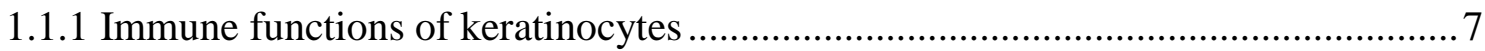

1.1.2 Nucleic acid fragment induced immune responses in keratinocytes...................... 7

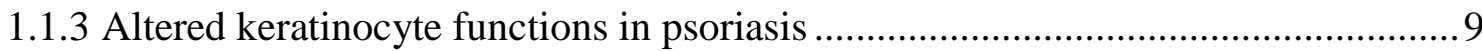

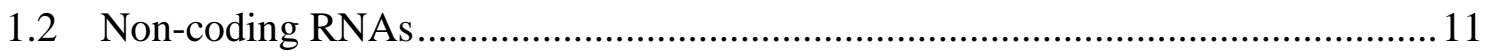

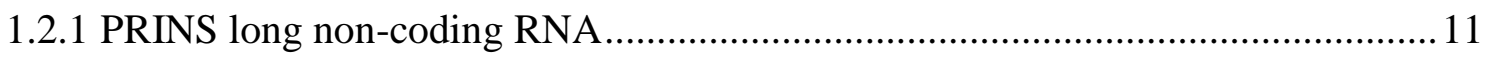

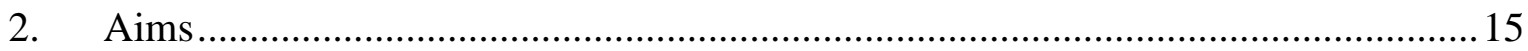

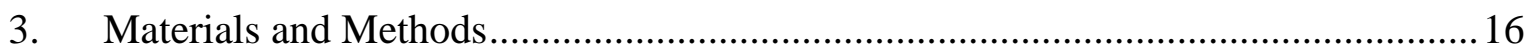

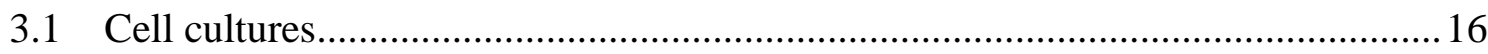

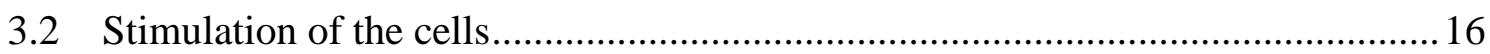

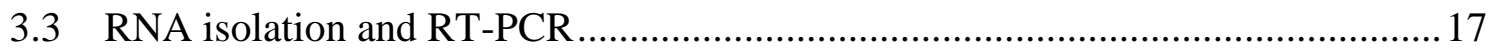

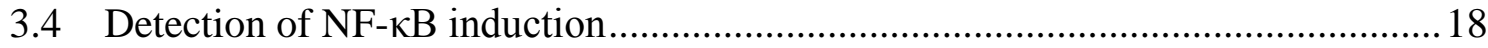

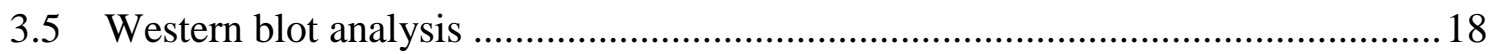

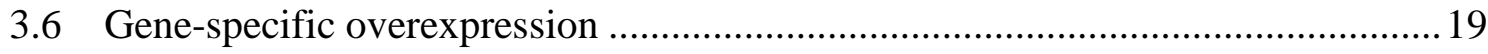

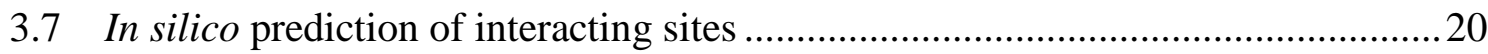

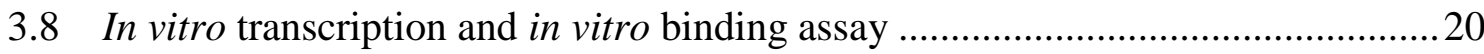

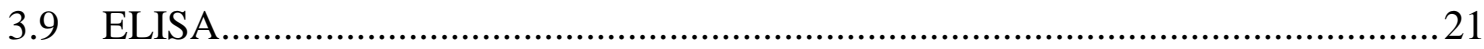

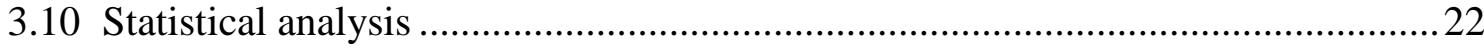

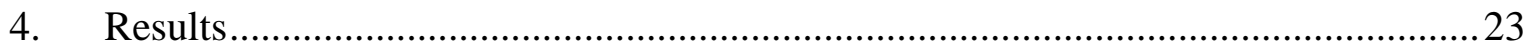

4.1 Keratinocytes respond to cytosolic nucleotide exposure with increased cytokine

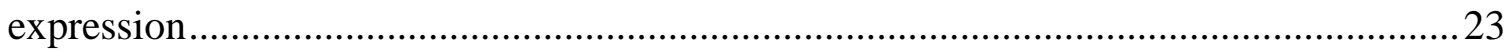

4.2 Poly(I:C) and poly(dA:dT) treatments induce NF- $\mathrm{B}$, MAP kinase and STAT

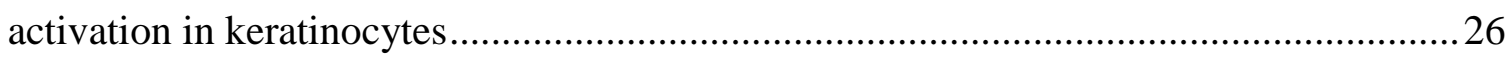


4.3 Cytokine expression of keratinocytes upon poly(I:C) and poly $(\mathrm{dA}: \mathrm{dT})$ treatment relies on NF- $\mathrm{BB}, \mathrm{p} 38$ and STAT signaling

4.4 PRINS expression decreases upon poly(dA:dT) treatment in NHEKs 31

4.5 PRINS overexpression alters IL-6 and IL-8 levels in keratinocytes 32

4.6 In silico analysis revealed putative interacting sites between the PRINS IncRNA and the IL-6 mRNA. 35

4.7 PRINS binds to IL-6 mRNA through direct, sequence-specific interaction 37

4.8 PRINS IncRNA regulates IL-6 expression in NHEKs through sequence-specific interaction 38

5. Discussion 40

6. Summary, novel findings of the experimental work 46

7. Acknowledgement 47

8. References 48 


\section{Introduction}

\subsection{The skin}

As the interacting surface between the body and the environment, the skin provides a physical and biochemical barrier and a sensory-receptive area, ensures adequate hydration and is responsible for the synthesis of vitamins and hormones, moreover actively defends the body against a variety of environmental, chemical and physical stimuli by acting as an active member of the innate immune system (1). The fine structure of the skin shows considerable regional variations in epidermal and dermal thickness, distribution of epidermal appendages and melanocyte content. Anatomically the skin can be divided into three layers, the epidermis and the dermis divided by the basal membrane, an extracellular matrix that is rich in type IV collagen and laminin and the subcutaneous tissue or hypodermis (2). The subcutaneous tissue is responsible for attaching the skin to the underlying bone and muscle and supplies the above layers with blood vessels and nerves. The subcutaneous tissue consists of loose connective tissue with fibroblasts, macrophages and adipocytes (3).

The dermis consists of connective tissue and harbors mechanoreceptors that provide the sense of touch and heat through nociceptors and thermoreceptors. It also contains the hair follicles, sweat glands, sebaceous glands, apocrine glands, lymphatic vessels and blood vessels (1).

The epidermis is composed mainly by keratinocytes, which undergo a specific differentiation program that determines a partition of epidermis into five layers (Fig. 1.). The innermost layer, called "stratum basale" or "stratum germinativum" is made up by keratinocytes that are still adherent to the basement membrane by hemidesmosomes and undergo constant proliferation forming the second layer, named "stratum spinosum". Keratinization is initiated in this layer by the production of lamellar bodies through the Golgi apparatus. The third layer is the "stratum granulosum", where the keratinocytes lose the nucleus and release the lamellar bodies to create a lipid barrier. The fourth layer, "stratum lucidum" is only present in palms and soles. The uppermost layer of the epidermis and the skin, "stratum corneum" is formed by keratin-filled dead keratinocytes (corneocytes) that had been covered by keratin and serve as the physical and biochemical barrier against external factors. The epidermis host not only 
keratinocytes, but immune cells, such as Langerhans-cells and lymphocytes and cells of the peripheral nervous system (Merkel cells) $(1,2)$.

The fine structure of the skin shows remarkable alterations in chronic skin diseases. In psoriasis the increased mitotic rate and premature maturation of keratinocytes leads to epidermal thickening (acanthosis) and the incomplete cornification of the cells leads to the retention of nuclei in the stratum corneum (parakeratosis) and the reduction or absence of the stratum granulosum (Fig. 1.). The redness of the lesion is due to the increased angiogenesis in the lesions, which allows for a greater influx of inflammatory cells into the dermis (4).
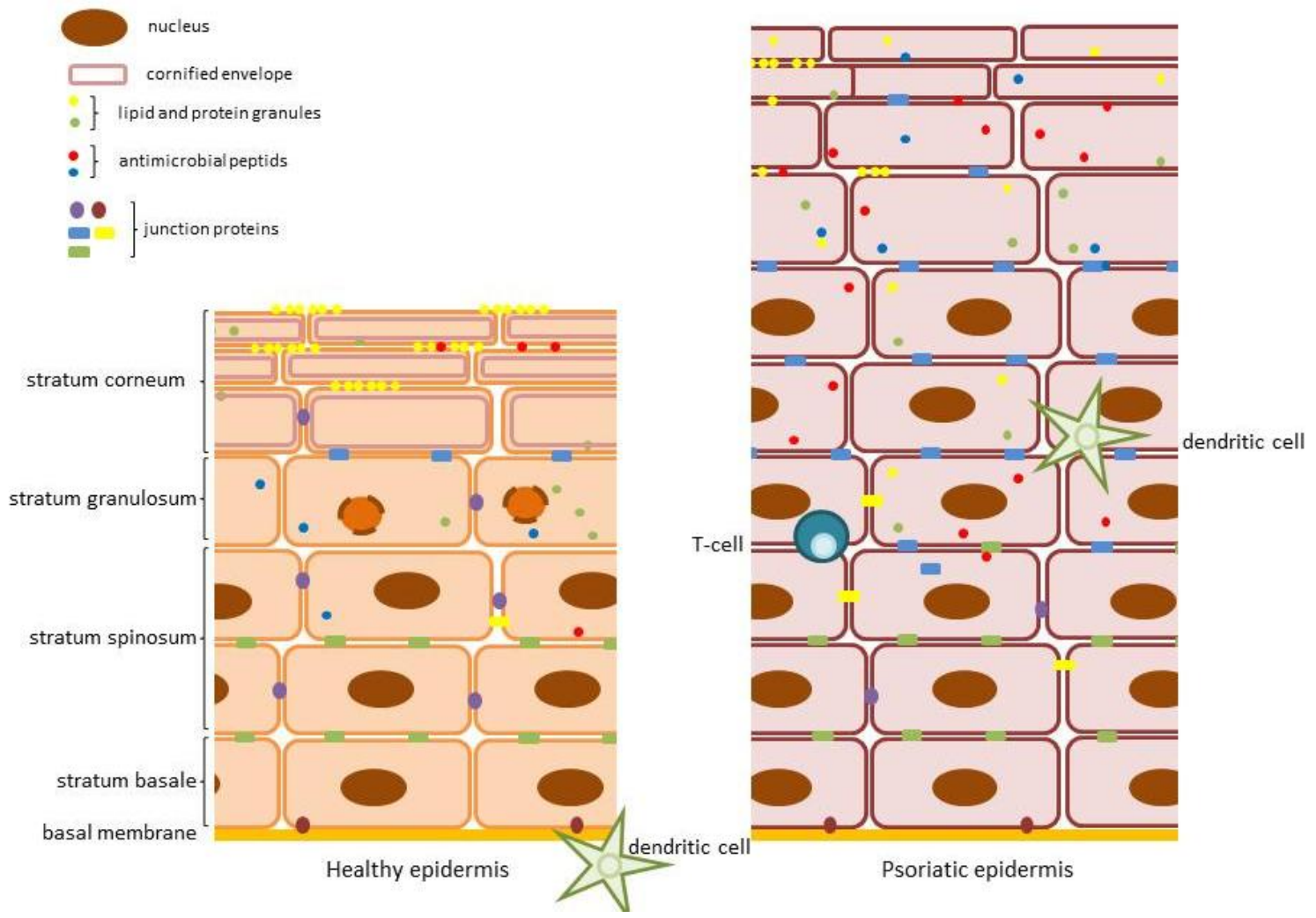

Figure 1. The structure of the epidermis in healthy and psoriatic conditions. In the healthy epidermis the proliferative keratinocytes of the stratum basale constantly proliferate and the daughter cells are moving up and form the second layer, named stratum spinosum. In the stratum granulosum keratinocytes lose their nucleus. The uppermost layer stratum corneum is formed by dead keratinocytes filled with keratin-filaments forming the cornified envelope. In psoriasis immune cells infiltrate the epidermis, while the increased mitotic rate of keratinocytes leads to epidermal thickening and the disturbed maturation leads to the retention of the nuclei in the stratum corenum. 


\subsubsection{Immune functions of keratinocytes}

The epidermis not only forms a physical and chemical barrier, but also an immune barrier against the invading pathogens. Besides skin resident professional immune cells in the epidermis e.g. Langerhans-cells, keratinocytes are also immunocompetent cells. They express a wide range of pattern recognition receptors (PRRs) and are responsive to various pathogen and danger associated molecular patterns (PAMPs and DAMPs) (6-9). These receptors make keratinocytes the first immune sentinels against pathogens, through their quick and efficient sensing and response. Keratinocytes express different Toll-like receptors (TLR), RIG-like (RLRs) receptors, and NOD-like (NLR) receptors recognizing a wide range of microbial compounds (7-11). Activation of the receptors triggers the induction of nuclear factor kappa $\mathrm{B}(\mathrm{NF}-\kappa \mathrm{B})$ and interferon regulatory factor, which induce the expression of inflammatory genes, mainly tumor necrosis factor $\alpha($ TNF- $\alpha$ ) and type I interferons (IFN). NLRs and PYHIN proteins form multiprotein complexes, called inflammasomes, which are responsible for cleaving the unprocessed pro-interleukin (IL) $-1 \beta$ and pro-IL-18 forms into mature, biologically active cytokines (12). Unlike professional immune cell types, keratinocytes express the precursors of these cytokines constantly, which in contact with the inflammasome activators instantly get activated and secreted, enabling the neighboring cells to respond by increased inflammatory cytokine production (13-15). The overactivation of these innate immune responses and the dysregulated interplay of the innate and adaptive immune responses can lead to chronic inflammatory diseases, such as psoriasis (4).

\subsubsection{Nucleic acid fragment induced immune responses in keratinocytes}

RNA and DNA fragments are derived mainly from the genetic material of various bacterial and viral pathogens and as PAMPs activate the immune reactions of keratinocytes. The range of cell entry and replication mechanisms led to a wide range of sensors for nucleic acids, which are mainly endosomal and cytosolic receptors. Since the microbial genomes are built from the same nucleotides as the host cell's, small differences in their size and chemical modifications, as well as intracellular localization are used to distinguish between self and foreign (16). Recent evidence indicate that in response to infection mitochondrial DNA can be released into the cytosol as DAMPs, contributing to the innate immune response (17). Moreover, the incomplete degradation of the genomic material of the dying cells can lead to 
the accumulation of nucleic acid fragments in the intracellular space. These self-derived fragments are also recognized as DAMPs, leading to a prolonged inflammation in chronic inflammatory diseases $(14,18)$.

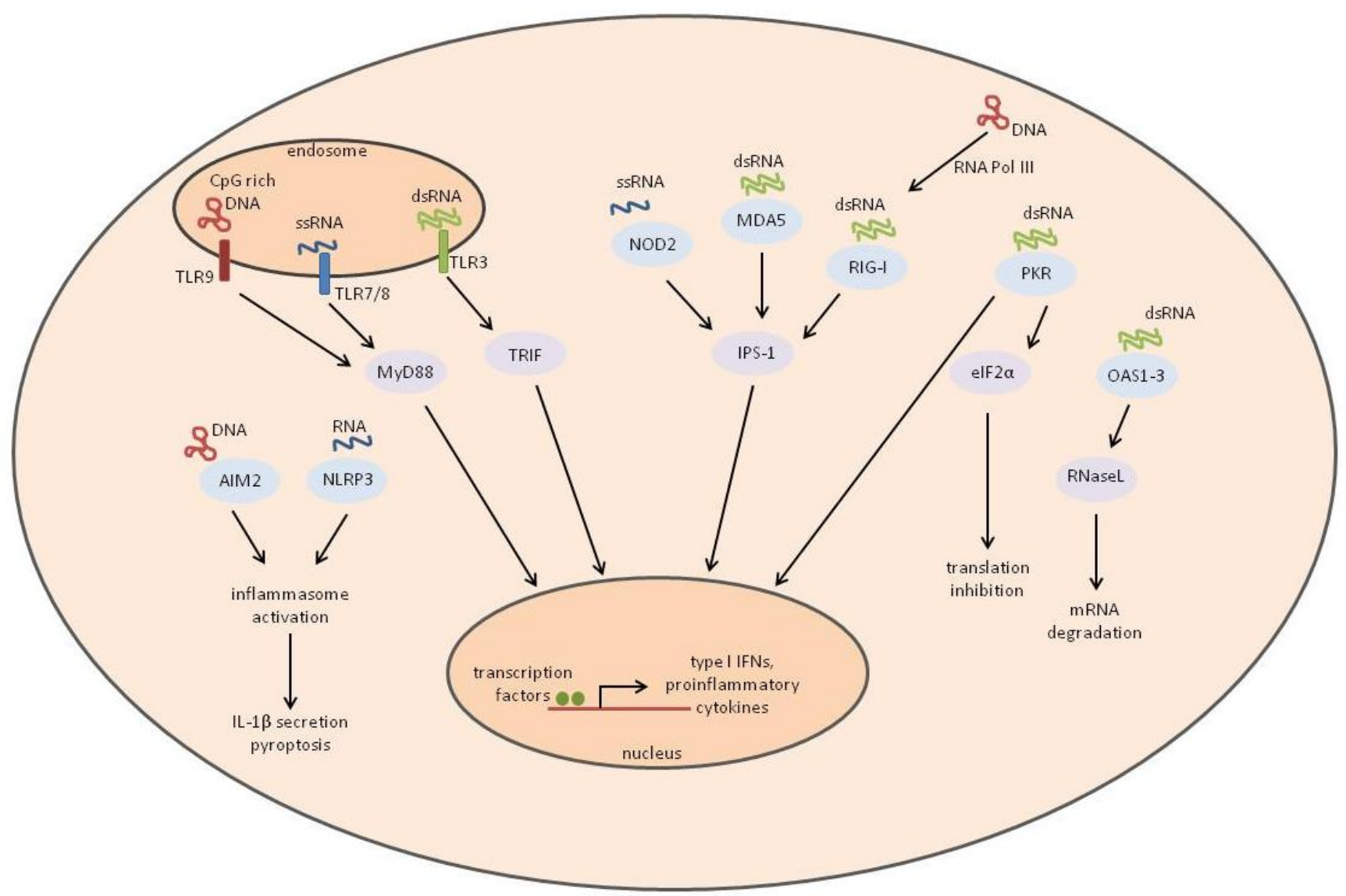

Figure 2. Cellular RNA and DNA sensors. Receptors in the endosome (TLR9, TLR7/8, TLR3) and cytosolic receptors (light blue) are activated by DNA and RNA fragments and through the activation of adaptor molecules (light purple) leads to the transcription of proinflammatory cytokines and type I interferons (IFNs). dsRNA - double-stranded RNA, dsDNA - double-stranded DNA, ssRNA - singlestranded RNA, TLR - Toll-like receptor, NOD2 - nucleotide oligomerization domain, RIG-I retinoic acid inducible gene I, MDA5 - melanoma differentiation associated gene-5, PKR - protein kinase RNA activated, OAS1-3 - 2'-5'-oligoadenylate synthetase, AIM2 - absent in melanoma 2, NLRP3 - NOD-like receptor 3, MyD88 - myeloid differentiation primary response 88, TRIF - TIR (Toll/interleukin-1 receptor) domain-containing adaptor protein inducing interferon $\beta$, IPS-1 interferon-beta promoter stimulator 1 , eIF $2 \alpha$ - eukaryotic translation initiation factor $2 \alpha$, RNaseL ribonuclease L, RNA Pol III - RNA polymerase III. Figure is based on Olejniczak et al, 2012 (19). 
Nucleic acid induced reactions have been mainly studied by using synthetic RNA analogue poly(I:C) and DNA analogue poly(dA:dT), which both induce type I interferon (IFN- $\alpha / \beta)$ and inflammatory cytokine expression in keratinocytes $(11,20-23)$. Poly(I:C) is recognized primarily by toll-like receptor 3 (TLR3) (24), although, TLR3-independent sensing of poly(I:C) has also been observed with involvement of retinoic acid induced gene I (RIG-I) and melanoma differentiation-associated gene 5 (25). Poly(dA:dT) recognition partially overlaps with poly(I:C) recognition, since RIG-I serves as a receptor after poly(dA:dT) has been transcribed by RNA polymerase III into double-stranded (ds) RNA molecules (26). Cyclic GMP-AMP synthase, a newly described cytosolic DNA receptor implicated in antiviral responses, binds dsDNA sequences independently and activates interferon regulatory factor 3 in cooperation with interferon- $\gamma$-inducible protein 16 (27). Poly(dA:dT) is the inducer of the absent in melanoma 2 (AIM2) inflammasome $(14,28)$, while poly(I:C) was described as an activator of the promiscuous signal activated NOD-like receptor pyrin domain containing 3 (NLRP3) inflammasome (29), leading to a subsequent IL-1 $\beta$ release in keratinocytes.

The basal expression of most inflammatory cytokines in keratinocytes is low and is regulated in response to stimuli at the transcriptional level. The activated PRRs induce signal transduction pathways of the NF- $\mathrm{BB}$, mitogen activated protein kinases (MAPK) and signal transducers of activator of transcription (STAT) signal transduction pathways, which have been reported to participate in nucleotide-induced inflammatory cytokine expression in several cell types $(20,23,26,29,30)$. Poly(I:C) was found to induce NF- $\kappa B$, p38, MAPK and

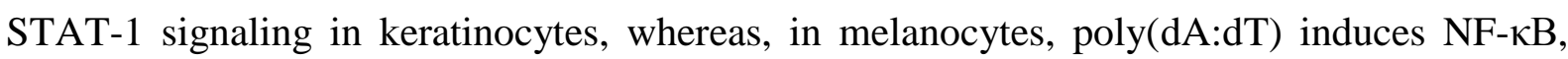
p38 and c-Jun N-terminal kinase (JNK) signaling, which differentially regulates cytokine expression $(20,23)$.

\subsubsection{Altered keratinocyte functions in psoriasis}

Psoriasis is a chronic inflammatory skin disease caused by the deregulated interplay of professional immune cells and keratinocytes. The disease affects approximately $2-3 \%$ of the Caucasian population. The etiology of the disease is complex, with the evidence that the interplay of environmental and life-style factors in individuals carrying multigenic susceptibility loci leads to the development of the symptoms. Psoriatic symptoms characterized by scaly, red, well-demarcated plaques on the skin, which can be triggered by 
mild trauma, such us scratching or sunburn, chemical irritants and infections, but some systemic drugs can also initiate these symptoms (4).

One of the endogenous triggering factors thought to initiate the disease are self-derived cytosolic nucleotide fragments $(11,13,14,18)$. Receptors for RNA and/or DNA fragments $(10,11,31)$, moreover their activators, self-derived RNA and DNA fragments and RNA:DNA duplexes are highly abundant in the lesional epidermis (14,32). During normal cornification, keratinocytes express deoxyribonucleases (DNases) (33); however, it was recently shown that reduced keratinocyte DNase activity in psoriasis results in suppressed DNA degradation and, as a consequence, parakeratosis (34) and the presence of excess DNA fragments in the cytosol. Similarly, disturbed ribonuclease activities were described in psoriatic skin $(35,36)$, which might result in excess RNA fragments. In the initiation phase, an antimicrobial peptide cathelicidine (LL-37) was shown to form a complex with the excess nucleotide fragments in the epidermis, and activate the pro-inflammatory responses of plasmacitoid dendritic cells (pDCs) and keratinocytes. The activated pDCs migrate to the lymph nodes and activate the naïve helper $T$ cells ( $T_{h}$ cells), such as $T_{h 1}, T_{h 17}$, which migrate to the dermis guided by keratinocyte derived cytokines and chemokines. The immune reactions initially induced by nucleotide fragments in keratinocytes are supported by the $\mathrm{T}_{\mathrm{h} 1}$ and $\mathrm{T}_{\mathrm{h} 17}$ derived cytokines and stimulate the hyperproliferation of keratinocytes.

The keratinocytes of the non-involved psoriatic epidermis already carry inherited changes in their molecular patterns compared to keratinocytes of the healthy epidermis, and are oversensitive to proliferative signals, which contribute to the development of the disease (37). The aim of our workgroup is to characterize these abnormal molecular patterns in the psoriatic non-lesional epidermis. To this end we previously performed a differential display $(38,39)$ and a cDNA microarray $(40)$ experiment comparing the gene expression of psoriatic non-involved and healthy epidermis. These experiments revealed deregulated extracellular matrix expression (38), identified a yet unknown long non-coding RNA, named PRINS (39), revealed splicing disturbances (41) and showed altered expression of inflammatory mediators IL-1 $\beta$ and IL-23 (40) and the inflammasome regulator caspase recruitment domain family member (CARD) 18 (28). 


\subsection{Non-coding RNAs}

With the completion of the human genome project, it has become obvious that proteincoding genes comprise only $2 \%$ of the genome, although the majority of the genome is transcribed into RNA. RNA molecules that lack protein-coding potential are collectively referred to as non-coding (nc) RNAs. In addition to the well-known housekeeping rRNAs, tRNAs and small nuclear RNAs (snRNAs), the most intensively studied subgroup of ncRNAs are the microRNAs (miRNAs), which are well characterized by their size and uniform function. Non-coding RNAs larger than 200 nucleotides are referred to as long ncRNAs (lncRNAs). They are markedly heterogeneous in size and cellular function, thus their classification is rather complicated $(42,43)$. The varying and still evolving taxonomy of lncRNA reflects the novelty of the field.

Currently lncRNA biology faces two challenges: the validation of lncRNAs identified by large-scale gene expression studies and the confirmation of their functionality in health and in disease. There is still a debate whether lncRNAs are functional or just transcriptional noise rapidly removed by cellular quality control mechanisms (44). Although various criteria, including expression levels, splicing variants and sequence conservation, have been proposed to differentiate between functional and non-functional lncRNAs, a consensus has not yet been achieved. The number of lncRNA genes (>70 000) in the human genome outnumbers proteincoding genes $(<20000)(45)$, but studies of their functional roles and detailed mechanisms account for less than $0.1 \%$ of all predicted lncRNAs (43). Thus an enormous effort is still needed to determine their specific functions, which is made more difficult by the low-level expression seen for most lncRNAs (45) and high inter-individual differences in lncRNA expression (46).

In the last decade, genome-scale transcription studies have uncovered non-coding RNAs as previously unrecognized players in the dysregulation of inflammatory functions (47-50) and disease pathogenesis (51-55).

\subsubsection{PRINS long non-coding RNA}

Our research group was the first to identify an lncRNA potentially contributing to psoriasis susceptibility: PRINS, the psoriasis susceptibility related non-coding RNA induced by stress. PRINS was identified by a differential display experiment as highly expressed in psoriatic 
non-lesional epidermis compared to healthy epidermis (39). The 3' end of the PRINS transcript is identical to the AK022045 RNA sequence. Real-time RT-PCR data confirmed that the highest PRINS expression can be found in psoriatic non-lesional epidermis, while there is a gradual decrease in its expression in psoriatic lesional epidermis and healthy epidermis, which suggested its possible contribution to psoriasis susceptibility (39). The expression of PRINS was found to be modified by a diverse set of cellular stressors, including starvation, ultraviolet B (UVB) irradiation, translation inhibition (56) and hypoxia (57), and silencing of PRINS in HaCaT cells during stress exposure decreased cellular viability (39). These results suggested its contribution to cellular stress responses.

Using various bioinformatical tools, we have analyzed genomic features of the PRINS gene (Fig. 3. A), which is located on the short arm of human chromosome 10 (map position 10p12.31) and is composed of two exons and an intron of approximately $7 \mathrm{~kb}$ in length (58).

The entire PRINS lncRNA resides in an intron of the recently annotated KIAA1217 gene, also known as SKT, which is involved in early stages of embryogenesis (59). Proximal to KIAA1217 is the OUT deubiquitinase 1 gene, whereas distal to KIAA1217 is the Rho GTPase activating protein 21. Interestingly, the miR603 miRNA is located in a KIAA1217 intron, $3^{\prime}$ of the PRINS coding region. A transcription start site was identified $6 \mathrm{~kb}$ proximal to the putative $5^{\prime}$ end of the PRINS gene using the ENCODE database (60). This region is marked by a high density of binding sites for several transcription factors, including GATA2, Fos, HDAC2 and STAT-3, and histone modification sites associated with active transcription, such as mono- and tri-methylation of lysine 4 of histone $\mathrm{H} 3$ (H3K4me1/3) and acetylation of lysine 9 and 27 (H3K9Ac, H3K27Ac), suggesting that a strongly regulated active promoter might be associated with the lncRNA. The region adjacent to the $3^{\prime}$ end of the PRINS IncRNA gene also contains histone modification sights, which, due to the close 3' proximity to the PRINS lncRNA gene, might be an enhancer element. Approximately two thirds of functioning human IncRNAs contain at least one element derived from a transposable element, which are seldom found in protein-coding genes (61). This is also true for the PRINS lncRNA, which contains three Alu elements comprising approximately one third of its sequence (Fig. 3. B). It is well established that transposable elements have been very important in the evolution of lncRNAs (62). PRINS lncRNA gene is most probably a primatespecific sequence and transposition was the major mechanism of its origin. Orthologues could 
be found only in the genomes of primates with variations in the extent of similarity (Fig. 3 . B). PRINS and the orthologues with the highest similarity among primate species reside on the short arm of chromosome 10.

A

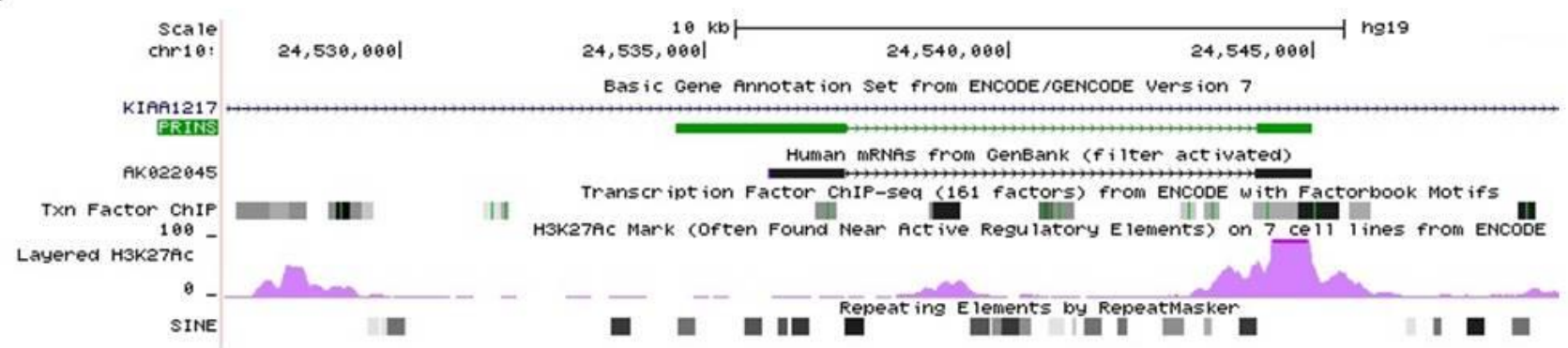

B

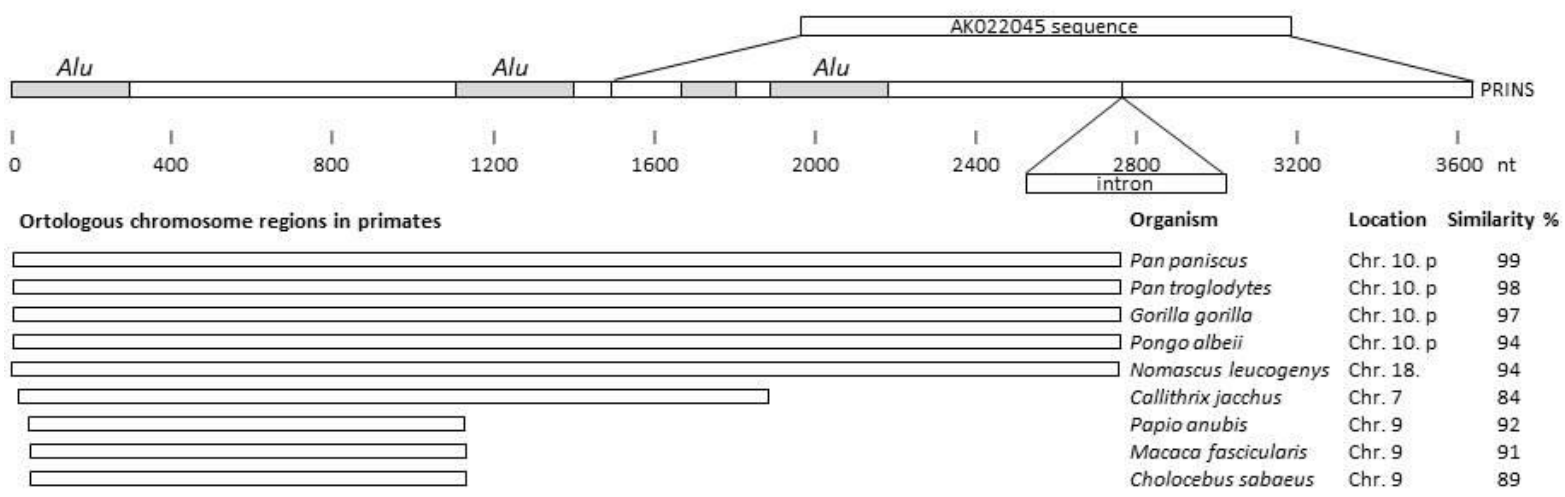

Figure 3. Major characteristics of the PRINS IncRNA identified by USCS Genome Browser (A) and NCBI BLAST (B). (A) PRINS gene is located in an intron of the KIAA1217 gene on Chromosome 10. The 3' end of the PRINS gene sequence is identical with the AK022045 RNA sequence. High density of transcription factor binding sites (Txn Factor ChIP) and acetylation of Histon H3 lysine 27 (H3K27Ac) in NHEKs was identified approximately $6 \mathrm{~kb}$ upstream from the PRINS gene and at the $3^{\prime}$ end of the gene, suggesting an active transcription. Short interspersed nuclear elements (SINE) are found on the sequence of PRINS, which were identified by BLAST similarity search as Alu elements within the PRINS lncRNA sequence (B). The PRINS gene is localized on the p12.1 arm of human Chr. 10, which is highly conserved in human and four other primate species. Although partial sequence similarity was found, it is largely due to the conservation of Alu elements in other primate species, where the PRINS sequence was distributed on other chromosomes. 
To identify interacting partners of PRINS, a cDNA microarray (63) and an in vitro protein binding assay (64) were previously carried out. The cDNA microarray identified the interferon- $\alpha$ inducible protein 6 (IFI6, also known as G1P3), which was downregulated in HeLa cells by PRINS silencing (63). The in vitro protein binding assay identified nucleophosmin (NPM), as a protein binding to PRINS. Functional studies showed, that silencing of PRINS resulted in alterations of UVB induced shuttling of NPM, showing the physical and functional interaction of PRINS and NPM (64). The subcellular localization of PRINS and the NMP protein also facilitates these functions. PRINS lncRNA is mainly localized in the nucleolus of normal human cultured keratinocytes; although, moderate perinuclear and cytoplasmic expression was also detected by in situ hybridization (64). This is in good agreement with reports that non-coding RNAs localize mainly to the nucleus (65). The PRINS sequence might also determine its cellular localization, as it includes the AGCCC pentamer with the sequence restrictions at positions -8 ( $\mathrm{T}$ or $\mathrm{A})$ and $-3(\mathrm{G}$ or $\mathrm{C}$ ) of a motif which was reported to be crucial for nuclear localization of lncRNAs (66). Our previous in situ hybridization results are in good agreement with this sequence-based analysis (64).

Together, the results from our previous experiments indicate that the evolutionarily young, primate- specific PRINS is one of the lncRNAs differentially expressed in psoriasis (51), and it plays a role in keratinocyte stress response. Its elevated expression in psoriatic non-lesional epidermis might contribute to the altered stress response of psoriatic keratinocytes and, thus, to disease pathogenesis.

Recent publications on PRINS non-coding RNA supported its involvement in inflammatory cellular processes. Microbial stimuli decreased PRINS expression in macrophages (67) and normal human epidermal keratinocytes (NHEKs) (56). Moreover PRINS was recently shown to potentially interact with chemokine (C-C motif) ligand 5 (CCL-5, also known as RANTES) in kidney epithelial cells (57). PRINS was also shown to be involved in the resistance against TNF- $\alpha$ induced apoptosis of colorectal cancer cells (68). These results suggest the possible contribution of PRINS to inflammatory processes. 


\section{Aims}

Our aims were to characterize nucleotide fragments induced immune responses in human keratinocytes by studying multiple regulatory layers of these processes. Therefore, we aimed to

- characterize the nucleotide fragment induced cytokine expression profile of different human keratinocyte cell types

- analyze the nucleotide fragment induced signal transduction pathways, and how they contribute to the nucleotide fragment induced cytokine expression in keratinocytes

- determine how dsDNA fragments affect the gene expression of PRINS long noncoding RNA in human keratinocytes

- determine how PRINS long non-coding RNA can affect the dsDNA induced cytokine expression in human keratinocytes 


\section{Materials and Methods}

\subsection{Cell cultures}

Normal human epidermal keratinocytes (NHEKs), the HaCaT cell line (69) and the HPVKER cell line (70) were used for the experiments. NHEKs were separated from skin specimens obtained from the Plastic Surgery Unit of our Department. Written informed consent was obtained from all investigated individuals. The study was approved by the Human Investigation Review Board of the University of Szeged and complied with the ethical standards of research and in accordance with the Helsinki Declaration. The epidermis was separated from the dermis with overnight incubation in dispase (Roche Diagnostics, Manheim, Germany), and keratinocytes were obtained after maceration in $0.25 \%$ trypsin. All cell types were grown in $75 \mathrm{~cm}^{2}$ cell culture flasks. NHEKs and HPV-KER cells were maintained in keratinocyte serum-free medium containing epidermal growth factor and bovine pituitary factor (Gibco Keratinocyte SFM Kit; Life Technologies, Copenhagen, Denmark) and supplemented with $1 \%$ antibiotic/antimycotic solution (PAA Laboratories GmBH, Pasching, Austria) and 1\% L-glutamine (PAA Laboratories). HaCaT cells were grown in DMEM with $4.5 \mathrm{~g} / \mathrm{l}$ glucose supplemented with $1 \%$ antibiotic/antimycotic solution, $1 \%$ L-glutamine and $10 \%$ fetal bovine serum. Cells were maintained at $37^{\circ} \mathrm{C}$ in a humidified atmosphere with $5 \% \mathrm{CO}_{2}$. The medium was changed every 2 days.

\subsection{Stimulation of the cells}

HPV-KER cells, HaCaT cells or third passage NHEKs were seeded into 6-well plates at a density of 200000 cells $/ \mathrm{ml}$. Cells were transfected with $0.666 \mu \mathrm{g} / \mathrm{ml}$ polydeoxyadenylic acidpolydeoxythymidylic acid double-stranded homopolymer [poly(dA:dT)] (InvivoGene, San Diego, CA, USA) or with $0.666 \mu \mathrm{g} / \mathrm{ml}$ polyinosinic-polycytidylic acid [poly(I:C)] (Sigma Aldrich, Saint Louis, MO, USA) using the X-tremeGene 9 transfection reagent (Roche Diagnostics). Cells were harvested at indicated time points. In some cases, before transfection with poly(dA:dT), cells were primed in supplement-free medium by addition of $5 \mathrm{ng} / \mathrm{ml}$ tumor necrosis factor- $\alpha$ (TNF- $\alpha)$ and $5 \mathrm{ng} / \mathrm{ml}$ interferon- $\gamma(\mathrm{IFN}-\gamma)$ for 24 hours, as indicated in Figure legends. 
For inhibition studies, cells were incubated 1 hour prior to poly(dA:dT)/poly(I:C) transfection with inhibitors for NF- $\kappa \mathrm{B}$ (Bay11-7085, $10 \mu \mathrm{M}$; MedChem Express, Monmouth Junction, NJ, USA), STAT-1 (Fludarabine, $10 \mu \mathrm{M}$; Sigma Aldrich), STAT-3 (Stattic, $5 \mu \mathrm{M}$; Sigma Aldrich), MEK1/2 (PD98059, $20 \mu \mathrm{M}$; Sigma Aldrich), JNK (SP600125, 10 $\mu$ M; Tocris Bioscience, Bristol, UK) and p38 (SB203580, $10 \mu \mathrm{M}$; Tocris Bioscience).

\subsection{RNA isolation and RT-PCR}

Total RNA was isolated from cells using TRIzol ${ }^{\circledR}$ Reagent (Invitrogen Corp., Carlsbad, CA, USA), following the manufacturer's instructions. Turbo DNA-free Kit (Ambion, Life Technologies) was used for the removal of contaminating DNA. cDNA was synthesized from $1 \mu \mathrm{g}$ total RNA using the iScript cDNA Synthesis Kit (Bio-Rad Laboratories, Hercules, CA, USA). Real-time RT-PCR experiments were carried out with the Universal Probe Library system (Roche Diagnostics) using a C1000 Touch Thermal Cycler (Bio-Rad Laboratories), using primers listed in Table 1. The expression of each gene was normalized to the expression of the $18 \mathrm{~S}$ rRNA gene. Relative mRNA levels were calculated by the $\Delta \Delta \mathrm{Ct}$ method.

Table 1. Primers and probes used for real-time RT-PCR experiments

\begin{tabular}{|c|c|c|c|c|}
\hline Manufacturer & mRNA & Strand & Primer sequences & Probe no. \\
\hline \multirow{12}{*}{$\begin{array}{l}\text { Roche } \\
\text { Diagnostics - } \\
\text { Universal } \\
\text { Probe Library }\end{array}$} & \multirow{2}{*}{$18 \mathrm{~S}$ rRNS } & Forward & CGC TCC ACC AAC TAA GAA CG & \multirow{2}{*}{77} \\
\hline & & Reverse & CTC AAC ACG GGA AAC CTC AC & \\
\hline & \multirow{2}{*}{ TNF- $\alpha$} & Forward & CAG CCT CTT CTC CTT CCT GAT & \multirow{2}{*}{29} \\
\hline & & Reverse & GCC AGA GGG CTG ATT AGA GA & \\
\hline & \multirow{2}{*}{ IL-1 $\alpha$} & Forward & GGT TGA GTT TAA GCC AAT CCA & \multirow{2}{*}{6} \\
\hline & & Reverse & TGC TGA CCT AGG CTT GAT GA & \\
\hline & \multirow{2}{*}{ IL-1 $\beta$} & Forward & AAA GCT TGG TGA TGT CTG GTC & \multirow{2}{*}{10} \\
\hline & & Reverse & AAA GGA CAT GGA GAA CAC CAC T & \\
\hline & \multirow{2}{*}{ IL-6 } & Forward & CAG GAG CCC AGC TAT GAA CT & \multirow{2}{*}{45} \\
\hline & & Reverse & GAA GGC AGC AGG CAA CAC & \\
\hline & \multirow{2}{*}{ CCL5 } & Forward & TGC CCA CAT CAA GGA GTA TTT & \multirow{2}{*}{59} \\
\hline & & Reverse & CTT TCG GGT GAC AAA GAC G & \\
\hline \multirow{3}{*}{$\begin{array}{l}\text { Thermo Fischer } \\
\text { Scientific }\end{array}$} & IL-8 & \multicolumn{2}{|r|}{ TaqMan Gene Expression Assays } & Hs00174103_m1 \\
\hline & PRINS & \multicolumn{2}{|r|}{ TaqMan Gene Expression Assays } & Hs03671803_s1 \\
\hline & TNF- $\alpha$ & \multicolumn{2}{|r|}{ TaqMan Gene Expression Assays } & Hs00174128_m1 \\
\hline
\end{tabular}




\subsection{Detection of NF- $\mathrm{NB}$ induction}

Luciferase assays were performed to determine the NF- $\kappa \mathrm{B}$ activity in response to poly(I:C)

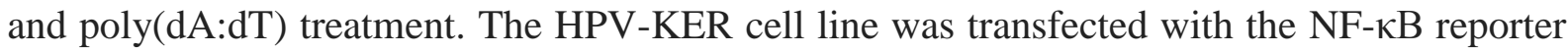
construct vector pNF-кB-luc Cis-Reporter Plasmid (Stratagene, La Jolla, CA, USA) and the pGL4.75 [hRluc/CMV] plasmid (Promega, Madison, WI, USA) with the use of the XtremeGene9 transfection reagent. The treated cells were washed twice with PBS, lysed with passive lysis buffer (Biotium, Hayward, CA, USA) and the luciferase activities in the lysates were measured using the Firefly \& Renilla Dual Luciferase Assay Kit (Biotium) and Thermo Luminoskan Ascent (Thermo Scientific, Rockford, IL, USA), according to the manufacturer's instructions. All samples were measured three times and the luciferase activity derived from the NF- $\kappa \mathrm{B}-$ luc plasmid was normalized to the activity of the Renilla luciferase activity from pGL4.75 [hRluc/CMV] plasmid.

\subsection{Western blot analysis}

HPV-KER cells were harvested at indicated time points after poly(dA:dT) or poly(I:C) transfection and lysed in lysis buffer supplemented with $0.5 \%$ SDS and $1 \%$ Halt $^{\mathrm{TM}}$ Protease and Phosphatase Inhibitor Cocktail (Thermo Scientific). Equal amounts of protein in ProTrack Loading Buffer (Lonza, Basel, Switzerland) were separated on a 7.5\% TGX Fast Cast Gel and transferred to nitrocellulose membrane $(0.45 \mu \mathrm{m}$; Bio-Rad Laboratories). After blocking the membrane in 5\% non-fat milk in Tris-Buffered Saline containing 0.2\% Tween20 , primary antibodies were incubated overnight at $4^{\circ} \mathrm{C}$ with constant agitation. HRPconjugated secondary antibodies were incubated for 60 minutes at room temperature (Table 2.). Signal was visualized with SuperSignal ${ }^{\mathrm{TM}}$ West Pico Chemiluminescent Substrate (Thermo Scientific) on a C-Digit Blot Scanner (LI-COR Corp. Lincoln, NE, USA). 
Table 2. List of primary and secondary antibodies used for western blot experiments.

\begin{tabular}{|l|l|l|l|l|l|}
\hline \multicolumn{1}{|c|}{$\begin{array}{c}\text { Primary } \\
\text { antibody }\end{array}$} & Manufacturer & Dilution & $\begin{array}{r}\text { Secondary } \\
\text { antibody }\end{array}$ & Manufacturer & Dilution \\
\hline anti-actin & Sigma Aldrich & $1: 2000$ & anti-rabbit HRP & $\begin{array}{l}\text { Southern } \\
\text { Biotech }\end{array}$ & $1: 2000$ \\
\hline $\begin{array}{l}\text { anti-phospho- } \\
\text { IKB } \alpha\end{array}$ & $\begin{array}{l}\text { Santa Cruz } \\
\text { Biotechnology }\end{array}$ & $1: 1000$ & anti-mouse HRP & $\begin{array}{l}\text { Southern } \\
\text { Biotech }\end{array}$ & $1: 2000$ \\
\hline $\begin{array}{l}\text { anti-phospho- } \\
\text { ERK1/2 }\end{array}$ & BioLegend & $1: 1000$ & anti-mouse HRP & $\begin{array}{l}\text { Southern } \\
\text { Biotech }\end{array}$ & $1: 2000$ \\
\hline $\begin{array}{l}\text { anti-phospho- } \\
\text { STAT-1 (S727) }\end{array}$ & $\begin{array}{l}\text { Cell Signaling } \\
\text { Technology }\end{array}$ & $1: 1000$ & anti-rabbit HRP & $\begin{array}{l}\text { Southern } \\
\text { Biotech }\end{array}$ & $1: 2000$ \\
\hline $\begin{array}{l}\text { anti-phospho- } \\
\text { STAT-3 (S727) }\end{array}$ & $\begin{array}{l}\text { Cell Signaling } \\
\text { Technology }\end{array}$ & $1: 1000$ & anti-rabbit HRP & $\begin{array}{l}\text { Southern } \\
\text { Biotech }\end{array}$ & $1: 2000$ \\
\hline $\begin{array}{l}\text { anti-phospho- } \\
\text { JNK } \\
\text { (T183/Y185) }\end{array}$ & Bio-Techne & $1: 500$ & anti-rabbit HRP & $\begin{array}{l}\text { Southern } \\
\text { Biotech }\end{array}$ & $1: 2000$ \\
\hline $\begin{array}{l}\text { anti-phospho- } \\
\text { p38 alpha } \\
\text { (T180/Y182) }\end{array}$ & Bio-Techne & $1: 1000$ & anti-mouse HRP & $\begin{array}{l}\text { Southern } \\
\text { Biotech }\end{array}$ & $1: 2000$ \\
\hline
\end{tabular}

\subsection{Gene-specific overexpression}

For overexpressing PRINS, the AK022045 cDNA sequence (Biological Resource Center (NBRC) National Institute of Technology and Evaluation, Chiba, Japan) was cloned into a pcDNA3.1(+) vector. The empty pcDNA3.1(+) vector served as a control.

The $\triangle$ PRINS construct was created by GeneArt gene synthesis (Thermo Scientific) by replacing the AK022045 region (position 538-622) with the following scrambled sequence, and cloned into a pcDNA3.1(+) vector: 5'-GTGCGTGGCGGAGACGTGGTGGTAGAC CGAATTGAGGAGGATCCGAAGGTTAGACGTAGGCGATCGCCGCTTCGGACGCGG TCGC-3'.

Transient transfection of NHEK cells was carried out at approximately $70 \%$ confluency in parallel to cytokine priming, using the X-tremeGENE HP DNA transfection protocol, as described by the manufacturer (Roche Diagnostics). The transfection efficiency was $85 \%$ on average, as determined by the transfection of a GFP reporter construct (Lonza, Basel, Switzerland) and analysis of GFP expression by flow cytometry. The effectiveness of overexpression was investigated with real-time RT-PCR (Fig. 4.). 


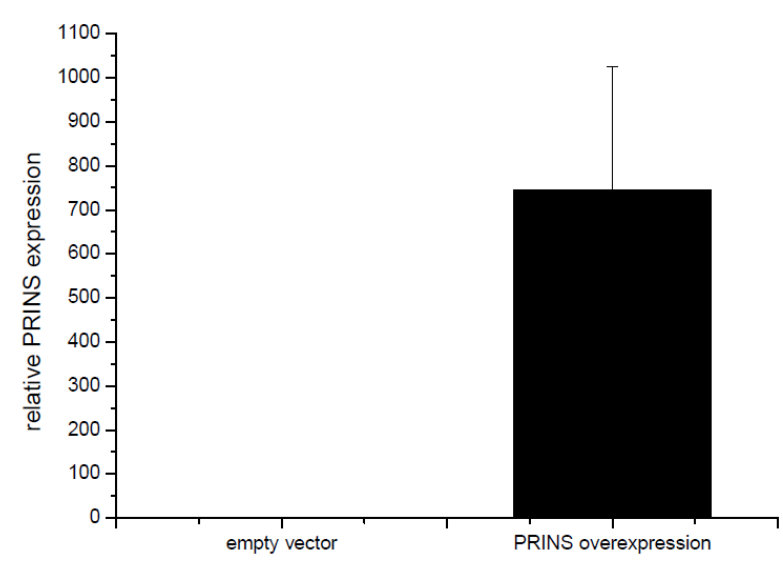

Figure 4. The evaulation of the effectiveness of PRINS overexpression by real-time RT-PCR. NHEKs were transfected with a pcDNA3.1(+) vector containing the PRINS cDNA, while the empty pcDNA3.1(+) vector was used as control. The PRINS expression of the empty vector transfected samples displays the basal expression of PRINS in keratinocytes with $\Delta \mathrm{c}_{\mathrm{T}} \sim 33 \pm 3$, while after overexpression of PRINS $\Delta \mathrm{c}_{\mathrm{T}^{\sim}} 24 \pm 3$.

\subsection{In silico prediction of interacting sites}

Sequence complementarity between PRINS (AK022045) and the mRNA of IL-1 $\alpha$ (M28983.1), IL-1 $\beta$ (NM_000576.2), IL-6 (NM_000600.4), IL-8 (NM_000584.3), TNF- $\alpha$ (NM_000594.3) and CCL-5 (NM_002985.2) was analyzed using two algorithms: RIsearch (71), which uses a simplified nearest-neighbor energy model, and INTARNA (72-74), which calculates the free-energy values of the interaction based on predicted global and local structures of mRNAs. The regions predicted by both programs were considered as putative interaction sites.

\subsection{In vitro transcription and in vitro binding assay}

PRINS and $\triangle$ PRINS RNA sequences were produced by in vitro transcription from pcDNA3.1(+) containing the AK022045 or $\triangle$ PRINS cDNA sequence, using Transcript Aid T7 In Vitro Transcription Kit (Thermo Scientific). Products were purified by the GeneJET RNA Purification Kit (Thermo Scientific). Quality and sequence-length analyses were carried out on reducing agarose gel-electrophoresis. The single-stranded RNA products were used in a fluorescent binding assay. The fluorescently labeled RNA sequence 5'6carboxyfluorescein(6-FAM)/GAAGCUCUAUCUCCCCUCCAGGAGCCCAGCUAUGAAC 


\section{UCCUUCUCCACAAGCGCCUUCGGUCCAGUUGCCUUCUCCCUGGGGCUGCUCCUG} GUGUUGCCUGCUGCCUUCCCUGCC-3', comprising positions 91-205 of the IL-6 (NM_000600.4) mRNA sequence, was produced by Integrated DNA Technologies.

An in vitro binding assay was carried out on a Monolith NT.115 Pico MicroScale Thermophoresis instrument (NanoTemper $\mathrm{GmbH}$, Germany), in nuclease-free water, at $25^{\circ} \mathrm{C}$, with $80 \%$ Laser Power, 10\% LED Power, by 2bind GmbH, Regensburg, Germany. Fluorescence enhancement of the 6-FAM labeled specific truncated IL-6 RNA sequence or a 6-FAM labeled unspecific DNA, as negative control, was measured after addition of PRINS or $\triangle$ PRINS. The concentration of fluorescently labeled molecules $\left(\mathrm{c}_{\mathrm{A}}\right)$ was $10 \mathrm{nM}$ constantly, while unlabeled RNA concentration $\left(\mathrm{c}_{\mathrm{T}}\right)$ ranged from $126.75 \mathrm{nM}$ to $61.9 \mathrm{pM}$. Initial fluorescence was analyzed for binding curves by the following formulation based on a 1:1 binding model:

$$
\begin{gathered}
A+T \leftrightarrow A T \\
F\left(c_{T}\right)=F_{u}+\left(F_{b}-F_{u}\right) * \frac{c_{A T}}{c_{A}} \\
\frac{c_{A T}}{c_{A}}=\frac{1}{2 c_{A}} *\left(c_{T}+c_{A}+K_{d}-\sqrt{\left(c_{T}+c_{A}+K_{d}\right)^{2}-4 c_{T} c_{A}}\right)
\end{gathered}
$$

$F_{u}$ fluorescence intensity in unbound state

$F_{b}$ fluorescence intensity in bound state

$c_{A}$ concentration of fluorescent molecule (constant)

$c_{T}$ concentration of

$c_{A T}$ concentration of formed complex

$K_{d}$ dissociation constant

$\frac{c_{A T}}{c_{A}}$ fraction bound

\subsection{ELISA}

Cell supernatants were centrifuged $\left(5000 \mathrm{rpm}, 4 \mathrm{~min}, 4^{\circ} \mathrm{C}\right)$ to pellet cell debris and the amount of cytokines IL- $1 \alpha$, IL-1 $\beta$, IL-6, IL-8, CCL-5 and TNF- $\alpha$ was determined by ELISA (IL-1 $\alpha$ Duo Set, IL-1 $\beta$ ELISA Duo Set and TNF- $\alpha$ Duo Set, Biotechne; Human IL-6 Mini 
TMB ELISA Development Kit, Human IL-8 TMB ELISA Development Kit, Human RANTES ATBS ELISA Development Kit, PeproTech, Rocky Hill, NJ, USA), according to the manufacturer's instructions.

\subsection{Statistical analysis}

Experiments were carried out in triplicates with at least three biological repeats, as indicated in Figure legends. For statistical analysis, one-way or two-way repeated measurement analysis of variance (ANOVA) was used to compare more than two groups, and one-tailed, paired Ttest was used to compare two groups, as indicated in the Figure legend. In case of a nonnormal distribution, nonparametric tests were used (Kruskal-Wallis test and Wilcoxon-test). Statistical analysis was carried out using R software Ver 3.2.2. and Sigma Plot Ver. 13.0, the significance level was set at $\mathrm{p} \leq 0.05$. 


\section{Results}

\subsection{Keratinocytes respond to cytosolic nucleotide exposure with increased cytokine expression}

Initially we compared dsRNA- and dsDNA-induced cytokine-expression profiles in three keratinocyte cell types: normal human epidermal keratinocytes (NHEKs), the HaCaT cell line (69) and the HPV-KER cell line (70). These results helped us to determine which cell type is best suited to study keratinocyte inflammatory reactions, and provided us details about the kinetics of poly(I:C) and poly(dA:dT) induced cytokine expression. Poly(I:C) strongly induced IL-6 and TNF- $\alpha$ expression in all three cell types, and poly(dA:dT) induced expression in all cell types with slightly different kinetics as well as expression that was an order of magnitude lower than that observed with poly(I:C) (Fig. 5.). Peak expression was observed 3 to 6 hours after poly(I:C) transfection, whereas peak expression after poly(dA:dT) transfection occurred 6 to 12 hours after treatment in all cell types studied. Reaction to poly(I:C) was much faster in HaCaT cells than the other cell types studied. In contrast, the kinetics of poly(dA:dT)-induced reaction did not differ in the three cell types. In agreement with our previous findings (70), the HPV-KER cell line and NHEK cells exhibited similar cytokine mRNA expression kinetics upon poly(I:C) and poly(dA:dT) induction.

Detailed studies on poly(I:C) induced inflammatory reactions of keratinocytes were previously conducted $(11,20,30,75)$, but analysis of poly(dA:dT) induced reactions in keratinocytes was mostly reduced to the study of inflammasome activation $(13,14,28)$. Therefore, we analyzed the expression and secretion of several inflammasome independent cytokines in NHEKs upon poly(dA:dT) treatment. We confirmed that poly(dA:dT) significantly induced the expression and secretion of IL-1 $\beta$ in keratinocytes (Fig. 6. D, I), as described previously (4). In addition, poly(dA:dT) induced very strong mRNA expression of IL-1 $\alpha$, IL-6, IL-8 and tumor necrosis factor (TNF)- $\alpha$ in NHEKs (Fig. 6. A-E). In a manner similar to mRNA expression, poly(dA:dT) transfection induced the secretion of the investigated cytokines (Fig. 6. F-J). 
A

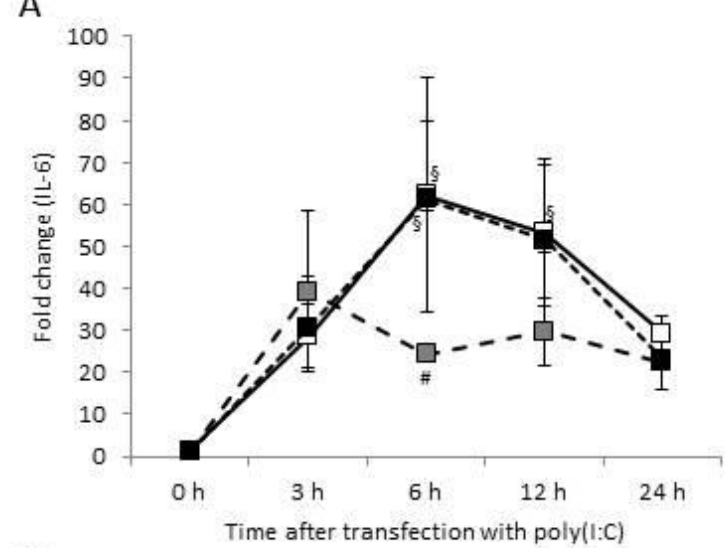

C

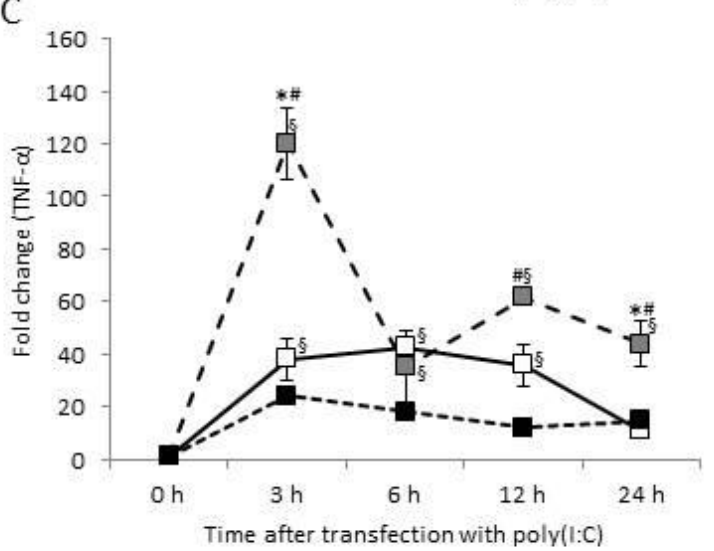

B

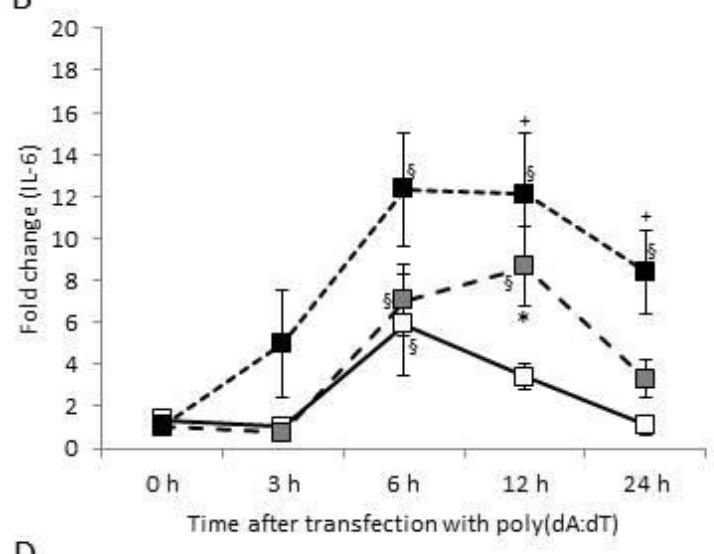

D

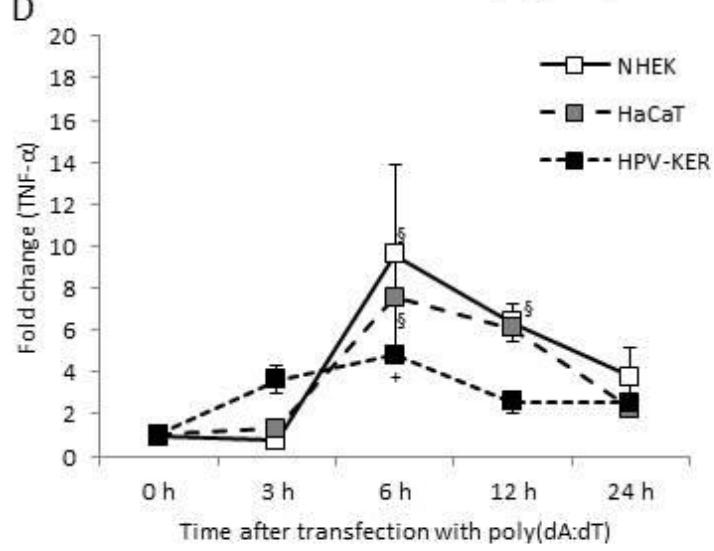

Figure 5. Kinetics of expression of the interleukin-6 (IL-6) and tumor necrosis factor $\alpha$ (TNF- $\alpha$ ) cytokines in normal human epidermal keratinocytes (NHEK), HaCaT and HPV-KER cell lines upon transfection with $0.666 \mu \mathrm{g} / \mathrm{ml}$ poly(I:C) (A, C) and poly(dA:dT) (B, D). Relative expression was determined by the $\Delta \Delta \mathrm{CT}$ method, normalized to $18 \mathrm{~S}$ rRNA expression and compared to the expression of the untreated 0 hour samples. Data are presented as mean of three independent experiments \pm standard error. Significance was determined by two-way repeated measurement ANOVA, *p<0.05 HaCaT vs NHEK; \# p< HaCaT vs HPV-KER; + p<0.05 HPV-KER vs NHEK; $\S$ $\mathrm{p}<0.05$ vs $0 \mathrm{~h}$ samples within a cell type. 

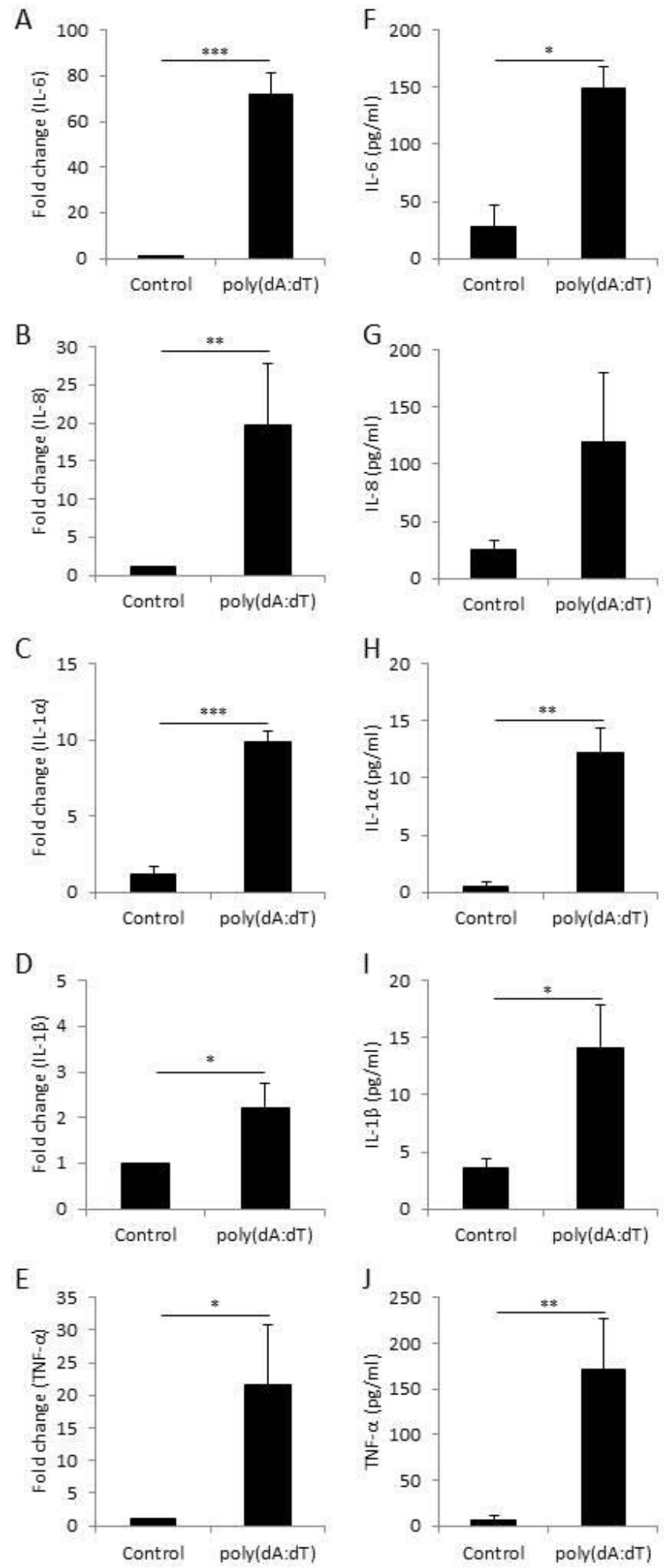

Figure 6. Poly(dA:dT) treatment induces the expression (A-E) and secretion (F-J) of inflammatory cytokines in NHEKs. NHEKs were transfected with $0.666 \mu \mathrm{g} / \mathrm{ml}$ poly(dA:dT) for 12 hours. mRNA expression was detected for cytokines by real-time RT-PCR, secretion of cytokines was determined by ELISA. Data are presented as mean $\pm \mathrm{SE}$ of at least three independent experiments, significance was determined by Student's T-test * $\mathrm{p} \leq 0.05 ; * * \mathrm{p} \leq 0.01 ; * * * \mathrm{p} \leq 0.001$. 


\subsection{Poly(I:C) and poly $(\mathrm{dA}: \mathrm{dT})$ treatments induce NF-кB, MAP kinase and STAT activation in keratinocytes}

NF- $\kappa \mathrm{B}$ activation in HPV-KER keratinocytes was assessed by an NF- $\kappa \mathrm{B}$-luciferase reporter

assay (Fig 7. A). The kinetic differences of NF- $\kappa \mathrm{B}$ activation between poly(I:C) and poly(dA:dT) transfected cells resembled the corresponding cytokine expression differences: peak-activation occurred at 6 hours after poly(I:C) treatment, whereas the peak activation with poly(dA:dT) occurred 24 hours after treatment. The delayed NF- $\kappa B$ signaling response to poly(dA:dT) was confirmed with detection of phosphorylated $\mathrm{I} \kappa \mathrm{B} \alpha$ by western blot analysis (Fig. 7. B and Fig. 8. A).

Western blot analysis of MAP kinase (Fig 7. C) and STAT (Fig 7. D) pathways showed that both poly(I:C) and poly(dA:dT) induced the phosphorylation of ERK1/2 and STAT-1 as well as STAT-3 signaling. Densitometric analysis showed a faster phosphorylation of STAT-1 and STAT-3 in poly(I:C) treated samples compared to poly(dA:dT) treatment (Fig. 8.). In addition, phosphorylation of p38 and JNK pathways were not affected at the studied time points, which was also confirmed by densitometric analysis (Fig. 8. C, D). 
A

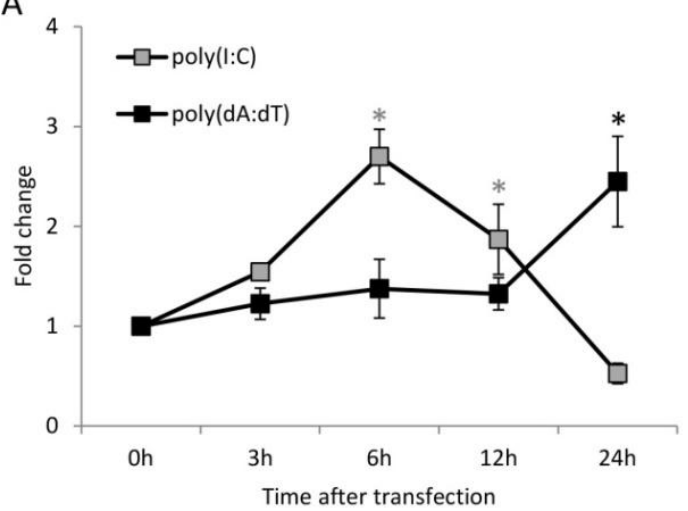

C

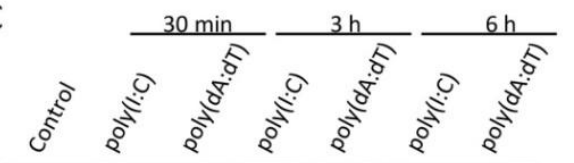

B

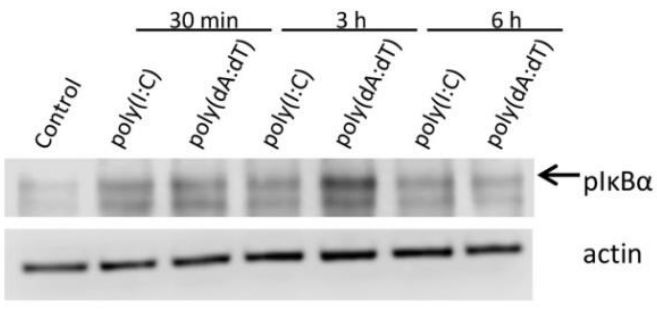

D

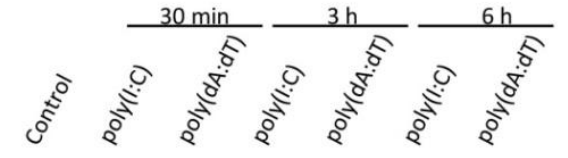

$\leftleftarrows p E R K 1 / 2$

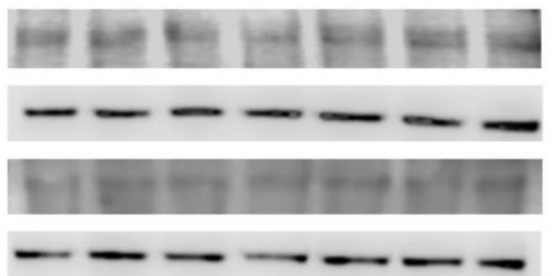

p-p38

actin

pJNK

actin

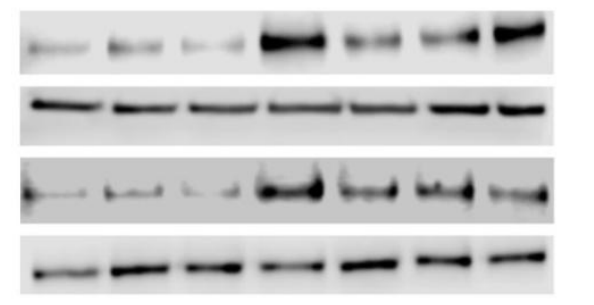

pSTAT-1

actin

pSTAT-3

actin

Figure 7. Activation of NF-кB, MAPK and STAT signal transduction pathways in HPV-KER cells upon poly(I:C) or poly(dA:dT) transfection assessed by $\mathrm{NF}-\kappa \mathrm{B}$-luciferase reporter assay (A) and western blot analysis (B-D). (A) NF- $\mathrm{kB}$ luciferase reporter assay exhibited faster activation of NF- $\mathrm{kB}$ transcription factor upon poly(I:C) treatment than poly(dA:dT) treatment. Raw luminescence intensity values were normalized to the intrinsic control renilla activity, and compared to the $0 \mathrm{~h}$ untreated samples. Data are presented as mean of three independent experiments \pm standard error; statistical significance was assessed by two-way repeated measurement ANOVA $* \mathrm{p}<0.05$, grey: poly(I:C) treatment compared to untreated $0 \mathrm{~h}$ samples, black: poly $(\mathrm{dA}: \mathrm{dT})$ treatment compared to untreated $0 \mathrm{~h}$ samples; (B) Increase in phosphorylated NF- $\kappa B$ inhibitor $\alpha(\mathrm{I} \kappa \mathrm{B} \alpha)$ after poly(I:C) or poly $(\mathrm{dA}: \mathrm{dT})$ treatment, peaking later after poly $(\mathrm{dA}: \mathrm{dT})$ treatment than after poly(I:C) treatment, arrow indicate the lane for phosphorylated IкB $\alpha$; (C) Phosphorylation of ERK1/2 increases after poly(I:C) or poly $(\mathrm{dA}: \mathrm{dT})$ treatment, peaking later after poly $(\mathrm{dA}: \mathrm{dT})$ treatment than after poly $(\mathrm{I}: \mathrm{C})$ treatment, arrows indicate from top to bottom the lanes for phosphorylated ERK1 and ERK2. Phosphorylation of p38 and JNK was not observed upon poly(I:C) or poly(dA:dT) treatment; (D) Phosphorylation of both STAT-1 and STAT-3 occurs faster in poly(I:C) treated samples than in poly(dA:dT) treated samples. Western blot results are representative for at least three independent experiments. Actin was used as loading control. 
A

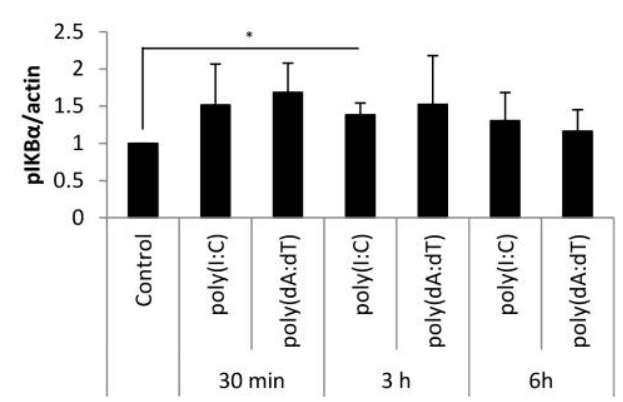

C

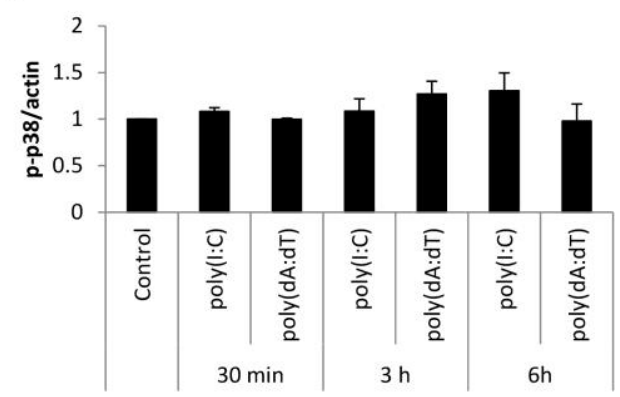

$E$

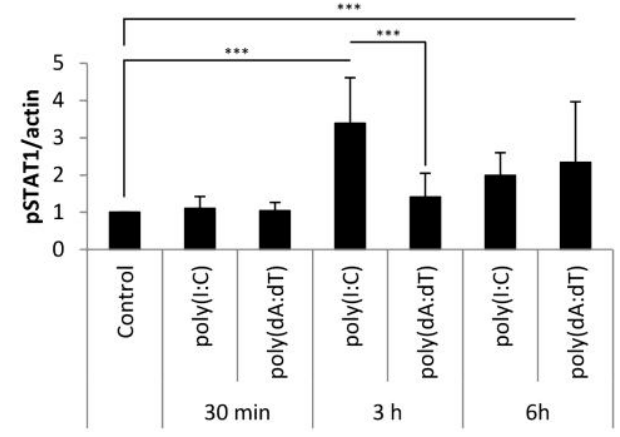

B

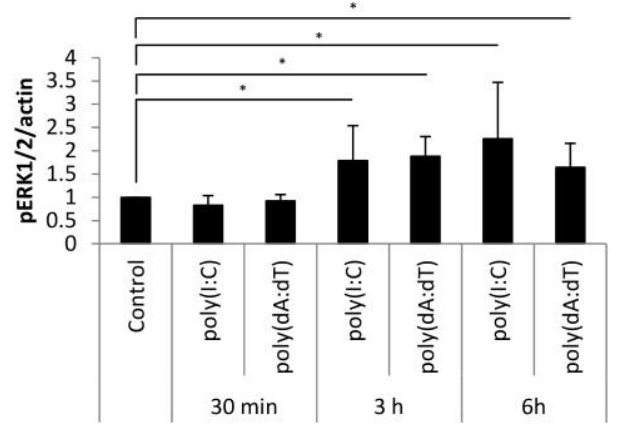

D

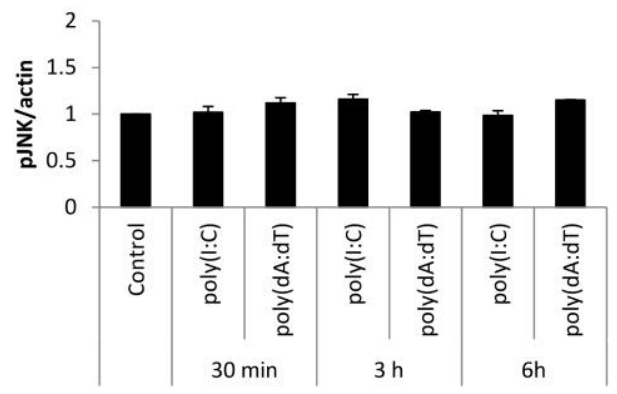

$\mathrm{F}$

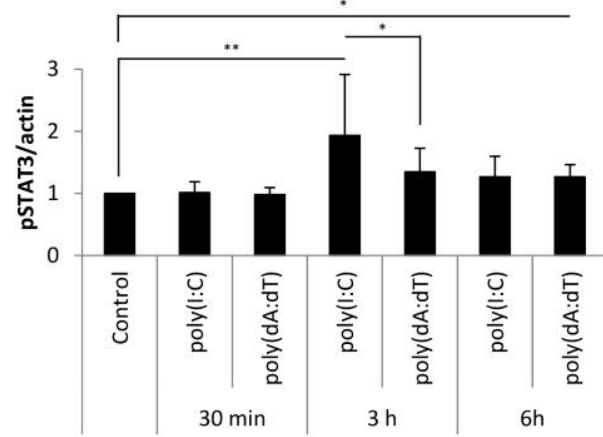

Figure 8. Densitometric analysis of Western blots on the phosphorylated forms IкBa (A), ERK1/2 (B), p38 (C), JNK (D), STAT-1 (E), STAT-3 (F) normalized to the level of the loading control actin. Densitometric analysis of the bands was carried out using Image Pro Plus software (Media Cybernetics Inc. Rockville, MD, USA). Intensity of bands from the protein of interest were normalized to the intensity of actin bands of the respective blots. Statistical analysis was carried out by two-way repeated measurement ANOVA. Data are presented as means $\pm \mathrm{SD}$ of the densitometric analysis of $\mathrm{n}=5(\mathrm{~A}, \mathrm{~B}, \mathrm{E}, \mathrm{F})$ or $\mathrm{n}=3(\mathrm{C}, \mathrm{D})$ blots. $* \mathrm{p}<0.05$; ** $<<0.01$; *** $<<0.001$ 


\subsection{Cytokine expression of keratinocytes upon poly(I:C) and poly(dA:dT) treatment relies on $\mathrm{NF}-\kappa \mathrm{B}, \mathrm{p38}$ and STAT signaling}

To address the role of the activated signaling routes in poly(I:C)- and poly(dA:dT)-induced cytokine expression, keratinocytes were pre-incubated with the specific inhibitors of NF- $\kappa \mathrm{B}$ (Bay 11-7085), MEK1/2 (PD95089), p38 (SB203580), JNK (SP600125), STAT-1 (Fludarabine) and STAT-3 (Stattic) for an hour before transfection with poly(I:C) for 6 hours or poly $(\mathrm{dA}: \mathrm{dT})$ for 12 hours. Time points of sample collection were determined with respect on the peak expression of cytokines (Fig. 5.). Inhibition of NF- $\kappa \mathrm{B}$ nearly completely abolished both the poly(I:C)- and poly(dA:dT)-induced expression of IL-6 and TNF- $\alpha$ (Fig. 9. A).

Although activation could not be confirmed by our western blot results (Fig. 7. C), inhibition of p38 signaling resulted in significantly decreased IL-6 and TNF- $\alpha$ expression (Fig. 9. B). In contrast, the inhibition of JNK signaling did not affect cytokine expression (Fig. 9. C). The inhibition of MEK1/2 signaling significantly increased the poly(I:C)- and poly(dA:dT)induced production of IL-6 (Fig. 9. D), suggesting a possible negative regulatory role of this pathway.

Specific inhibition of STAT-3 signaling significantly decreased both poly(I:C)- and poly(dA:dT)-induced cytokine expression (Fig. 9. F), whereas the inhibition of STAT-1 affected only IL-6 expression (Fig. 9. E).

Thus, whereas both poly(I:C)- and poly(dA:dT)-induced IL-6 expression was affected by most of the studied signaling routes, TNF- $\alpha$ expression was only affected by NF- $\kappa B, p 38$ and STAT-3. 
A

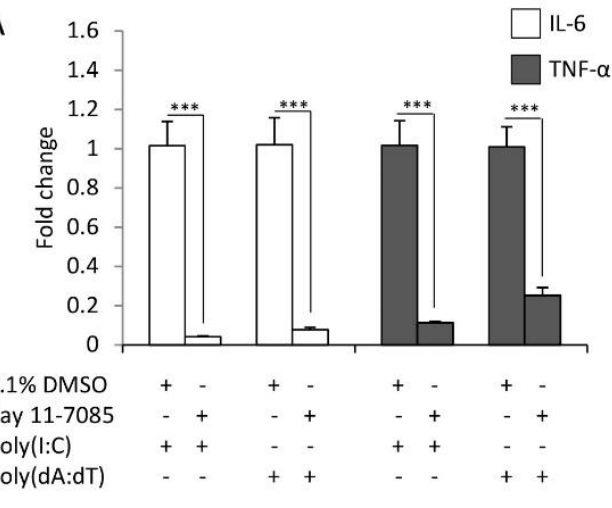

C

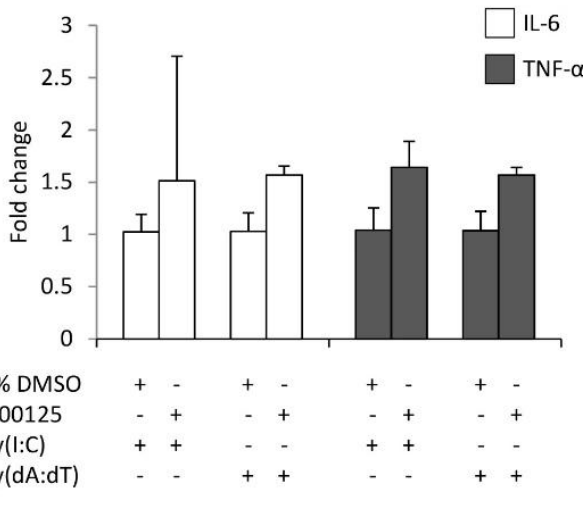

$\mathrm{E}$

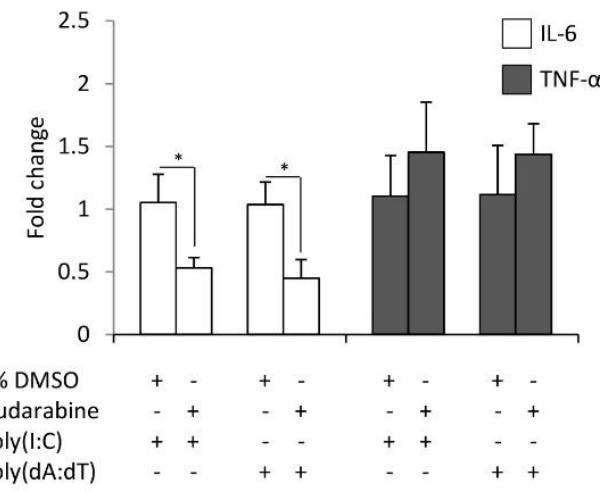

B

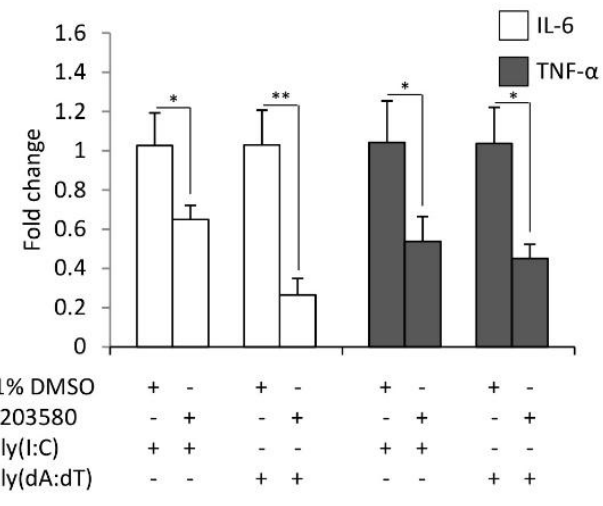

D

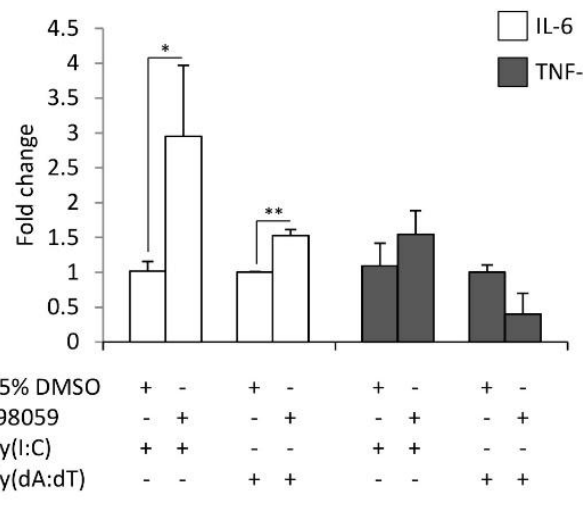

$\mathrm{F}$

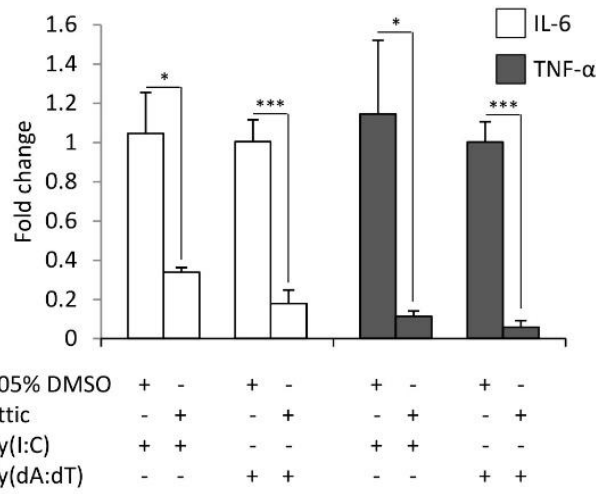

Figure 9. Inhibition of different signaling routes has divergent effects on the expression of the IL-6 (white bars) and TNF- $\alpha$ (grey bars) cytokines in keratinocytes. The effect of inhibition of NF-kB (A), p38 (B), JNK (C), MEK1/2 (D), STAT-1 (E) and STAT-3 (F) on poly(I:C) (6 hours after transfection) and poly(dA:dT) (12 hours after transfection) induction of IL-6 (white bars) and TNF- $\alpha$ (grey bars) expression in HPV-KER cells. Fold change of mRNA expression values were determined by the $\Delta \Delta \mathrm{CT}$ method, normalized to $18 \mathrm{~S}$ rRNA expression. As all inhibitors were dissolved in DMSO, the relative mRNA expression levels were compared to the expression levels in samples treated with DMSO + poly(I:C) or DMSO + poly(dA:dT), respectively. Poly(I:C) and poly(dA:dT) induction was in every case significant compared to the untreated control samples; no significant difference was observed between the cytokine-expression level of the samples treated with poly(I:C), poly(dA:dT), DMSO + poly(I:C) or DMSO + poly(dA:dT). Data are represented as the means of three independent experiments \pm standard error; ${ }^{*} \mathrm{p} \leq 0.05 ;{ }^{*} \mathrm{p} \leq 0.01 ; * * * \mathrm{p} \leq 0.001$ determined by Student's T-test. 


\subsection{PRINS expression decreases upon poly $(\mathrm{dA}: \mathrm{dT})$ treatment in NHEKs}

We and others have demonstrated altered PRINS expression upon exposure to inflammatory molecules $(56,67)$. Therefore we set out to examine PRINS expression upon poly(I:C) and poly $(\mathrm{dA}: \mathrm{dT})$ treatments. Poly $(\mathrm{dA}: \mathrm{dT})$ treatment significantly decreased the expression of PRINS in NHEKs (Fig. 10. A.), and a similar tendency was seen in the HPV-KER cell line (Fig. 10. C). Interestingly in $\mathrm{HaCaT}$ cells poly(dA:dT) treatment induced a trend of increased expression of PRINS (Fig. 10. B). Poly(I:C) treatment did not lead to significant PRINS expression changes (data not shown). Significant change in PRINS expression was only prevalent in NHEKs, thus NHEKs were used to determine whether PRINS plays a role in keratinocyte immune responses.
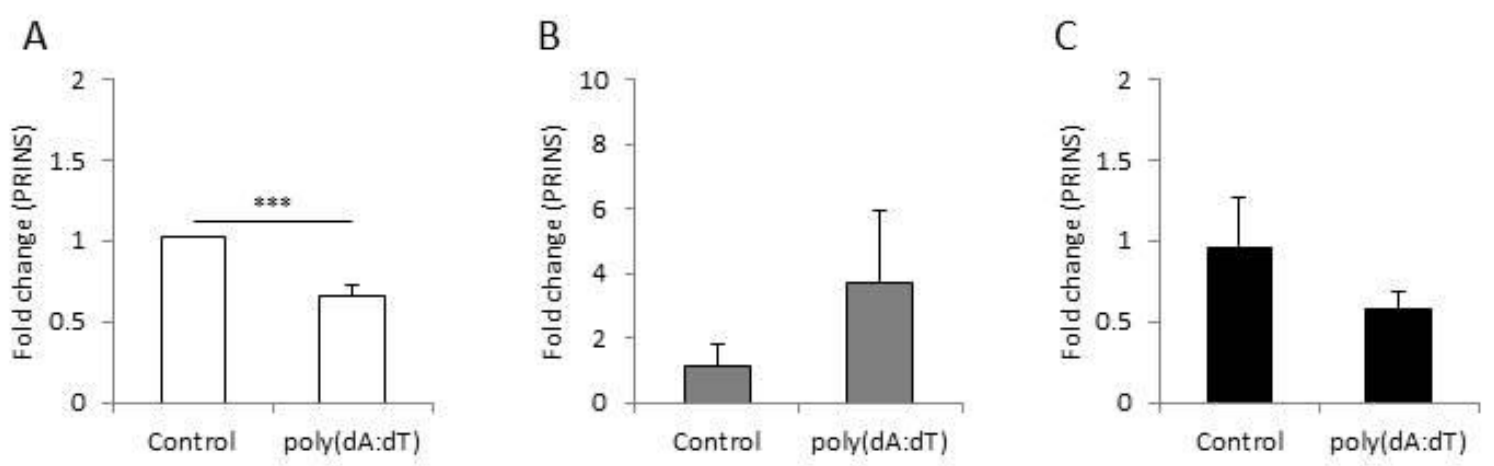

Figure 10. PRINS expression changed upon poly(dA:dT) transfection in NHEKs (A), HaCaT cells (B) and HPV-KER cells (C). Cells were transfected by poly(dA:dT) for 12 hours, and relative expression was determined by the $\Delta \Delta \mathrm{CT}$ method, normalized to $18 \mathrm{~S}$ rRNA expression and compared to the expression of the untreated samples. Data are presented as mean of three independent experiments \pm SE. Significance was determined by Student's T-test, $* * * \mathrm{p} \leq 0.001$. 


\subsection{PRINS overexpression alters IL-6 and IL-8 levels in keratinocytes}

The change in PRINS expression upon inflammatory stimuli suggests the possible contribution of PRINS to inflammatory responses of NHEK cells. To determine whether PRINS can regulate inflammatory cytokine expression, cells were transfected with a plasmid based construct for overexpressing PRINS, and the expression of cytokines was studied after poly(dA:dT) treatment. Unfortunately, in our initial experiments we found high intraindividual differences in the rate of poly(dA:dT) induced cytokine expression, which strongly inhibited the proper evaluation of the results. Upon these findings we introduced a model to increase inflammation by priming the cells with TNF- $\alpha$ and interferon (IFN)- $\gamma$ for 24 hours before poly(dA:dT) transfection, which resulted in a similar decreased PRINS expression as poly(dA:dT) transfection alone (Fig. 11. A). The combined TNF- $\alpha$ and IFN- $\gamma$ priming step is often applied before poly $(\mathrm{dA}: \mathrm{dT})$ treatment to gain pronounced inflammasome activation $(14,28)$; however the cumulative effect of this treatment on the expression of other cytokines has not been examined thoroughly. Indeed, IL-1 $\beta$ secretion was enhanced by the TNF- $\alpha$ and IFN- $\gamma$ priming compared to poly(dA:dT) treatment alone, but IL- $1 \beta$ mRNA expression was not affected by priming (Fig. 11. E, Fig. 12. D). Similarly, priming had no effect on TNF- $\alpha$ mRNA expression (Fig. 11. F). However, priming induced significantly higher mRNA expression of the other investigated cytokine genes (Fig. 11. B-D), and higher secretion of IL-1 $\alpha$, IL-1 $\beta$ and IL-8 (Fig. 12. B-D).

To analyze the role of PRINS in these inflammatory reactions, we overexpressed PRINS during the combined priming and poly(dA:dT) treatment. Expression and secretion of IL-6 and IL-8 were significantly decreased by PRINS overexpression (Fig. 13.), whereas mRNA expression and secretion of IL- $1 \alpha$, IL- $1 \beta$ and TNF- $\alpha$ were not affected (data not shown). These results suggest that PRINS can influence the regulation of other inflammatory processes. 

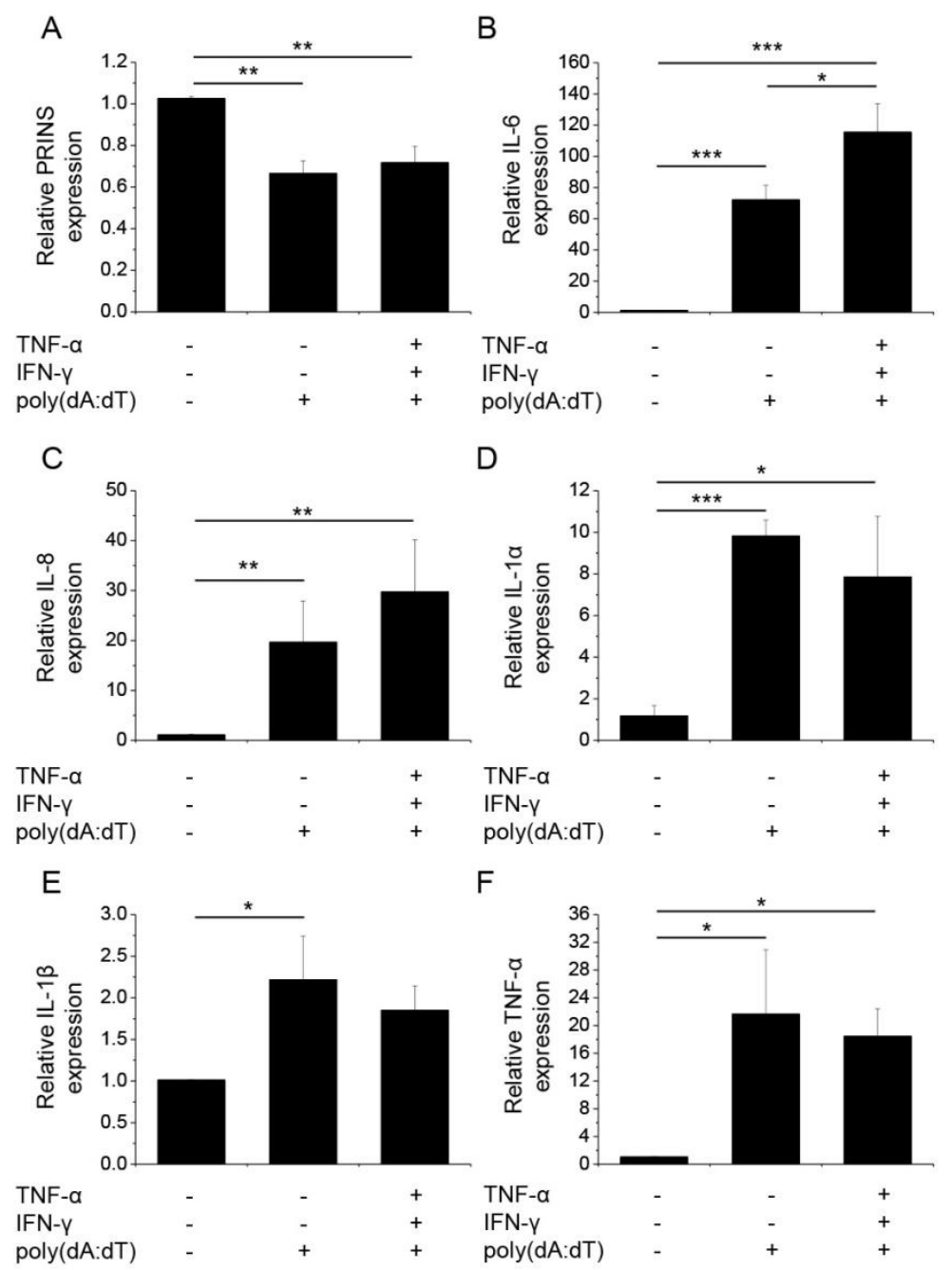

Figure 11. Poly(dA:dT) treatment decreased the expression of PRINS but induced the mRNA expression of cytokines. NHEKs were transfected with $0.666 \mu \mathrm{g} / \mathrm{ml}$ poly(dA:dT) for 12 hours with or without priming for 24 hours with $5 \mathrm{ng} / \mathrm{ml} \mathrm{TNF-} \alpha$ and IFN- $\gamma$. RNA expression was detected for PRINS (A) and cytokines IL-6 (B), IL-8 (C), IL-1 $\alpha$ (D), IL-1 $\beta$ (E), TNF- $\alpha$ (F) by real-time RT-PCR. Data are presented as mean \pm SE of five independent experiments $* \mathrm{p} \leq 0.05 ; * * \mathrm{p} \leq 0.01 ; * * * \mathrm{p} \leq 0.001$. 

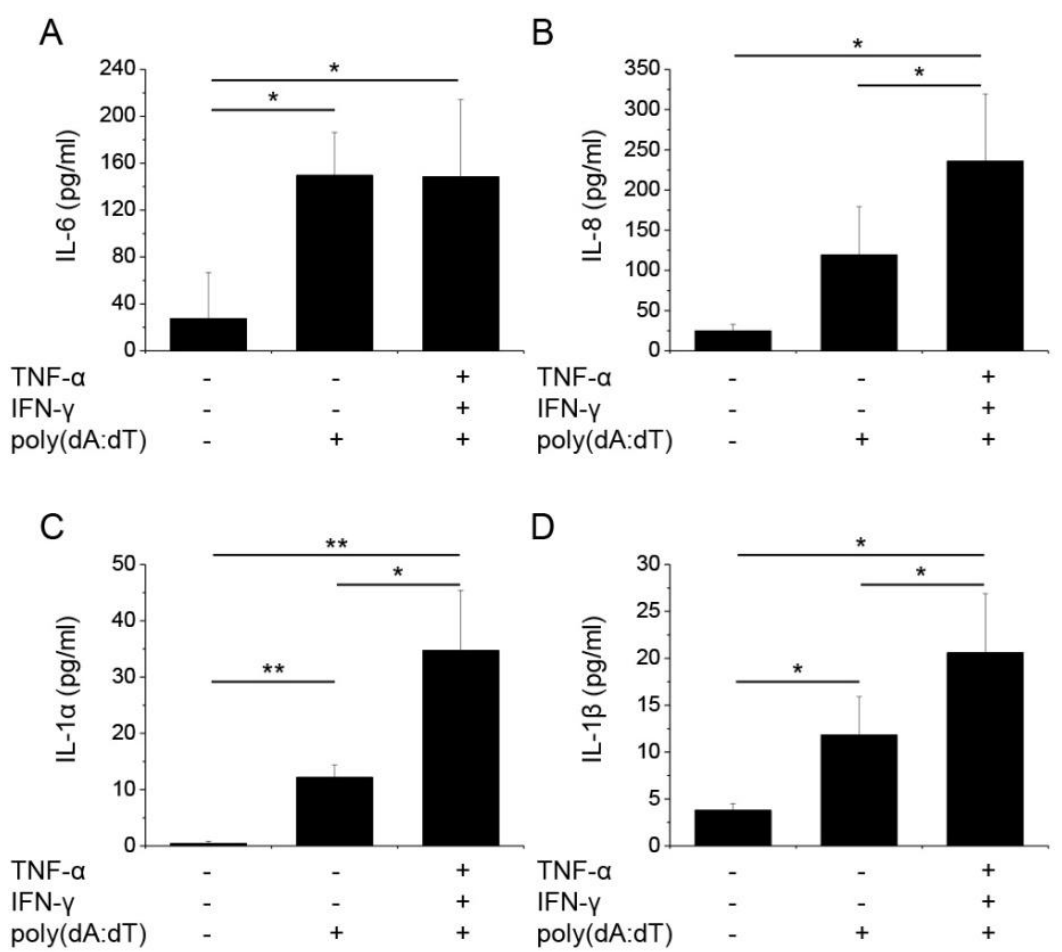

Figure 12. Poly(dA:dT) treatment induced the secretion of cytokines by NHEKs. NHEKs were transfected with poly(dA:dT) for 12 hours with or without priming for 24 hours with $5 \mathrm{ng} / \mathrm{ml} \mathrm{TNF- \alpha}$ and IFN- $\gamma$. Secretion of cytokines IL-6 (A), IL-8 (B), IL-1 $\alpha$ (C), IL-1 $\beta$ (D) was detected by ELISA from cell supernatant. Data are presented as mean $\pm \mathrm{SE}$ of five independent experiments. ${ }^{*} \mathrm{p} \leq 0.05$; ** $\mathrm{p} \leq 0.01 ; * * * \mathrm{p} \leq 0.001$. 

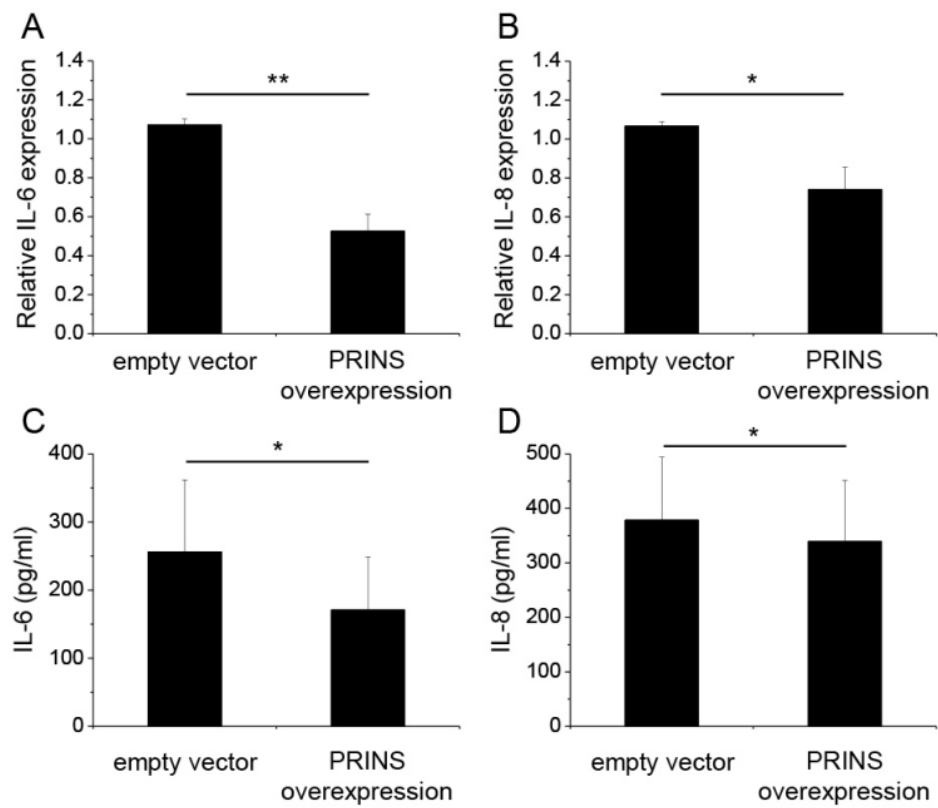

Figure 13. Overexpression of PRINS alters the expression and secretion of IL-6 and IL-8. In parallel to priming with $5 \mathrm{ng} / \mathrm{ml}$ TNF- $\alpha$ and IFN- $\gamma$, NHEKs were transfected with a pcDNA3.1(+) vector containing the PRINS cDNA; an empty pcDNA3.1(+) vector was used as control. After 24 hours, cells were transfected with poly(dA:dT). RNA expression of cytokines IL-6 (A), IL-8 (B) was detected by real-time RT-PCR. Secretion of cytokines IL-6 (C), IL-8 (D), was detected by ELISA from cell supernatants. Data are presented as mean $\pm \mathrm{SE}$ of four independent experiments. ${ }^{*} \mathrm{p} \leq 0.05$; $* * \mathrm{p} \leq 0.01$.

\subsection{In silico analysis revealed putative interacting sites between the PRINS IncRNA and the IL-6 mRNA}

The mRNA of the chemokine CCL-5 was previously predicted to interact with PRINS; however it was not reported whether this interaction affects the stability of the CCL-5 mRNA (57). Therefore, we measured mRNA expression and secretion of CCL-5 during PRINS overexpression, and found that both decreased (Fig. 14.) in a manner similar to the changes observed for IL-6 and IL-8. The similarity of these expression profiles led us to hypothesize similar mechanism(s) for IL-6, IL-8 and CCL-5 regulation mediated by PRINS.

To predict interactions between PRINS (AK022045) and the mRNAs of IL-6 (NM_000600.4) and IL-8 (NM_000584.3), we performed an in silico analysis using the INTARNA $(73,74)$ and the RIsearch (71) softwares. As sequence details of the CCL-5 mRNA and PRINS interaction have not been described in detail (57), we also included the CCL-5 
mRNA (NM_002985.2) in the in silico analysis. As a control for the reliability of the prediction analyses, mRNA sequences of cytokines not affected by PRINS overexpression (IL-1 $\alpha$ - M28983.1, IL-1 $\beta$ - NM_000576.2, TNF- $\alpha$ - NM_000594.3) were also included. The regions predicted by both algorithms were considered putative interacting sites. Putative interaction sites were not predicted for the cytokines not affected by PRINS overexpression (IL-1 $\alpha$, IL-1 $\beta$, TNF- $\alpha$ ) in this analysis. PRINS interaction regions were only predicted for the IL-6 and CCL-5 mRNAs (Fig. 15. B, C), two mediators affected by PRINS overexpression. A distance of approximately $200 \mathrm{nt}$ separates the predicted interaction sites in the PRINS sequence, and the corresponding sites occur in the 5' untranslated region (UTR) of IL-6 and the 3' UTR of CCL-5 (Fig. 15. A). No interaction site was predicted for IL-8.
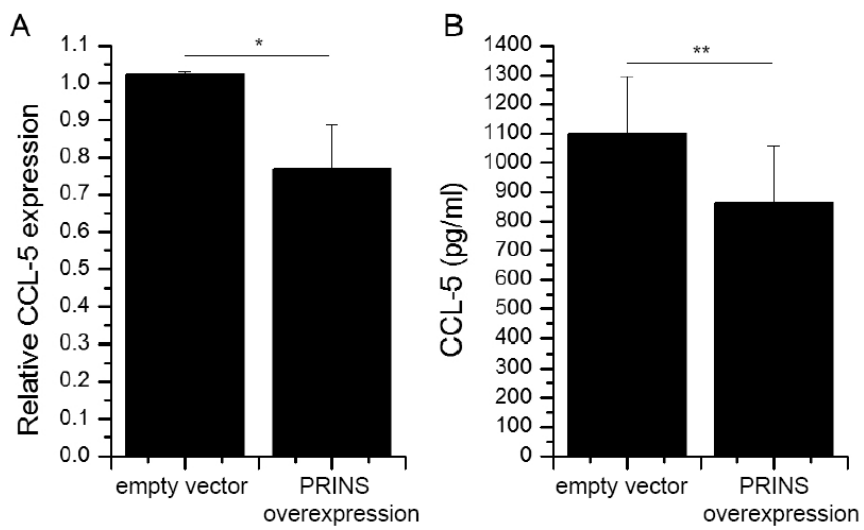

Figure 14. Overexpression of PRINS alters the expression and secretion of CCL-5. In parallel to priming with $5 \mathrm{ng} / \mathrm{ml}$ TNF- $\alpha$ and IFN- $\gamma$, NHEKs were transfected with a pcDNA3.1(+) vector containing the PRINS cDNA; an empty pcDNA3.1(+) vector was used as control. After 24 hours, cells were transfected with poly(dA:dT). RNA expression of CCL-5 was detected by real-time RT-PCR, secretion of CCL-5was measured by ELISA from cell supernatants. Data are presented as mean $\pm \mathrm{SE}$ of four independent experiments. $* \mathrm{p} \leq 0.05 ; * * \mathrm{p} \leq 0.01$. 


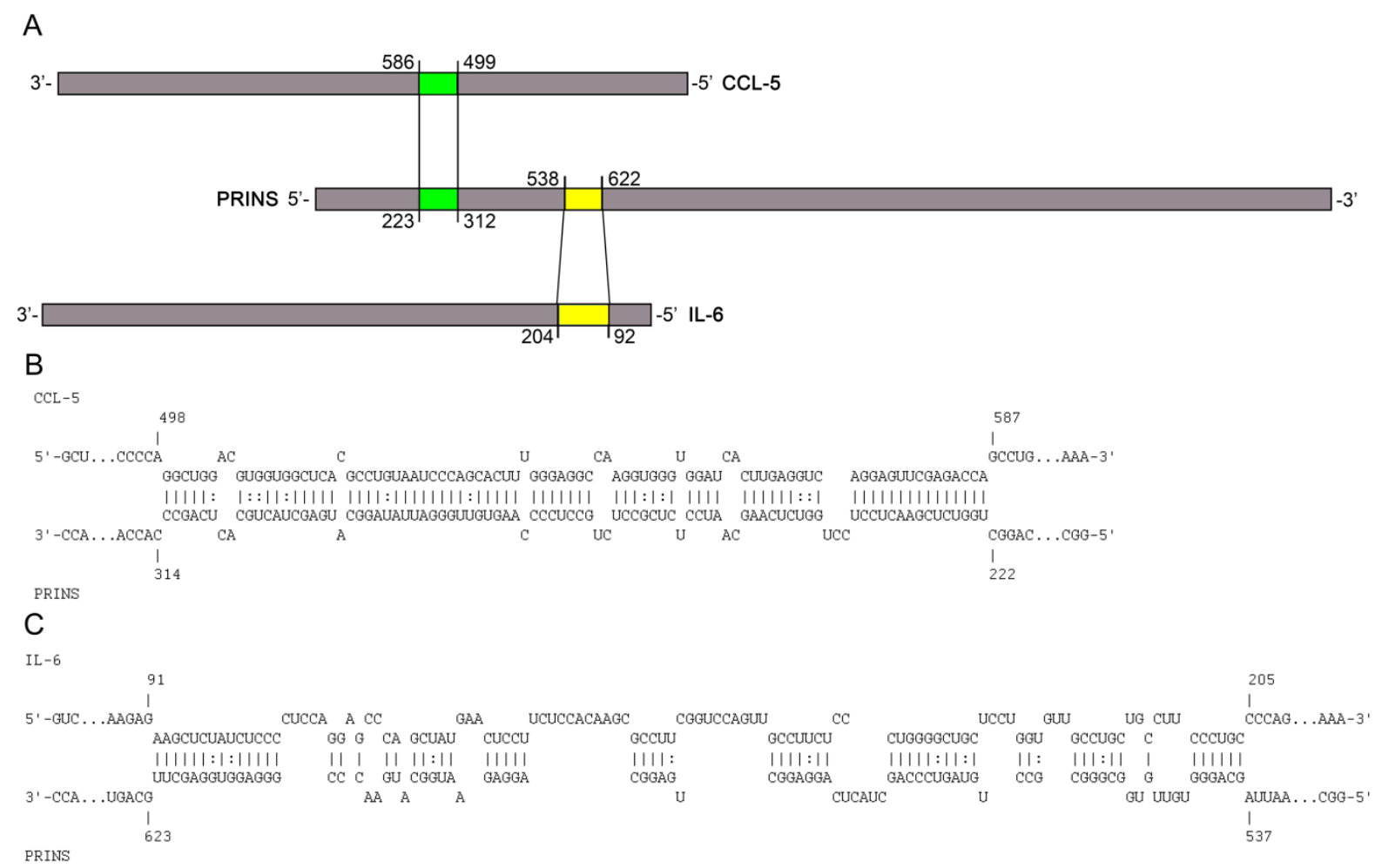

Figure 15. Putative interactions of PRINS IncRNA with CCL-5 and IL-6 mRNAs. Schematic representation of the in silico predicted interaction sites in the PRINS sequence for the CCL-5 and IL6 mRNAs (A). PRINS sequences predicted to interact with CCL-5 mRNA (B) and IL-6 mRNA (C). Nucleotide positions are given based on the AK022045, NM_000600.4 and NM_002985.2 reference sequences.

\subsection{PRINS binds to IL-6 mRNA through direct, sequence-specific interaction}

To validate the predicted interaction site, an in vitro binding experiment was carried out using the PRINS lncRNA and the IL-6 mRNA. Binding affinity was determined using the single-stranded PRINS RNA and a fluorescently labeled, truncated IL-6 mRNA sequence containing the predicted interacting sequence. The $\triangle$ PRINS sequence, in which the predicted interaction site to IL-6 was replaced by scrambled sequence, was used as a control. As a negative control, a fluorescently labeled DNA sequence with no similarity to either PRINS or IL-6 RNAs was used. While PRINS exhibited a very high binding affinity to the labeled IL-6 mRNA (Fig. 16. A, Kd=10.3436 nM), specific binding for $\triangle$ PRINS (Fig. 16. B) or the unspecific labeled DNA could not be detected. This in vitro result confirms the specificity of 
the in silico predicted regions (538-622 of PRINS, AK022045, and 92-204 of IL-6 mRNA, NM_000600.4).
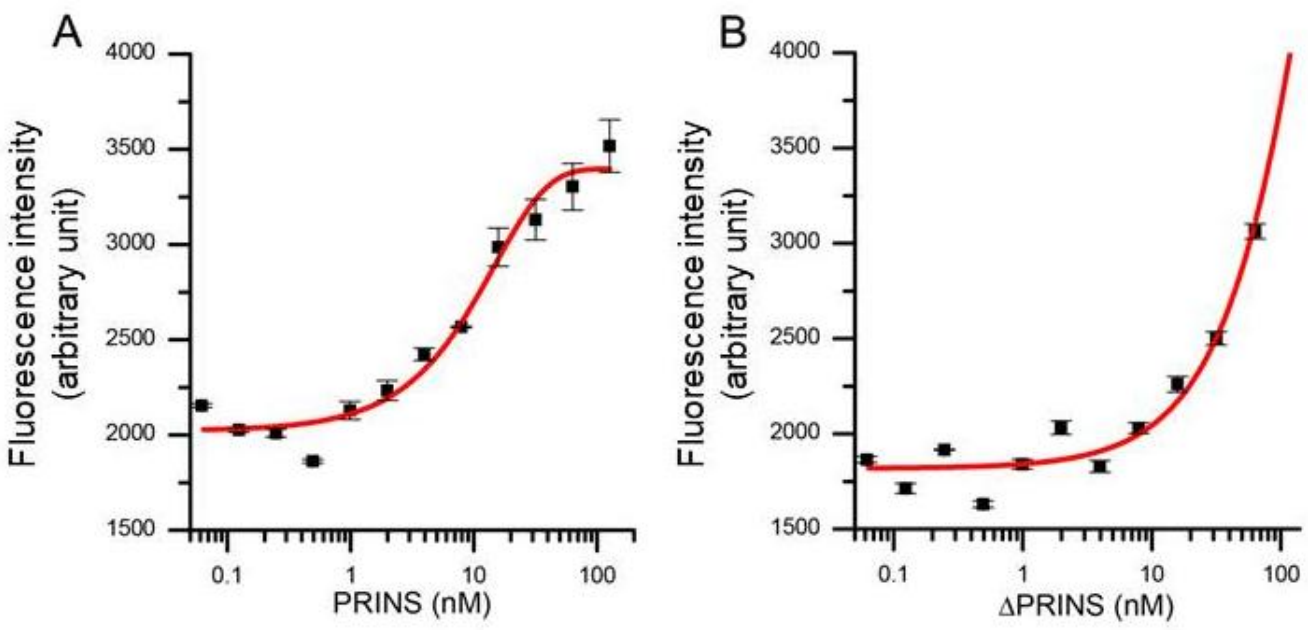

Figure 16. PRINS specifically binds to IL-6 mRNA. The binding affinity of PRINS (A) and $\triangle$ PRINS (B) to IL-6 mRNA was determined by analyzing the initial fluorescence enhancement caused by specific binding. The concentration of labeled IL-6 mRNA was constant (10nM), while the concentration of PRINS and $\triangle$ PRINS varied from $62 \mathrm{pM}$ to $127 \mathrm{nM}$.

\subsection{PRINS IncRNA regulates IL-6 expression in NHEKs through sequence- specific interaction}

To validate the functionality of the in silico predicted and in vitro determined IL-6 mRNA interacting region in the PRINS sequence, we performed the overexpression experiments in NHEKs with vectors containing the wildtype PRINS or $\triangle$ PRINS (with scrambled IL-6 binding site) sequences, during the combined priming and poly(dA:dT) treatment. IL-6 expression was not affected by overexpression of $\triangle \mathrm{PRINS}$ but was, in contrast, significantly decreased by PRINS overexpression (Fig. 17. A), and similar tendencies were seen in the amount of secreted IL-6 (Fig. 17. D). To confirm the specificity of this region in IL-6 regulation, the expression of CCL-5 was also studied. CCL-5 expression and secretion decreased similarly both in cells overexpressing $\triangle$ PRINS and in cells overexpressing PRINS (Fig. 17. B, E). IL-8 expression upon PRINS or $\triangle$ PRINS overexpression showed a similar tendency to IL-6 expression, although significant differences could not be detected (Fig. 17. $\mathrm{C}, \mathrm{F})$. These result demonstrated that the binding site in the PRINS sequence is essential and specific for the regulation of IL-6 expression. 

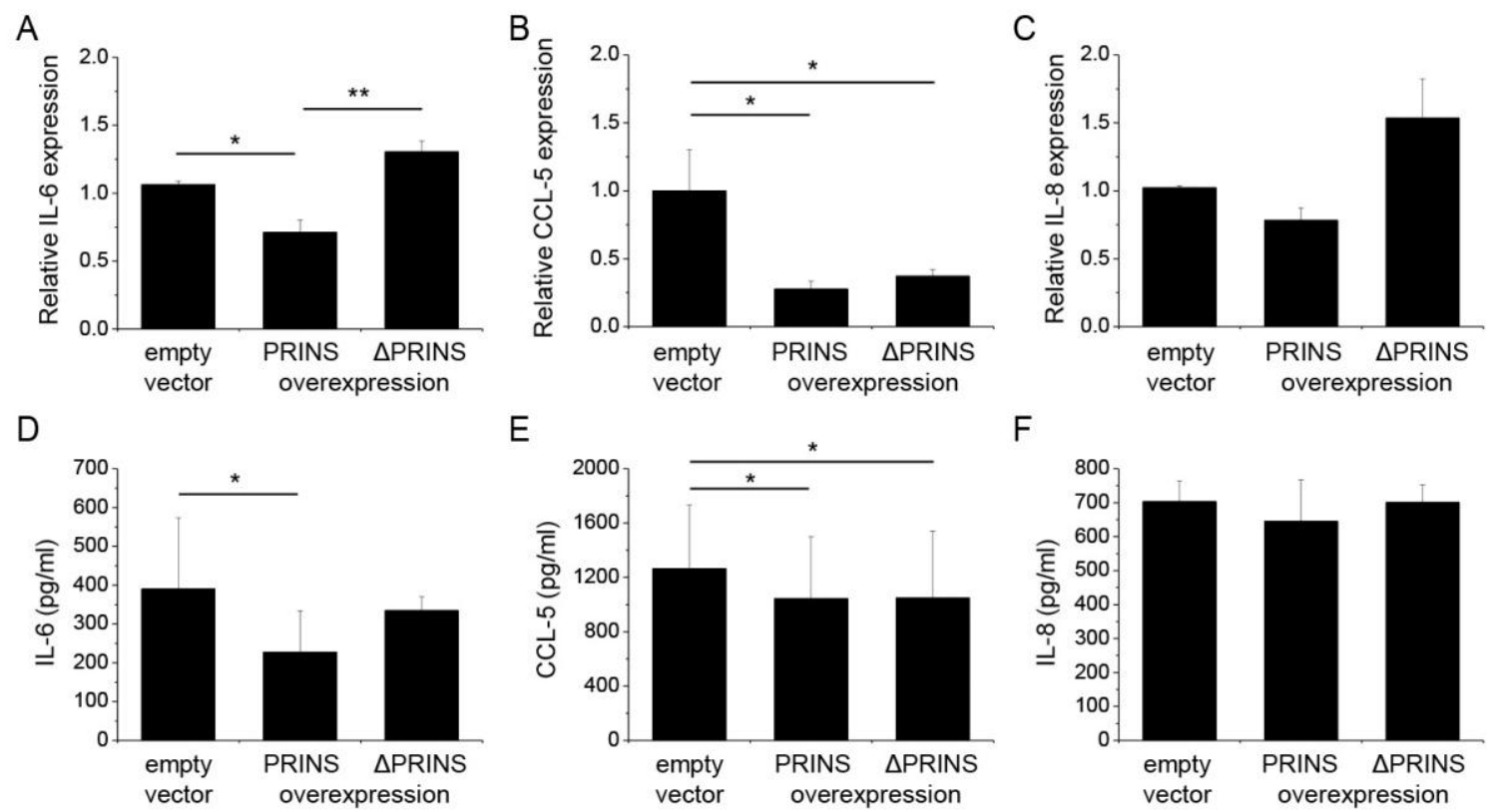

Figure 17. The 538-622 nt region of PRINS is required for the regulation of IL-6 expression. In parallel to priming with $5 \mathrm{ng} / \mathrm{ml}$ TNF- $\alpha$ and IFN- $\gamma$, NHEKs were transfected with a pcDNA3.1(+) vector containing the PRINS cDNA or the $\triangle$ PRINS cDNA (containing a scrambled version of the IL-6 binding site at positions 538-622 nt); the empty pcDNA3.1(+) vector served as control. Expression of cytokines IL-6 (A), CCL-5 (B) and IL-8 (C) was detected by real-time RT-PCR. Secretion of cytokines IL-6 (D), CCL-5 (E), IL-8 (F) was detected by ELISA from cell supernatants. Nucleotide positions based on the AK022045 reference sequence. Data are presented as mean \pm SE of three independent experiments $* \mathrm{p} \leq 0.05 ; * * \mathrm{p} \leq 0.01$. 


\section{Discussion}

RNA and DNA fragments are known as important PAMPs or DAMPs that induce innate immune processes of professional immune cells, such as macrophages and dendritic cells (DCs) (26,76-78), as well as non-professional immune cells, such as keratinocytes $(20,21)$. Accumulation of nucleotide fragments in keratinocytes contributes to the pathogenesis of psoriasis leading to parakeratosis (34), as well as in the promotion of inflammation by activating DCs (18) and to the activation of inflammasomes in keratinocytes $(14,28)$.

We have a deeper knowledge on RNA and DNA fragments induced processes in professional immune cells, much less is known for non-professional immune cells, such as keratinocytes. Thus, we aimed to study these reactions in keratinocytes. To study keratinocyte immune functions we applied treatments with the cytosolic dsRNA-analogue poly(I:C) and the cytosolic dsDNA-analogue poly(dA:dT), and characterized the immune responses of these cells with different approaches. The transcriptional regulation of signal transduction pathways and the posttranscriptional control by an IncRNA were also analyzed.

Our results are in agreement with recent reports describing inflammasome activation in keratinocytes $(13,14,28)$ and IL-6, IL-8 and TNF- $\alpha$ induction in canine keratinocytes (21) and human melanocytes (23) upon poly(dA:dT) exposition.

Previously we found that the inflammatory responses of the widely used HaCaT cell line upon exposure to Propionibacterium acnes differ from that of NHEKs, while the HPV-KER cell line (established and characterized in our laboratory) shows similar inflammatory $(70,79)$ and ultraviolet-B-irradiation-induced responses to NHEKs (64). Therefore, we compared the IL-6 and TNF- $\alpha$ expression of NHEK, HaCaT (69) and HPV-KER (70) cells after poly(I:C) and poly(dA:dT) exposure. In line with our previous findings (70), we found that the cytokine expression patterns in the HaCaT cells significantly differ from the responses of HPV-KER and NHEK cells. Moreover, HaCaT cells are thought to be less suitable to study inflammatory signaling pathways due to their constant NF- $\kappa B$ activation (80), therefore the HPV-KER cell line was selected to study the transcriptional regulation of nucleotide fragment induced cytokine expression.

NF- $\kappa \mathrm{B}$, MAPKs and STAT signaling have been reported to participate in nucleotidefragment-induced inflammatory cytokine expression in several cell types $(23,25,26,29,30)$; 
however, limited information is available for these signaling events in keratinocytes upon nucleotide fragment induction (20,75). According to our results, poly(I:C) induces activation of the studied signaling pathways in a shorter time than poly(dA:dT), and a corresponding shift in cytokine expression peaks was observed. The difference in peak timing is likely due to direct activation of TLR3 signaling by poly(I:C) (81); while it has been shown that poly(dA:dT) must first be transcribed to RNA before activating NF- $\kappa B$ through RIG-I dependent sensing (26) (Fig. 18.).

In addition to poly(I:C)- and poly(dA:dT)-induced NF- $\kappa \mathrm{B}$ activation, phosphorylation of ERK1/2, STAT-1 and STAT-3 was also observed; but the phosphorylation of other studied MAPKs (p38 and JNK) was not affected. In contrast, a previous study using keratinocytes reported poly(I:C) induction of p38 signaling but no induction of ERK1/2 signaling (20). In melanocytes, another epidermal cell type, poly(dA:dT)-induced phosphorylation of p38 and JNK signaling was observed without ERK1/2 activation (23). These differences might be due to differences in time points used: our study examined p38 phosphorylation 30 minutes after poly(I:C) and poly(dA:dT) transfection in HPV-KER cells, whereas the previous study examined p38 phosphorylation in NHEKs 15 minutes after treatment, observing a reduction after 30 minutes (20). These results suggest that poly(I:C)- and poly(dA:dT)-induced p38 phosphorylation might be a rapid event in keratinocytes. Although we could not confirm p38 phosphorylation, inhibition of $\mathrm{p} 38$ signaling during transfection with poly(I:C) or poly(dA:dT) resulted in decreased IL- 6 and TNF- $\alpha$ expression, which is in agreement with a previous report on poly(I:C)-induced TNF- $\alpha$ expression in keratinocytes (20).

In monocytes and melanocytes, inhibition of ERK1/2 and JNK signaling pathways abolished nucleotide-induced IL-6 and TNF- $\alpha$ expression $(23,82)$. In mouse models, the disruption of ERK1/2 signaling by the inhibition of dual specificity mitogen-activated protein kinase kinase 1 and 2 (MEK1/2) functions have been shown to have anti-inflammatory effects $(82,83)$. 


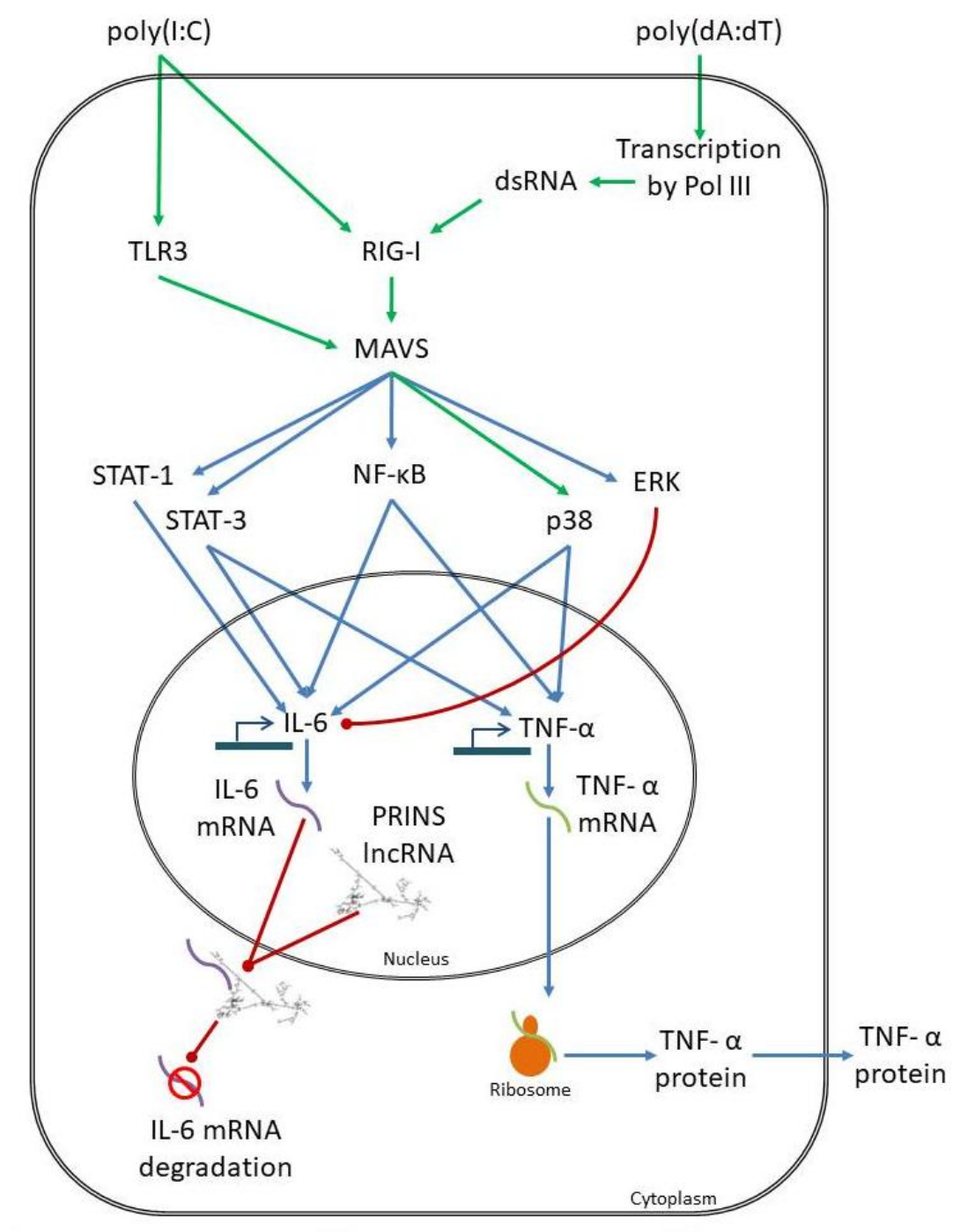

$\longrightarrow$ Induction based on our results $\longrightarrow$ Induction based on previous reports $\longrightarrow$ Inhibition based on our results

Figure 18. Schematic representation of $\operatorname{poly}(\mathrm{I}: \mathrm{C})$ and $\operatorname{poly}(\mathrm{dA}: \mathrm{dT})$ induced signaling events and posttranscriptional mRNA expression control in keratinocytes. Our results indicate that poly(I:C) and poly $(\mathrm{dA}: \mathrm{dT})$ induce the same inflammatory pathways; however the mode of sensing differs leading to the observed kinetic differences. The receptors for poly(I:C) sensing are toll-like receptor 3 (TLR3) (24) and retinoic acid induced gene I (RIG-I) (25). In contrast, poly(dA:dT) is transcribed to double-stranded (ds) RNA by RNA polymerase III (Pol III) and is subsequently sensed by RIG-I (26). The transcription step might be responsible for the delayed response to poly(dA:dT). The receptors activate the NF- $\mathrm{BB}$, MAPK and STAT signaling routes through the adaptor molecule mitochondrial antiviral signaling protein (MAVS), and, thus, regulate the transcription of the cytokines. The mRNA of the cytokines either is translated by ribosomes and the protein is secreted by the cells, as in the case of TNF- $\alpha$, or they undergo posttranscriptional degradation induced by the sequence specific binding of PRINS lncRNA, as in the case of IL-6 
In contrast, in our experiments the disruption of ERK1/2 signaling through inhibition of MEK1/2 kinases increased the expression of the inflammatory mediator IL-6. These results are in agreement with previous in vivo findings that therapeutic inhibition of MEK1/2 in patients is often accompanied by an inflammatory skin rash (84). The results suggest that ERK1/2 signaling - in contrast to other cell types - has a negative regulatory function in inflammatory reactions in keratinocytes. Previous reports have already demonstrated similar results: ERK1/2 signaling was shown to negatively regulate NF- $\kappa \mathrm{B}$ activation (85), and inhibition of MEK1/2 led to increased NF- $\mathrm{B}$, STAT-1 and interferon-regulatory factor signaling in human keratinocytes (86), although, we did not observe an increase in NF- $\mathrm{B}$ activation upon inhibition of ERK1/2 signaling.

STAT signaling is known to be induced by inflammatory cytokines (87) and by poly(I:C) treatment $(20,75)$. We found that in addition to poly(I:C), poly(dA:dT) also induced STAT-1 and STAT-3 signaling in keratinocytes. Moreover, similarly to the observed NF- $\mathrm{B}$ activation, STAT-1 and STAT-3 activation both exhibited a delay after poly(dA:dT) transfection compared to poly(I:C) treatment. Poly(I:C)-induced STAT-1 activation has been shown to regulate TLR-3 and TNF- $\alpha$ expression (20). In our experiments, STAT-1 was found to regulate poly(I:C)- and poly(dA:dT)-induced IL-6 expression, whereas TNF- $\alpha$ was not affected. Inhibition of STAT-3 abolished both poly(I:C)- and poly(dA:dT)-induced IL-6 and TNF- $\alpha$ expression, showing the different regulatory functions of each STAT transcription factors.

Due to large-scale gene-expression studies the number of annotated human non-coding RNAs has increased rapidly (88), but functional roles have been assigned only to a few of them $(89,90)$. PRINS was one of the first lncRNAs described to be dysregulated in a disease, namely in psoriasis (39). The expression of PRINS increases in response to various cellular stressors (56) in HaCaT cells, as well as to hypoxia in HK-2 cells (57) suggesting that PRINS contributes to the stress response of the cells. We aimed to study how PRINS expression is changed in response to nucleotide fragment induction in keratinocytes, and whether PRINS plays a role in the nucleotide fragment induced stress responses of keratinocytes. We found that poly $(\mathrm{dA}: \mathrm{dT})$ treatment decreased PRINS expression in NHEKs in line with previous reports in NHEKs and macrophages upon inflammatory stimuli $(56,67)$. To gain a more pronounced and more uniform inflammatory cytokine expression in NHEKs, we introduced a 
combined treatment. Since before poly(dA:dT) treatment a priming step with the cytokines TNF- $\alpha$ and IFN- $\gamma-$ which were described as key elements in keratinocyte immune responses (40) - is often applied to induce a pronounced inflammasome activation (14), we analysed the effect of the priming step on the expression of various cytokines. Priming induced significantly enhanced IL-6 and IL-8 mRNA expression. In addition, cytokine secretion was also significantly increased compared to poly $(\mathrm{dA}: \mathrm{dT})$ treatment alone.

PRINS was recently described to potentially interact with the CCL-5 mRNA (57), but the functions of this interaction remained to be elucidated. In this study, we demonstrate that PRINS overexpression decreases the expression of IL-6, IL-8 and CCL-5 in keratinocytes upon poly(dA:dT) treatment. In addition, decreased IL-6 expression was observed upon PRINS overexpression in UVB treated samples as well. Using in silico analysis, regions in the PRINS sequence were predicted to interact with the CCL-5 and IL-6 mRNA. As inhibition of transcription by DNA:IncRNA triplex formation or posttranscriptional destabilization of the mRNA by mRNA-lncRNA duplex formation has been reported (89), we analyzed the sequences and found that the interacting site on IL-6 spans two exons, indicating an mRNAlncRNA interaction. Moreover, PRINS demonstrated perinuclear localization in keratinocytes (64), making it possible to exert its effect at the posttranscriptional level. The mRNA-lncRNA interaction was validated in vitro: PRINS showed a very high binding affinity $(\mathrm{Kd}=10.3436$ $\mathrm{nM}$ ) to IL-6 mRNA, and the destruction of the predicted binding site abolished the ability of PRINS to bind to the IL-6 mRNA. The binding site of PRINS lies within the 5' UTR of the IL-6 mRNA, which is a rare phenomenon. The majority ( 40\%) of lncRNAs bind to the 3' UTR of their target mRNAs, while only around 5\% of lncRNAs is able to bind to the 5' UTR of their target (91). The functionality of the mRNA-lncRNA interaction was also observed at the cellular level, as overexpression of $\triangle$ PRINS, in which the IL-6 interacting site is scrambled, did not decrease IL-6 levels. Thus, we demonstrated that PRINS is able to bind the IL-6 mRNA and this specific interaction destabilizes IL-6 expression and secretion in NHEKs (Fig. 18.).

Similarly to IL-6, PRINS overexpression decreased the expression of IL-8, but no interaction site could be predicted on IL-8 mRNA. We hypothesize that this is a secondary effect (92), however we cannot exclude the possibility of a yet unknown interaction site between PRINS and IL-8 mRNA. 
Like many other non-coding RNAs, PRINS seems to have multiple cellular functions (43). It binds to nucleophosmin, a chaperon protein, and facilitates its transition from the nucleolus to the nucleoplasm upon UVB irradiation (64). Additionally, our recent results suggest that PRINS is involved in the regulation of inflammation by inhibiting cytokine expression.

In this study, we show the similarities as well as the differences in inflammatory signaling events of keratinocytes induced by dsRNA and dsDNA, moreover provide a novel model of posttranscriptional control of cytokine expression in these cells by an lncRNA. Although dsRNA and dsDNA are recognized by different sets of receptors, they induce the same inflammatory signaling pathways in keratinocytes, however with different kinetics and magnitude of activation. Our data revealed that transfection with the synthetic dsRNA and dsDNA analogues poly(I:C) and poly(dA:dT) induced activation of NF- $\kappa B$ and STAT signaling, which along with p38 signaling were also shown to be functional in inducing cytokine mRNA expression. Moreover, we showed the negative regulatory role of ERK1/2 signaling in nucleotide-induced cytokine mRNA expression. Another negative regulatory role was proven for PRINS lncRNA in poly(dA:dT) induced IL-6 and CCL-5 expression, through sequence specific binding to the mRNA of the cytokines. Based on our current and previous findings $(39,56,57)$, we hypothesize that elevated PRINS expression in psoriatic uninvolved epidermis may contribute to downregulation of the inflammatory functions in psoriatic keratinocytes and maintenance of normal phenotype.

Studies of the last decade have highlighted disturbances in the signal transduction events in psoriasis that have led to the development of targeted therapeutics against specific signaling components. However, there is still a lack of knowledge on every pre- and posttranscriptional aspect of these mechanisms. Our studies were performed using a non-professional immune cell type, keratinocytes; however the same mechanisms might be also relevant in professional immune cells. These results deepen the existing knowledge and contribute to the understanding of these signaling events and the posttranscriptional control in keratinocytes, moreover widen our knowledge on the cellular functions of PRINS and, in general, about lncRNAs. 


\section{Summary, novel findings of the experimental work}

In this study, we characterized the dsRNA and dsDNA induced immune responses in human keratinocytes by studying pre- and posttranscriptional regulation of cytokine expression.

- We compared the dsRNA and dsDNA induced cytokine expression in three keratinocyte cell types: NHEKs, HaCaT cells and HPV-KER cells. We found that transfection by the synthetic dsRNA and dsDNA analogue poly(I:C) and poly(dA:dT) induce the expression of IL-6 and TNF- $\alpha$ with notable kinetic differences and rate of induction.

- We found that poly(I:C) and poly(dA:dT) induce the same inflammatory signaling pathways in keratinocytes, albeit with different kinetics and magnitude of activation. Our data revealed that transfection with poly(I:C) and poly(dA:dT) induced activation of NF- $\mathrm{KB}$ and STAT signaling, which along with p38 signaling were also shown to be functional in inducing cytokine mRNA expression. We also showed the negative regulatory role of ERK1/2 signaling in nucleotide-induced IL-6 mRNA expression in keratinocytes, which seems to be a celltype specific event.

- By studying the expression pattern of PRINS IncRNA we found decreased expression upon poly(dA:dT) transfection in NHEKs, while poly(I:C) did not led to altered expression of PRINS.

- We have identified a potential negative regulatory role for PRINS lncRNA in poly(dA:dT) induced IL-6 and CCL-5 expression. In-depth analysis of this phenomenon revealed the sequence specific interaction between PRINS and the mRNA of IL-6 and CCL-5, which might be responsible for the posttranscriptional control of the mRNA expression. These results led us to hypothesize that elevated PRINS expression in psoriatic uninvolved epidermis may contribute to the downregulation of the inflammatory functions in psoriatic keratinocytes and maintenance of the normal phenotype. 


\section{Acknowledgement}

I would like to express my deepest gratitude to my supervisor, Professor Márta Széll, for her constant support and supervision of my work. She always stood by, when I needed her guidance and support, but also provided me enough independence during my scientific work.

I would like to thank Professor Lajos Kemény for the opportunity to be able to join the MTASZTE Dermatological Research Group and perform my studies here.

It also gives me a pleasure to thank Professor Zsuzsanna Bata-Csörgö for her ideas and comments related to my work and during the preparation of the manuscripts.

I would like to express my special thanks to Kornélia Szabó for her support and valuable suggestions, and her continuous help with technical questions and issues during my work.

I am grateful to my colleagues Anikó Göblös, Lilla Erdei, Beáta Szilvia Bolla, Barbara Konczné Gubán and Renáta Bozó for introducing and helping me with the research techniques and for their friendship and support during the years. I also thank all of my colleagues, who have helped me at any stages at the Department of Dermatology and Allergology and at the MTA-SZTE Dermatological Research Group.

During my work at the research group, I was lucky to supervise the work of two talented and enthusiastic undergraduate students: Letizia La Rosa form the University of Catania and Luca Janovák from the University of Szeged. They both have contributed to the manual work which led to the results of this Thesis, and through the supervision of their laboratory work and Bachelor's Thesis preparation I had a great opportunity to learn about research management and improve my skills on how to introduce and guide students in their scientific research.

My special thanks go to my friends and family, for their patience, constant support, encouragement and endless love. And last but not least, thank you Gergő for your love. Without you and your special support in the last two years I would not be here now. Thank you!

This study was supported by several research grants from the National Research, Development and Innovation Office (OTKA K105985, K111885, GINOP-2.3.2-15-2016-00015) and by the National Talent Program (NTP-NFTÖ-17-B-0164) provided by the Hungarian Ministry of Human Capacities. 


\section{References}

1. Di Meglio P, Perera GK, Nestle FO. The multitasking organ: recent insights into skin immune function. Immunity (2011) 35:857-69. doi:10.1016/j.immuni.2011.12.003

2. Watt FM. Mammalian skin cell biology: at the interface between laboratory and clinic. Science (2014) 346:937-40. doi:10.1126/science.1253734

3. Khavkin J, Ellis DAF. Aging Skin: Histology, Physiology, and Pathology. Facial Plast Surg Clin North Am (2011) 19:229-234. doi:10.1016/j.fsc.2011.04.003

4. Nestle FO, Kaplan DH, Barker J. Mechanism of disease: Psoriasis. N Engl J Med (2009) 361:496-509.

5. Roberson EDO, Bowcock AM. Psoriasis genetics: breaking the barrier. Trends Genet (2010) 26:415-23. doi:10.1016/j.tig.2010.06.006

6. Pivarcsi A, Koreck A, Bodai L, Széll M, Szeg C, Belso N, Kenderessy-Szabó A, BataCsörgo Z, Dobozy A, Kemény L. Differentiation-regulated expression of toll-like receptors 2 and 4 in HaCat keratinocytes. Arch Dermatol Res (2004) 296:120-124. doi:10.1007/s00403-004-0475-2

7. Köllisch G, Kalali BN, Voelcker V, Wallich R, Behrendt H, Ring J, Bauer S, Jakob T, Mempel M, Ollert M. Various members of the Toll-like receptor family contribute to the innate immune response of human epidermal keratinocytes. Immunology (2005) 114:531-41. doi:10.1111/j.1365-2567.2005.02122.x

8. Baker BS, Ovigne J-M, Powles A V, Corcoran S, Fry L. Normal keratinocytes express Toll-like receptors (TLRs) 1, 2 and 5: modulation of TLR expression in chronic plaque psoriasis. $B r \quad J$ Dermatol (2003) 148:670-9. Available at: http://www.ncbi.nlm.nih.gov/pubmed/12752123

9. Mempel M, Voelcker V, Köllisch G, Plank C, Rad R, Gerhard M, Schnopp C, Fraunberger P, Walli AK, Ring J, et al. Toll-Like Receptor Expression in Human Keratinocytes: Nuclear Factor $\kappa \mathrm{B}$ Controlled Gene Activation by Staphylococcus aureus is Toll-Like Receptor 2 but Not Toll-Like Receptor 4 or Platelet Activating Factor Receptor Dependent. J Invest Dermatol (2003) 121:1389-1396. doi:10.1111/j.1523-1747.2003.12630.x 
10. Tervaniemi M, Katayama S, Skoog T, Siitonen H, Vuola J, Nuutila K, Sormunen R, Johnsson A, Linnarsson S, Suomela S, et al. NOD-like receptor signaling and inflammasome-related pathways are highlighted in psoriatic epidermis. Sci Rep (2016) 6:22745. doi:10.1038/srep22745

11. Prens EP, Kant M, van Dijk G, van der Wel LI, Mourits S, van der Fits L. IFN-alpha enhances poly-IC responses in human keratinocytes by inducing expression of cytosolic innate RNA receptors: relevance for psoriasis. J Invest Dermatol (2008) 128:932-938. doi:10.1038/sj.jid.5701087

12. Rathinam V a K, Vanaja SK, Fitzgerald $\mathrm{K}$ a. Regulation of inflammasome signaling. Nat Immunol (2012) 13:333-2. doi:10.1038/ni.2237

13. Kopfnagel V, Wittmann M, Werfel T. Human keratinocytes express AIM2 and respond to dsDNA with IL-1 $\beta$ secretion. Exp Dermatol (2011) 20:1027-9. doi:10.1111/j.16000625.2011.01382.x

14. Dombrowski Y, Peric M, Koglin S, Kammerbauer C, Göss C, Anz D, Simanski M, Gläser R, Harder J, Hornung V, et al. Cytosolic DNA triggers inflammasome activation in keratinocytes in psoriatic lesions. Sci Transl Med (2011) 3:82ra38. doi:10.1126/scitranslmed.3002001

15. Nestle FO, Di Meglio P, Qin J-Z, Nickoloff BJ. Skin immune sentinels in health and disease. Nat Rev Immunol (2009) 9:679-91. doi:10.1038/nri2622

16. Luecke S, Paludan SR. Molecular requirements for sensing of intracellular microbial nucleic acids by the innate immune system. Cytokine (2016) 98:4-14. doi:10.1016/j.cyto.2016.10.003

17. West AP, Khoury-Hanold W, Staron M, Tal MC, Pineda CM, Lang SM, Bestwick M, Duguay BA, Raimundo N, MacDuff DA, et al. Mitochondrial DNA stress primes the antiviral innate immune response. Nature (2015) 520:553-557. doi:10.1038/nature14156

18. Lande R, Gregorio J, Facchinetti V, Chatterjee B, Wang Y-H, Homey B, Cao W, Wang Y-H, Su B, Nestle FO, et al. Plasmacytoid dendritic cells sense self-DNA coupled with antimicrobial peptide. Nature (2007) 449:564-9. doi:10.1038/nature06116 
19. Olejniczak M, Galka-Marciniak P, Polak K, Fligier A, Krzyzosiak WJ. RNAimmuno: a database of the nonspecific immunological effects of RNA interference and microRNA reagents. RNA (2012) 18:930-5. doi:10.1261/rna.025627.110

20. Dai X, Sayama K, Tohyama M, Shirakata Y, Yang L, Hirakawa S, Tokumaru S, Hashimoto K. The NF-kappaB, p38 MAPK and STAT1 pathways differentially regulate the dsRNA-mediated innate immune responses of epidermal keratinocytes. Int Immunol (2008) 20:901-9. doi:10.1093/intimm/dxn048

21. Luff JA, Yuan H, Kennedy D, Schlegel R, Felsburg P, Moore PF. Keratinocyte antiviral response to poly(dA:dT) stimulation and papillomavirus infection in a canine model of X-linked severe combined immunodeficiency. PLoS One (2014) 9:1-8. doi:10.1371/journal.pone.0102033

22. Luff JA, Yuan H, Suter MM, Müller EJ, Schlegel R, Moore PF. Canine keratinocytes upregulate type I interferons and proinflammatory cytokines in response to poly(dA: dT) but not to canine papillomavirus. Vet Immunol Immunopathol (2013) 153:177-186. doi:10.1016/j.vetimm.2013.02.001

23. Wang S, Liu D, Ning W, Xu A. Cytosolic dsDNA triggers apoptosis and proinflammatory cytokine production in normal human melanocytes. Exp Dermatol (2015) 24:298-300. doi:10.1111/exd.12621

24. Alexopoulou L, Holt AC, Medzhitov R, Flavell RA. Recognition of double-stranded RNA and activation of NF-кB by Toll-like receptor 3. Nature (2001) 413:732-738. doi:10.1038/35099560

25. Cheng G, Zhong J, Chung J, Chisari F V. Double-stranded DNA and double-stranded RNA induce a common antiviral signaling pathway in human cells. Proc Natl Acad Sci U S A (2007) 104:9035-9040. doi:10.1073/pnas.0703285104

26. Ablasser A, Bauernfeind F, Hartmann G, Latz E, Fitzgerald KA, Hornung V. RIG-I dependent sensing of poly $(\mathrm{dA}-\mathrm{dT})$ via the induction of an RNA polymerase III transcribed RNA intermediate. Nat Immunol (2009) 10:1065-72. doi:10.1038/ni.1779

27. Almine JF, O’Hare CAJ, Dunphy G, Haga IR, Naik RJ, Atrih A, Connolly DJ, Taylor J, Kelsall IR, Bowie AG, et al. IFI16 and cGAS cooperate in the activation of STING 
during DNA sensing in human keratinocytes. Nat Commun (2017) 8:14392. doi:10.1038/ncomms14392

28. Göblös A, Danis J, Vas K, Bata-Csörgő Z, Kemény L, Széll M. Keratinocytes express functional CARD18, a negative regulator of inflammasome activation, and its altered expression in psoriasis may contribute to disease pathogenesis. Mol Immunol (2016) 73:10-18. doi:10.1016/j.molimm.2016.03.009

29. Shin J-M, Choi D-K, Sohn K-C, Kim S-Y, Min Ha J, Ho Lee Y, Im M, Seo Y-J, Deok Kim C, Lee J-H, et al. Double-stranded RNA induces inflammation via the NF- $\mathrm{B}$ pathway and inflammasome activation in the outer root sheath cells of hair follicles. Sci Rep (2017) 7:44127. doi:10.1038/srep44127

30. Zhou M-W, Jiang R-H, Kim K-D, Lee J-H, Kim C-D, Yin W-T, Lee J-H. Rosmarinic acid inhibits poly(I:C)-induced inflammatory reaction of epidermal keratinocytes. Life Sci (2016) 155:189-194. doi:10.1016/j.lfs.2016.05.023

31. Cao T, Shao S, Li B, Jin L, Lei J, Qiao H, Wang G. Up-regulation of Interferoninducible protein 16 contributes to psoriasis by modulating chemokine production in keratinocytes. Sci Rep (2016) 6:25381. doi:10.1038/srep25381

32. Molès J-P, Griez A, Guilhou J-J, Girard C, Nagot N, Van de Perre P, Dujols P. Cytosolic RNA:DNA Duplexes Generated by Endogenous Reverse Transcriptase Activity as Autonomous Inducers of Skin Inflammation in Psoriasis. PLoS One (2017) 12:e0169879. doi:10.1371/journal.pone.0169879

33. Fischer H, Szabo S, Scherz J, Jaeger K, Rossiter H, Buchberger M, Ghannadan M, Hermann M, Theussl H-C, Tobin DJ, et al. Essential Role of the Keratinocyte-Specific Endonuclease DNase1L2 in the Removal of Nuclear DNA from Hair and Nails. $J$ Invest Dermatol (2011) 131:1208-1215. doi:10.1038/jid.2011.13

34. Fischer H, Buchberger M, Napirei M, Tschachler E, Eckhart L. Inactivation of DNase1L2 and DNase2 in keratinocytes suppresses DNA degradation during epidermal cornification and results in constitutive parakeratosis. Sci Rep (2017) 7:6433. doi:10.1038/s41598-017-06652-8

35. Ruiz-Romeu E, Ferran M, Giménez-Arnau A, Bugara B, Lipert B, Jura J, Florencia EF, 
Prens EP, Celada A, Pujol RM, et al. MCPIP1 RNase Is Aberrantly Distributed in Psoriatic Epidermis and Rapidly Induced by IL-17A. J Invest Dermatol (2016) 136:1599-1607. doi:10.1016/J.JID.2016.04.030

36. Kopfnagel V, Wagenknecht S, Harder J, Hofmann K, Kleine M, Buch A, Sodeik B, Werfel T. RNase 7 strongly promotes TLR9-mediated DNA sensing by human plasmacytoid dendritic cells. J Invest Dermatol (2017) E-pub ahea: doi:10.1016/j.jid.2017.09.052

37. Bata-Csorgo Z, Cooper KD, Ting KM, Voorhees JJ, Hammerberg C. Fibronectin and alpha5 integrin regulate keratinocyte cell cycling. A mechanism for increased fibronectin potentiation of $\mathrm{T}$ cell lymphokine-driven keratinocyte hyperproliferation in psoriasis. J Clin Invest (1998) 101:1509-1518. doi:10.1172/JCI171

38. Széll M, Bata-Csörgő Z, Koreck A, Pivarcsi A, Polyánka H, Szeg C, Gaál M, Dobozy A, Kemény L. Proliferating keratinocytes are putative sources of the psoriasis susceptibility-related EDA + (extra domain A of fibronectin) oncofetal fibronectin. $J$ Invest Dermatol (2004) 123:537-46. doi:10.1111/j.0022-202X.2004.23224.x

39. Sonkoly E, Bata-Csörgő Z, Pivarcsi A, Polyánka H, Kenderessy-Szabó A, Molnár G, Szentpáli K, Bari L, Megyeri K, Mándi Y, et al. Identification and characterization of a novel, psoriasis susceptibility-related noncoding RNA gene, PRINS. J Biol Chem (2005) 280:24159-67. doi:10.1074/jbc.M501704200

40. Szabó K, Bata-Csörgő Z, Dallos A, Bebes A, Francziszti L, Dobozy A, Kemény L, Széll M. Regulatory Networks Contributing to Psoriasis Susceptibility. Acta Derm Venereol (2014) 94:380-5. doi:10.2340/00015555-1708

41. Szlavicz E, Szabo K, Groma G, Bata-Csorgo Z, Pagani F, Kemeny L, Szell M. Splicing factors differentially expressed in psoriasis alter mRNA maturation of diseaseassociated EDA+ fibronectin. Mol Cell Biochem (2017) 436:189-199. doi:10.1007/s11010-017-3090-1

42. St.Laurent G, Wahlestedt C, Kapranov P. The Landscape of long noncoding RNA classification. Trends Genet (2015) 31:249-251. doi:10.1016/j.tig.2015.03.007

43. Kapusta A, Feschotte C. Volatile evolution of long noncoding RNA repertoires: 
mechanisms and biological implications. Trends Genet (2014) 30:439-452. doi:10.1016/j.tig.2014.08.004

44. Palazzo AF, Lee ES. Non-coding RNA: What is functional and what is junk? Front Genet (2015) 5:1-11. doi:10.3389/fgene.2015.00002

45. Iyer MK, Niknafs YS, Malik R, Singhal U, Sahu A, Hosono Y, Barrette TR, Prensner JR, Evans JR, Zhao S, et al. The landscape of long noncoding RNAs in the human transcriptome. Nat Genet (2015) 47:199-208. doi:10.1038/ng.3192

46. Kornienko AE, Dotter CP, Guenzl PM, Gisslinger H, Gisslinger B, Cleary C, Kralovics R, Pauler FM, Barlow DP. Long non-coding RNAs display higher natural expression variation than protein-coding genes in healthy humans. Genome Biol (2016) 17:14. doi:10.1186/s13059-016-0873-8

47. Ilott NE, Heward JA, Roux B, Tsitsiou E, Fenwick PS, Lenzi L, Goodhead I, HertzFowler C, Heger A, Hall N, et al. Long non-coding RNAs and enhancer RNAs regulate the lipopolysaccharide-induced inflammatory response in human monocytes. Nat Commun (2014) 5:3979. doi:10.1038/ncomms4979

48. Roux BT, Heward JA, Donnelly LE, Jones SW, Lindsay MA. Catalog of Differentially Expressed Long Non-Coding RNA following Activation of Human and Mouse Innate Immune Response. Front Immunol (2017) 8:1038. doi:10.3389/fimmu.2017.01038

49. Imamura K, Imamachi N, Akizuki G, Kumakura M, Kawaguchi A, Nagata K, Kato A, Kawaguchi Y, Sato H, Yoneda M, et al. Long noncoding RNA NEAT1-dependent SFPQ relocation from promoter region to paraspeckle mediates IL8 expression upon immune stimuli. Mol Cell (2014) 53:393-406. doi:10.1016/j.molcel.2014.01.009

50. Li Z, Chao T-C, Chang K-Y, Lin N, Patil VS, Shimizu C, Head SR, Burns JC, Rana TM. The long noncoding RNA THRIL regulates TNF $\alpha$ expression through its interaction with hnRNPL. Proc Natl Acad Sci U S A (2014) 111:1002-1007. doi:10.1073/pnas.1313768111

51. Tsoi LC, Iyer MK, Stuart PE, Swindell WR, Gudjonsson JE, Tejasvi T, Sarkar MK, Li B, Ding J, Voorhees JJ, et al. Analysis of long non-coding RNAs highlights tissuespecific expression patterns and epigenetic profiles in normal and psoriatic skin. 
Genome Biol (2015) 16:24. doi:10.1186/s13059-014-0570-4

52. Li Z, Rana TM. Decoding the noncoding: Prospective of lncRNA-mediated innate immune regulation. RNA Biol (2014) 11: Available at: http://www.ncbi.nlm.nih.gov/pubmed/25136794 [Accessed September 24, 2014]

53. Abba ML, Patil N, Leupold JH, Moniuszko M, Utikal J, Niklinski J, Allgayer H. MicroRNAs as novel targets and tools in cancer therapy. Cancer Lett (2017) 387:8494. doi:10.1016/j.canlet.2016.03.043

54. Maass PG, Luft FC, Bähring S. Long non-coding RNA in health and disease. $J$ Mol Med (2014) 92:337-346. doi:10.1007/s00109-014-1131-8

55. Gutschner T, Diederichs S. The hallmarks of cancer: a long non-coding RNA point of view. RNA Biol (2012) 9:703-719. doi:10.4161/rna.20481

56. Bari L, Bacsa S, Sonkoly E, Bata-Csörgő Z, Kemény L, Dobozy A, Széll M. Comparison of stress-induced PRINS gene expression in normal human keratinocytes and HaCaT cells. Arch Dermatol Res (2011) 303:745-52. doi:10.1007/s00403-011$1162-8$

57. Yu T-M, Palanisamy K, Sun K-T, Day Y-J, Shu K-H, Wang I-K, Shyu W-C, Chen P, Chen Y-L, Li C-Y. RANTES mediates kidney ischemia reperfusion injury through a possible role of HIF-1 $\alpha$ and LncRNA PRINS. Sci Rep (2016) 6:18424. doi:10.1038/srep18424

58. Széll M, Danis J, Bata-Csörgő Z, Kemény L. PRINS, a primate-specific long noncoding RNA, plays a role in the keratinocyte stress response and psoriasis pathogenesis. Pflügers Arch - Eur J Physiol (2016) 468:935-943. doi:10.1007/s00424016-1803-z

59. Suda H, Lee KJ, Semba K, Kyushima F, Ando T, Araki M, Araki K, Inomata Y, Yamamura KI. The Skt gene, required for anorectal development, is a candidate for a molecular marker of the cloacal plate. Pediatr Surg Int (2011) 27:269-273. doi:10.1007/s00383-010-2785-0

60. Rosenbloom KR, Sloan CA, Malladi VS, Dreszer TR, Learned K, Kirkup VM, Wong MC, Maddren M, Fang R, Heitner SG, et al. ENCODE data in the UCSC Genome 
Browser: year 5 update. Nucleic Acids Res (2013) 41:D56-63. doi:10.1093/nar/gks1172

61. Kelley DR, Rinn JL. Transposable elements reveal a stem cell specific class of long noncoding RNAs. Genome Biol (2012) 13:R107. doi:10.1186/gb-2012-13-11-r107

62. Kapusta A, Kronenberg Z, Lynch VJ, Zhuo X, Ramsay LA, Bourque G, Yandell M, Feschotte C. Transposable Elements Are Major Contributors to the Origin, Diversification, and Regulation of Vertebrate Long Noncoding RNAs. PLoS Genet (2013) 9: doi:10.1371/journal.pgen.1003470

63. Szegedi K, Sonkoly E, Nagy N, Németh IB, Bata-Csörgő Z, Kemény L, Dobozy A, Széll M. The anti-apoptotic protein G1P3 is overexpressed in psoriasis and regulated by the non-coding RNA, PRINS. Exp Dermatol (2010) 19:269-78. doi:10.1111/j.16000625.2010.01066.x

64. Szegedi K, Göblös A, Bacsa S, Antal M, Németh IB, Bata-Csörgő Z, Kemény L, Dobozy A, Széll M. Expression and Functional Studies on the Noncoding RNA, PRINS. Int J Mol Sci (2013) 14:205-25. doi:10.3390/ijms14010205

65. Kapranov P, Cheng J, Dike S, Nix DA, Duttagupta R, Willingham AT, Stadler PF, Hertel J, Hackermüller J, Hofacker IL, et al. RNA maps reveal new RNA classes and a possible function for pervasive transcription. Science (80- ) (2007) 316:1484-1488. doi:10.1126/science. 1138341

66. Zhang B, Gunawardane L, Niazi F, Jahanbani F, Chen X, Valadkhan S. A Novel RNA Motif Mediates the Strict Nuclear Localization of a Long Noncoding RNA. Mol Cell Biol (2014) 34:2318-2329. doi:10.1128/MCB.01673-13

67. Pawar K, Hanisch C, Eliseo S, Vera P, Einspanier R, Sharbati S. Down regulated lncRNA MEG3 eliminates mycobacteria in macrophages via autophagy. Sci Rep (2016) 6:19416. doi:10.1038/srep19416

68. Hanisch C, Sharbati J, Kutz-Lohroff B, Huber O, Einspanier R, Sharbati S. TFF3dependent resistance of human colorectal adenocarcinoma cells HT-29/B6 to apoptosis is mediated by miR-491-5p regulation of lncRNA PRINS. Cell Death Discov (2017) 3:16106. doi:10.1038/cddiscovery.2016.106

69. Boukamp P, Petrussevska RT, Breitkreutz D, Hornung J, Markham A, Fusenig NE. 
Normal Keratinization in a Spontaneously Immortalized Aneuploid Human Keratinocyte Cell Line. J Cell Biol (1988) 106:761-771.

70. Tax G, Urbán E, Palotás Z, Puskás R, Kónya Z, Bíró T, Kemény L, Szabó K. Propionic Acid Produced by Propionibacterium acnes Strains Contri-butes to Their Pathogenicity. Acta Derm Venereol (2016) 96:43-49. doi:10.2340/00015555-2154

71. Wenzel A, Akbasli E, Gorodkin J. RIsearch: Fast RNA-RNA interaction search using a simplified nearest-neighbor energy model. Bioinformatics (2012) 28:2738-2746. doi:10.1093/bioinformatics/bts519

72. Smith C, Heyne S, Richter AS, Will S, Backofen R. Freiburg RNA Tools: a web server integrating INTARNA, EXPARNA and LOCARNA. Nucleic Acids Res (2010) 38:W373-7. doi:10.1093/nar/gkq316

73. Busch A, Richter AS, Backofen R. IntaRNA: Efficient prediction of bacterial sRNA targets incorporating target site accessibility and seed regions. Bioinformatics (2008) 24:2849-2856. doi:10.1093/bioinformatics/btn544

74. Wright PR, Georg J, Mann M, Sorescu DA, Richter AS, Lott S, Kleinkauf R, Hess WR, Backofen R. CopraRNA and IntaRNA: predicting small RNA targets, networks and interaction domains. Nucleic Acids Res (2014) 42:W119-23. doi:10.1093/nar/gku359

75. Dai X, Sayama K, Yamasaki K, Tohyama M, Shirakata Y, Hanakawa Y, Tokumaru S, Yahata Y, Yang L, Yoshimura A, et al. SOCS1-Negative Feedback of STAT1 Activation Is a Key Pathway in the dsRNA-Induced Innate Immune Response of Human Keratinocytes. J Invest Dermatol (2006) 126:1574-1581. doi:10.1038/sj.jid.5700294

76. Rathinam VAK, Jiang Z, Waggoner SN, Sharma S, Cole LE, Waggoner L, Vanaja SK, Monks BG, Ganesan S, Latz E, et al. The AIM2 inflammasome is essential for host defense against cytosolic bacteria and DNA viruses. Nat Immunol (2010) 11:395-402. doi:10.1038/ni.1864

77. Barbuto S, Idoyaga J, Villa-Perelló M, Longhi MP, Breton G, Steinman RM, Miur TW. Induction of innate and adaptive immunity by delivery of poly dA:dT to dendritic cells. 
Nat Chem Biol (2013) 9:250-256. doi:10.1016/j.cardfail.2013.04.005.Sleep

78. Kis-Toth K, Szanto A, Thai T-H, Tsokos GC. Cytosolic DNA-activated human dendritic cells are potent activators of the adaptive immune response. J Immunol (2011) 187:1222-34. doi:10.4049/jimmunol.1100469

79. Oláh A, Ambrus L, Nicolussi S, Gertsch J, Tubak V, Kemény L, Soeberdt M, Abels C, Bíró T. Inhibition of fatty acid amide hydrolase exerts cutaneous anti-inflammatory effects both in vitro and in vivo. Exp Dermatol (2016) 25:328-330. doi:10.1111/exd.12930

80. Lewis DA, Hengeltraub SF, Gao FC, Leivant MA, Spandau DF. Aberrant NF-kappaB activity in $\mathrm{HaCaT}$ cells alters their response to UVB signaling. J Invest Dermatol (2006) 126:1885-92. doi:10.1038/sj.jid.5700333

81. Takeuchi O, Hemmi H, Akira S. Interferon response induced by Toll-like receptor signaling. J Endotoxin Res (2004) 10:252-256. doi:10.1179/096805104225005896

82. Jaffee BD, Manos EJ, Collins RJ, Czerniak PM, Favata MF, Magolda RL, Scherle PA, Trzaskos JM. Inhibition of MAP Kinase Kinase (MEK) Results in an Antiinflammatory Response in Vivo. Biochem Biophys Res Commun (2000) 268:647-651. doi:10.1006/bbrc.2000.2184

83. Duan W, Chan JHP, Wong CH, Leung BP, Wong WSF. Anti-inflammatory effects of mitogen-activated protein kinase kinase inhibitor U0126 in an asthma mouse model. $J$ Immunol (2004) 172:7053-9. doi:10.4049/JIMMUNOL.172.11.7053

84. Lulli D, Carbone M, Pastore S. The MEK Inhibitors Trametinib and Cobimetinib Induce a Type I Interferon Response in Human Keratinocytes. Int J Mol Sci (2017) 18:2227. doi:10.3390/ijms 18102227

85. Maeng YS, Min JK, Kim JH, Yamagishi A, Mochizuki N, Kwon JY, Park YW, Kim YM, Kwon YG. ERK is an anti-inflammatory signal that suppresses expression of NFผB-dependent inflammatory genes by inhibiting IKK activity in endothelial cells. Cell Signal (2006) 18:994-1005. doi:10.1016/j.cellsig.2005.08.007

86. Lulli D, Carbone ML, Pastore S. Epidermal growth factor receptor inhibitors trigger a type I interferon response in human skin. Oncotarget (2016) 7:47777-47793. 
doi:10.18632/oncotarget.10013

87. Andrés RM, Hald A, Johansen C, Kragballe K, Iversen L. Studies of Jak/STAT3 expression and signalling in psoriasis identifies STAT3-Ser727 phosphorylation as a modulator of transcriptional activity. Exp Dermatol (2013) 22:323-328. doi:10.1111/exd.12128

88. Derrien T, Johnson R, Bussotti G, Tanzer A, Djebali S, Tilgner H, Guernec G, Martin D, Merkel A, Knowles DG, et al. The GENCODE v7 catalog of human long noncoding RNAs: Analysis of their gene structure, evolution, and expression. Genome Res (2012) 22:1775-1789. doi:10.1101/gr.132159.111

89. Kung JTY, Colognori D, Lee JT. Long noncoding RNAs: past, present, and future. Genetics (2013) 193:651-69. doi:10.1534/genetics.112.146704

90. Heward JA, Lindsay MA. Long non-coding RNAs in the regulation of the immune response. Trends Immunol (2014) 35:408-419. doi:10.1016/j.it.2014.07.005

91. Szcześniak MW, Makałowska I. IncRNA-RNA Interactions across the Human Transcriptome. PLoS One (2016) 11:e0150353. doi:10.1371/journal.pone.0150353

92. Scheller J, Chalaris A, Schmidt-Arras D, Rose-John S. The pro- and anti-inflammatory properties of the cytokine interleukin-6. Biochim Biophys Acta-Mol Cell Res (2011) 1813:878-888. doi:10.1016/j.bbamcr.2011.01.034 


$$
\text { I. }
$$




\title{
Differential Inflammatory-Response Kinetics of Human Keratinocytes upon Cytosolic RNA- and DNA-Fragment Induction
}

\author{
Judit Danis ${ }^{1,2, *}$, Luca Janovák ${ }^{1}$, Barbara Gubán ${ }^{1}$, Anikó Göblös ${ }^{1,2}{ }^{2}$, Kornélia Szabó ${ }^{2}$, \\ Lajos Kemény 1,2 (iD, Zsuzsanna Bata-Csörgő 1,2 and Márta Széll 2,3 \\ 1 Department of Dermatology and Allergology, University of Szeged, 6720 Szeged, Hungary; \\ janovakluca@gmail.com (L.J.); konczne.guban.barbara.eszter@med.u-szeged.hu (B.G.); \\ goblos.aniko@med.u-szeged.hu (A.G.); kemeny.lajos@med.u-szeged.hu (L.K.); \\ bata.zsuzsa@med.u-szeged.hu (Z.B.-C.) \\ 2 MTA-SZTE Dermatological Research Group, 6720 Szeged, Hungary; szabo.kornelia@med.u-szeged.hu (K.S.); \\ szell.marta@med.u-szeged.hu (M.S.) \\ 3 Department of Medical Genetics, University of Szeged, 6720 Szeged, Hungary \\ * Correspondence: danis.judit@med.u-szeged.hu; Tel.: +36-62-54-52-78
}

Received: 8 February 2018; Accepted: 6 March 2018; Published: 8 March 2018

\begin{abstract}
Keratinocytes are non-professional immune cells contributing actively to innate immune responses partially by reacting to a wide range of molecular patterns by activating pattern recognition receptors. Cytosolic nucleotide fragments as pathogen- or self-derived trigger factors are activating inflammasomes and inducing anti-viral signal transduction pathways as well as inducing expression of inflammatory cytokines. We aimed to compare the induced inflammatory reactions in three keratinocyte cell types-normal human epidermal keratinocytes, the HaCaT cell line and the HPV-KER cell line-upon exposure to the synthetic RNA and DNA analogues poly(I:C) and poly $(\mathrm{dA}: \mathrm{dT})$ to reveal the underlying signaling events. Both agents induced the expression of interleukin- 6 and tumor necrosis factor $\alpha$ in all cell types; however, notable kinetic and expression level differences were found. Western blot analysis revealed rapid activation of the nuclear factor $\kappa B$ (NF-kB), mitogen activated protein kinase and signal transducers of activator of transcription (STAT) signal transduction pathways in keratinocytes upon poly(I:C) treatment, while poly(dA:dT) induced slower activation. Inhibition of NF-kB, p38, STAT-1 and STAT-3 signaling resulted in decreased cytokine expression, whereas inhibition of mitogen-activated protein kinase kinase $1 / 2$ (MEK1/2) signaling showed a negative feedback role in both poly(I:C)- and poly(dA:dT)-induced cytokine expression. Based on our in vitro results nucleotide fragments are able to induce inflammatory reactions in keratinocytes, but with different rate and kinetics of cytokine expression, explained by faster activation of signaling routes by poly(I:C) than poly(dA:dT).
\end{abstract}

Keywords: cytosolic nucleotide fragments; keratinocyte; poly(I:C); poly(dA:dT); signal transduction pathway; interleukin-6; tumor necrosis factor $\alpha$

\section{Introduction}

The skin provides the primary interface between the body and the environment and forms a physical barrier against invading pathogens. Keratinocytes - the main cell type of the epidermis-form the physical barrier of the stratum corneum and are immunocompetent cells as well, making the epidermis an active member of the immune system.

Keratinocytes express a wide range of pattern recognition receptors and are responsive to various pathogen associated molecular patterns [1-4], including RNA and DNA fragments, which have 
been implicated in antiviral defense of keratinocytes [5,6]. Cytosolic RNA and DNA fragments are also known as pathogen- as well as damage-associated molecular patterns (PAMPs and DAMPs), which induce innate immune functions of professional and non-professional immune cells. In non-infectious skin diseases, such as psoriasis, receptors for RNA and/or DNA fragments [7-9], moreover their activators: self-derived RNA and DNA fragments and RNA:DNA duplexes are highly abundant in the lesional epidermis $[10,11]$. During normal cornification, keratinocytes express deoxyribonucleases (DNases) [12]; however, it was recently shown that reduced keratinocyte DNase activity in psoriasis results in suppressed DNA degradation and, as a consequence, parakeratosis [13] and the presence of excess DNA fragments in the cytosol. Similarly, disturbed ribonuclease activities were described in psoriatic skin [14,15], which might result in excess RNA fragments.

These self-derived fragments activate among others the absent in melanoma 2 (AIM2) inflammasome $[10,16,17]$ and inflammatory cytokine expression through their receptors in keratinocytes $[7,11,18]$ initiating inflammatory events. Nucleotide fragment induced reactions have been studied by using synthetic RNA analogue poly(I:C) and DNA analogue poly(dA:dT), which both induce type I interferon (IFN- $\alpha / \beta$ ) and inflammatory cytokine expression in keratinocytes $[7,18-20]$. Poly(I:C) is recognized primarily by toll-like receptor 3 (TLR3) [21], although, TLR3-independent sensing of poly(I:C) has also been observed with involvement of retinoic acid induced gene I (RIG-I) and melanoma differentiation-associated gene 5 [22]. Poly(dA:dT) recognition partially overlaps with poly(I:C) recognition, since RIG-I serves as a receptor after poly(dA:dT) has been transcribed by RNA polymerase III into double-stranded (ds) RNA molecules [23]. Cyclic GMP-AMP synthase (cGAS), a newly described cytosolic DNA receptor implicated in antiviral responses, binds dsDNA sequences independently and activates interferon regulatory factor 3 in cooperation with interferon- $\gamma$-inducible protein $16[6]$.

The basal expression of most inflammatory cytokines is low and is regulated in response to stimuli at the transcriptional level, mediated by transcription factors of the nuclear factor $\mathrm{kB}(\mathrm{NF}-\mathrm{kB})$, mitogen activated protein kinases (MAPK) and signal transducers of activator of transcription (STAT) signal transduction pathways [18], which have been reported to participate in nucleotide-induced inflammatory cytokine expression in several cell types [23-26]. Poly(I:C) was found to induce NF-KB, p38 and STAT-1 signaling in keratinocytes, whereas, in melanocytes, poly(dA:dT) induces NF- $\mathrm{BB}, \mathrm{p} 38$ and c-Jun N-terminal kinase (JNK) signaling, which differentially regulates cytokine expression [18,24].

Although Cheng and coworkers have reported that sensing of poly(I:C) or poly(dA:dT) and the induced inflammatory reactions after exposure to these molecules partially overlap [22]; no comprehensive data is available for these reactions in keratinocytes. We aimed to compare poly(I:C)- and poly(dA:dT)-induced inflammatory reactions in keratinocytes and the underlying signal transduction events. We found that poly(I:C) and poly(dA:dT) induce similar signal transduction events in keratinocytes; however, the kinetics are faster and the rate of cytokine induction is higher in response to poly(I:C). Moreover, our results suggest a negative feedback role for the activation of extracellular signal-regulated protein kinases 1 and 2 (ERK1/2) signaling in keratinocytes, for both poly(I:C)- and poly(dA:dT)-induced inflammatory signaling.

\section{Results}

\subsection{Keratinocytes Respond to Poly(I:C) and Poly(dA:dT) with Increased Interleukin-6 (IL-6) and Tumor Necrosis Factor $\alpha(T N F-\alpha)$ Expression}

To study cytosolic RNA- and DNA-induced cytokine-expression profiles in keratinocytes, we used three keratinocyte cell types: normal human epidermal keratinocytes (NHEKs), the HaCaT cell line [27] and the HPV-KER cell line [28]. Poly(I:C) strongly induced IL-6 and TNF- $\alpha$ expression in all three cell types, and poly(dA:dT) induced expression in all cell types with slightly different kinetics as well as expression that was an order of magnitude lower than that observed with poly(I:C) (Figure 1). Peak expression was observed 3 to $6 \mathrm{~h}$ after poly(I:C) transfection, whereas peak expression after poly(dA:dT) transfection occurred 6 to $12 \mathrm{~h}$ after treatment in all cell types studied. Reaction to 
poly(I:C) in HaCaT cells differed significantly from the other cell types (Figure 1A,C). In contrast, poly $(\mathrm{dA}: \mathrm{dT}$ )-induced reaction differed in all three cell types (Figure 1B,D). Previously we found that the HPV-KER cell line and NHEK cells exhibited similar cytokine mRNA expression [28], which agreed with our finding on the expression kinetics upon poly(I:C) induction.

To study the induced signaling pathways in keratinocytes, we used only the HPV-KER cell line. HPV-KER cells previously showed similar reactions to NHEKs [28] and HaCaT cells exhibited a slightly different cytokine-expression profile, moreover HaCaT cells are known to exhibit constant activation of inflammatory signaling [29], while high intra-individual differences were observed in the inflammatory inductions of NHEKs.

A

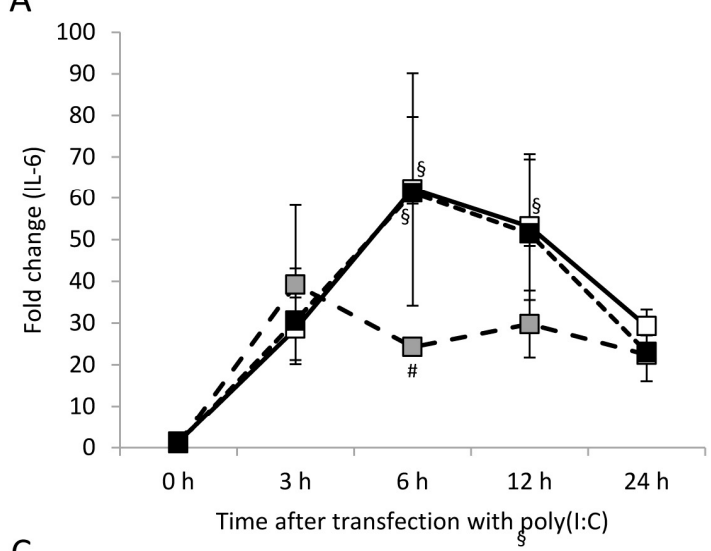

C

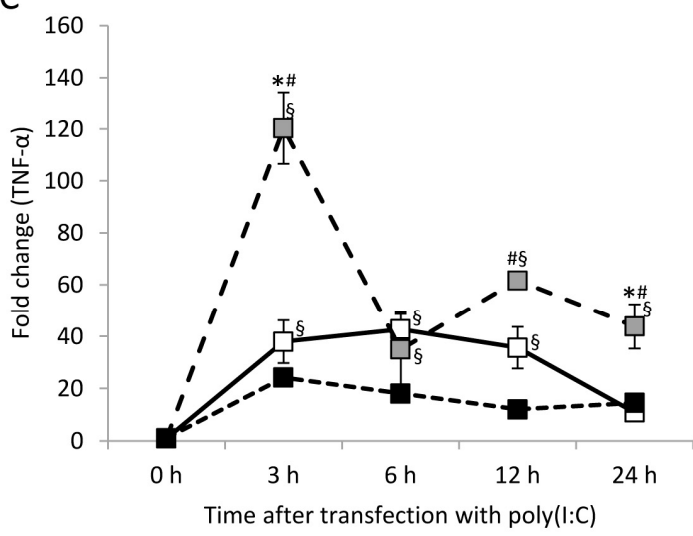

B

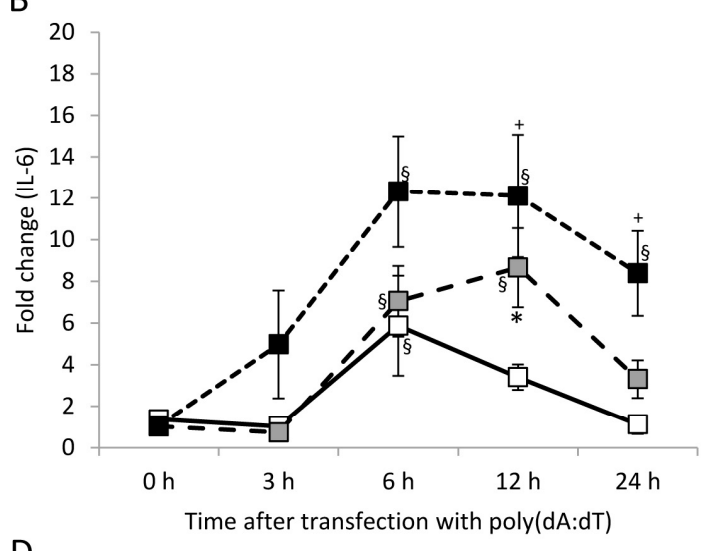

D

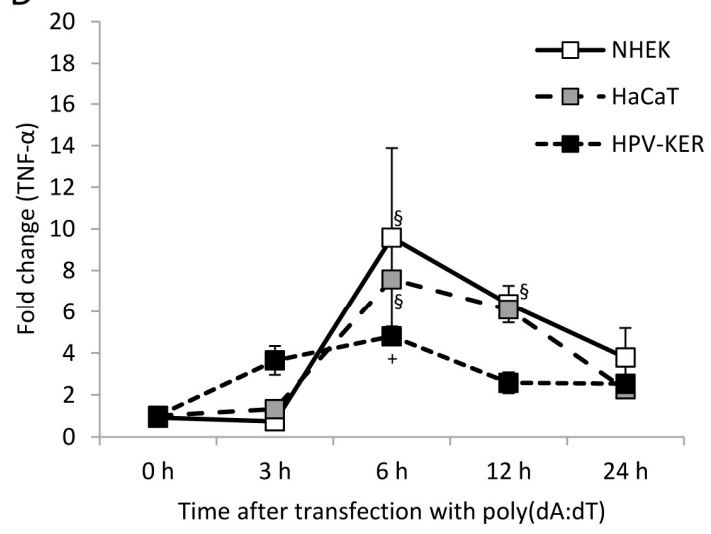

Figure 1. Kinetics of expression of the interleukin-6 (IL-6) and tumor necrosis factor $\alpha$ (TNF- $\alpha$ ) cytokines in normal human epidermal keratinocytes (NHEK) and HaCaT and HPV-KER cell lines upon transfection with $0.666 \mu \mathrm{g} / \mathrm{mL}$ poly(I:C) $(\mathbf{A}, \mathbf{C})$ and poly $(\mathrm{dA}: \mathrm{dT})(\mathbf{B}, \mathbf{D})$. Relative expression was determined by the $\Delta \Delta C_{\mathrm{t}}$ method, normalized to $18 \mathrm{~S}$ rRNA expression and compared to the expression of the untreated $0 \mathrm{~h}$ samples. Data are presented as mean of three independent experiments \pm standard error. Significance was determined by two-way repeated measurement analysis of variance (ANOVA), ${ }^{*} p<0.05$ HaCaT vs. NHEK; ${ }^{*} p<$ HaCaT vs. HPV-KER; ${ }^{+} p<0.05$ HPV-KER vs. NHEK; ${ }^{\S} p<0.05$ vs. $0 \mathrm{~h}$ samples within a cell type.

2.2. Poly(I:C) and Poly(dA:dT) Treatment Induces Nuclear Factor $\kappa B$ (NF- $\kappa B)$, Mitogen Activated Protein Kinase (MAPK) and Signal Transducers of Activator of Transcription (STAT) Activation in Keratinocytes

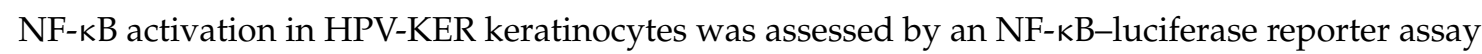
(Figure 2A). The kinetic differences of NF-KB activation between poly(I:C) and poly(dA:dT) transfected cells resembled the corresponding cytokine expression differences: peak-activation occurred at $6 \mathrm{~h}$ after poly(I:C) treatment, whereas the peak activation with poly $(\mathrm{dA}: \mathrm{dT})$ occurred $24 \mathrm{~h}$ after treatment. 
The delayed NF- $k B$ signaling response to poly $(\mathrm{dA}: \mathrm{dT})$ was confirmed with detection of phosphorylated NF- $\kappa B$ inhibitor $\alpha(\mathrm{I} \kappa \mathrm{B} \alpha)$ by western blot analysis (Figure 2B and Figure S1A).

A

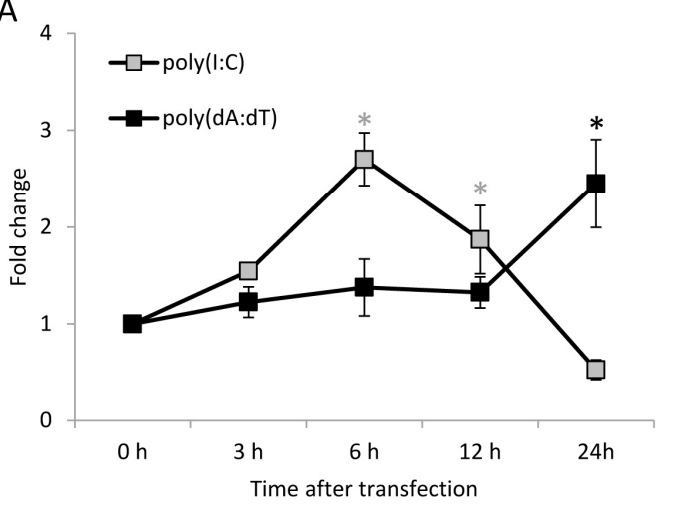

C

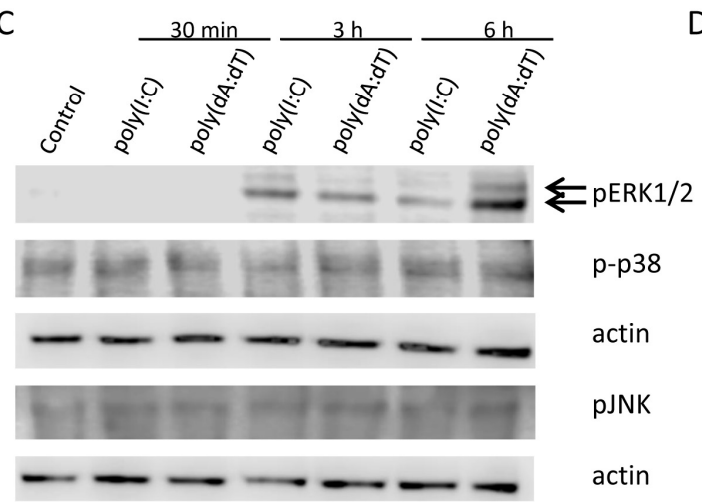

B

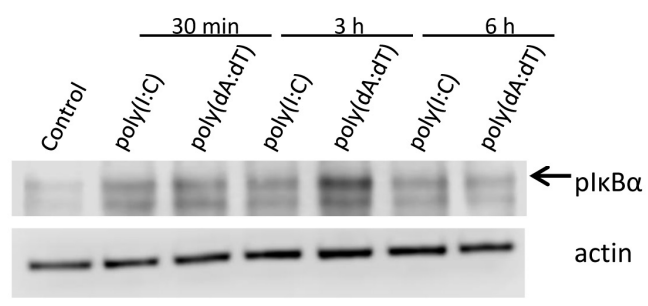

D
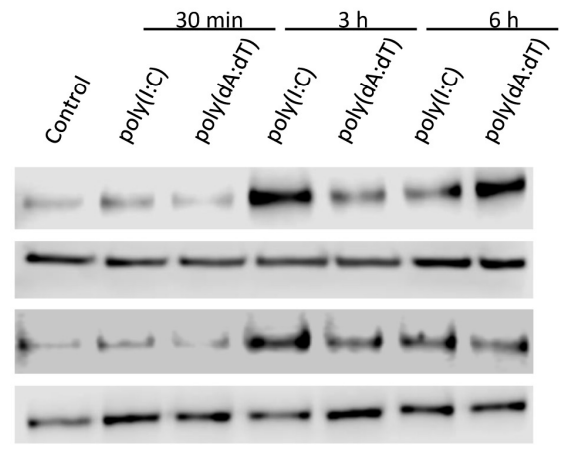

pSTAT-1

actin

pSTAT-3

actin

Figure 2. Activation of Nuclear Factor $\kappa B(\mathrm{NF}-\kappa \mathrm{B})$, Mitogen Activated Protein Kinase (MAPK) and Signal Transducers of Activator of Transcription (STAT) signal transduction pathways in HPV-KER cells upon poly(I:C) or poly(dA:dT) transfection assessed by NF-kB-luciferase reporter assay (A) and western blot analysis (B-D). (A) NF- $\kappa B$ luciferase reporter assay exhibited faster activation of NF- $\mathrm{B}$ transcription factor upon poly(I:C) treatment than poly $(\mathrm{dA}: \mathrm{dT})$ treatment. Raw luminescence intensity values were normalized to the intrinsic control renilla activity, and compared to the $0 \mathrm{~h}$ untreated samples. Data are presented as mean of three independent experiments \pm standard error; statistical significance was assessed by two-way repeated measurement ANOVA * $p<0.05$, grey: poly(I:C) treatment compared to untreated $0 \mathrm{~h}$ samples, black: poly $(\mathrm{dA}: \mathrm{dT})$ treatment compared to untreated 0 h samples; (B) Increase in phosphorylated NF-kB inhibitor $\alpha(\mathrm{I} \kappa \mathrm{B} \alpha)$ after poly(I:C) or poly $(\mathrm{dA}: \mathrm{dT})$ treatment, peaking later after poly $(\mathrm{dA}: \mathrm{dT})$ treatment than after poly $(\mathrm{I}: \mathrm{C})$ treatment, arrow indicate the lane for phosphorylated IKB $\alpha$; (C) Phosphorylation of ERK1/2 increases after poly(I:C) or poly(dA:dT) treatment, peaking later after poly $(\mathrm{dA}: \mathrm{dT})$ treatment than after poly(I:C) treatment, arrows indicate from top to bottom the lanes for phosphorylated ERK1 and ERK2. Phosphorylation of p38 and JNK was not observed upon poly(I:C) or poly(dA:dT) treatment; (D) Phosphorylation of both STAT-1 and STAT-3 occurs faster in poly(I:C) treated samples than in poly(dA:dT) treated samples. Western blot results are representative for at least three independent experiments. Actin was used as loading control.

Western blot analysis of MAP kinase (Figure 2C) and STAT (Figure 2D) pathways showed that both poly(I:C) and poly(dA:dT) induced the phosphorylation of ERK1/2 and STAT-1 as well as STAT-3 signaling. Densitometric analysis showed a faster phosphorylation of STAT-1 and STAT-3 in poly(I:C) treated samples compared to poly(dA:dT) treatment (Figure S1). In addition, phosphorylation of p38 MAPK and JNK pathways were not affected at the studied time points, which was also confirmed by densitometric analysis (Figure S1C,D). 
2.3. Cytokine Expression of Keratinocytes upon Poly(I:C) and Poly $(d A: d T)$ Treatment Relies on NF- $k B, p 38$ and STAT Signaling

To address the role of the activated signaling routes in poly(I:C)- and poly(dA:dT)-induced cytokine expression, keratinocytes were pre-incubated with the specific inhibitors of NF- $\mathrm{KB}$ (Bay 11-7085), dual specificity mitogen-activated protein kinase kinase1 and 2 (MEK1/2) (PD95089), p38 (SB203580), JNK (SP600125), STAT-1 (fludarabine) and STAT-3 (Stattic) for an hour before transfection with poly(I:C) or poly(dA:dT).

Time points of sample collection were determined with respect on the peak expression of cytokines (Figure 1). Inhibition of NF-kB nearly completely abolished both the poly(I:C)- and poly(dA:dT)-induced expression of IL-6 and TNF- $\alpha$ (Figure 3A).

Although activation could not be confirmed by our western blot results (Figure 2C), inhibition of p38 signaling resulted in significantly decreased IL-6 and TNF- $\alpha$ expression (Figure 3B). In contrast, the inhibition of JNK signaling did not affect cytokine expression (Figure 3C). The inhibition of MEK-1 signaling significantly increased the poly(I:C)- and poly(dA:dT)-induced production of IL-6 (Figure 3D), suggesting a possible negative regulatory role of this pathway.

Specific inhibition of STAT-3 signaling significantly decreased both poly(I:C)- and poly(dA:dT)-induced cytokine expression (Figure 3F), whereas the inhibition of STAT-1 affected only IL-6 expression (Figure 3E). Thus, whereas both poly(I:C)- and poly(dA:dT)-induced IL-6 expression was affected by most of the studied signaling routes, TNF- $\alpha$ expression was only affected by NF- $\mathrm{kB}$, p38 and STAT-3.

A

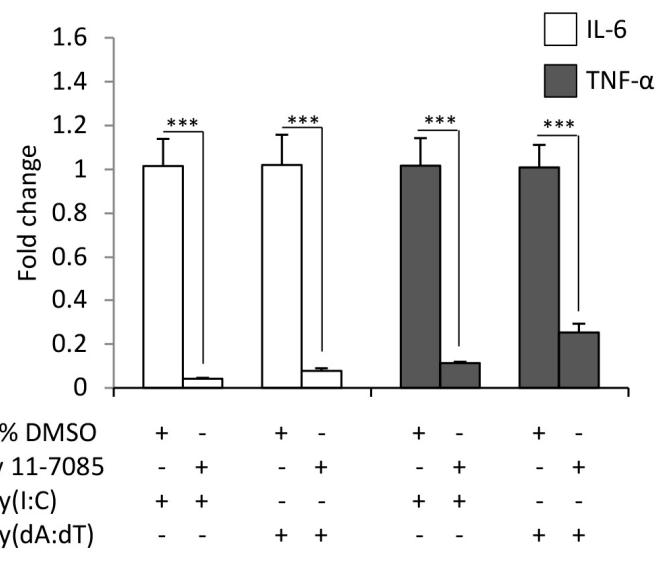

C

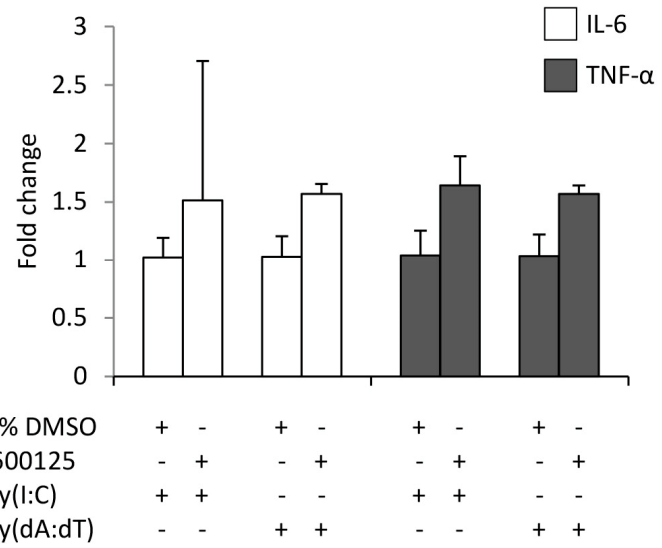

B

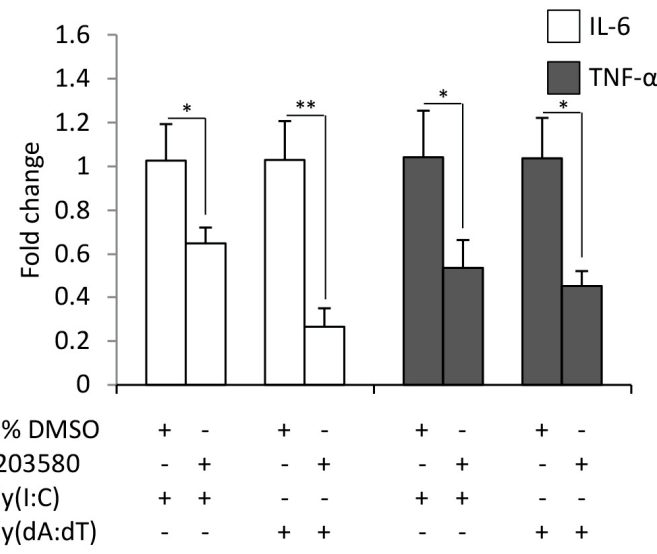

D

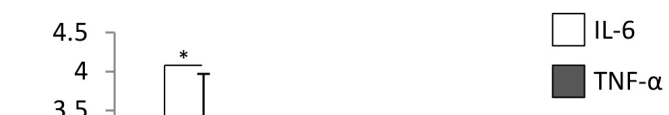

$0.25 \%$ DMSO

PD98059

poly(l:C)

poly(dA:dT)

Figure 3. Cont. 
E

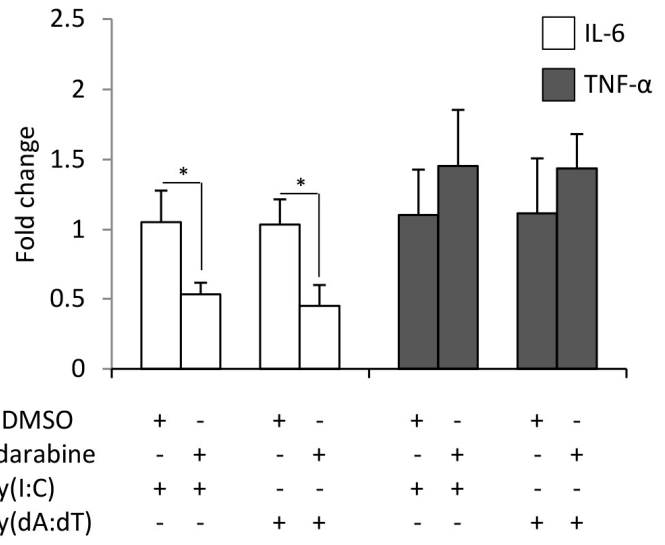

$\mathrm{F}$

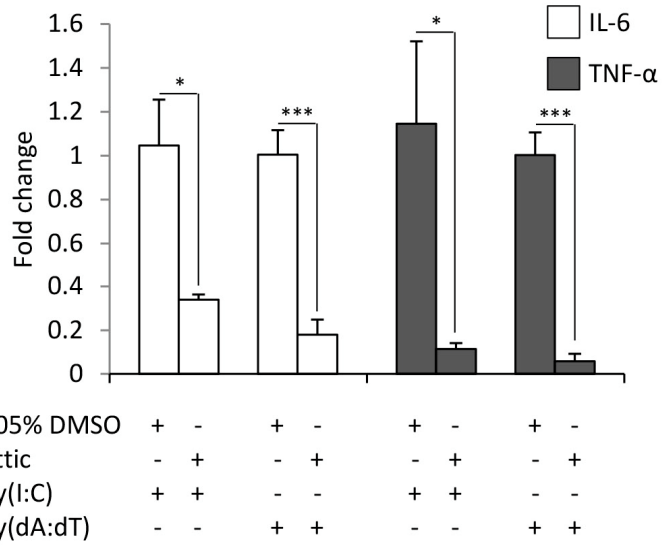

Figure 3. Inhibition of different signaling routes has divergent effects on the expression of the IL-6 (white bars) and TNF- $\alpha$ (grey bars) cytokines in keratinocytes. The effect of inhibition by NF-kB (A), p38 (B), c-Jun N-terminal kinase (JNK) (C), mitogen-activated protein kinase kinase 1 and2 (MEK1 /2) (D), STAT-1 (E) and STAT-3 (F) on poly(I:C) (6 h after transfection) and poly(dA:dT) (12 h after transfection) induction of IL-6 (white bars) and TNF- $\alpha$ (grey bars) expression in HPV-KER cells. Fold change of mRNA expression values were determined by the $\Delta \Delta C_{\mathrm{t}}$ method, normalized to $18 \mathrm{~S}$ rRNA expression. As all inhibitors were dissolved in dimethyl sulfoxide (DMSO), the relative mRNA expression levels were compared to the expression levels in samples treated with DMSO + poly(I:C) or $\mathrm{DMSO}+\operatorname{poly}(\mathrm{dA}: \mathrm{dT})$, respectively. Poly $(\mathrm{I}: \mathrm{C})$ and poly(dA:dT) induction was in every case significant compared to the untreated control samples; no significant difference was observed between the cytokine-expression level of the samples treated with poly(I:C), poly(dA:dT), DMSO + poly(I:C) or $\mathrm{DMSO}+$ poly $(\mathrm{dA}: \mathrm{dT})$. Data are represented as the means of three independent experiments \pm standard error; ${ }^{*} p<0.05 ;{ }^{* *} p<0.01 ;{ }^{* * *} p<0.001$ determined by Student's $t$-test.

\section{Discussion}

RNA and DNA fragments are known as important PAMPs or DAMPs that induce innate immune processes of professional immune cell types, such as macrophages and dendritic cells [23,30-32], as well as non-professional immune cells, such as keratinocytes [18]. Accumulation of nucleotide fragments in keratinocytes is involved in the pathogenesis of psoriasis leading to parakeratosis [13], as well as in the promotion of inflammation by activating dendritic cells [33] and in the activation of inflammasomes in keratinocytes $[10,17]$. However, the induced inflammatory signaling pathways and how they contribute to cytokine expression in keratinocytes were not previously studied.

In this study, we characterized innate immune responses of human keratinocytes to the cytosolic exposure of the dsRNA analogue poly(I:C) and the dsDNA analogue poly(dA:dT). We compared the IL-6 and TNF- $\alpha$ expression of NHEK, HaCaT [27] and HPV-KER [28] cells after poly(I:C) and poly $(\mathrm{dA}: \mathrm{dT})$ exposure. Previously we found that the inflammatory responses of the widely used HaCaT cell line upon exposure to Propionibacterium acnes differ from that of NHEKs, while the HPV-KER cell line (established and characterized in our laboratory) shows similar inflammatory $[28,34]$ and ultraviolet-B irradiation-induced responses to NHEKs [35]. In line with our previous findings [28], we found that the cytokine expression patterns in the HaCaT cells differ significantly from the responses of HPV-KER and NHEK cells. Moreover, HaCaT cells are thought to be less suitable to study inflammatory signaling pathways due to their constant NF-KB activation [29].

$\mathrm{NF}-\mathrm{KB}, \mathrm{MAPKs}$ and STAT signaling have been reported to participate in nucleotide-fragment-induced inflammatory cytokine expression in several cell types [22-26]; however, limited information is available for these signaling events in keratinocytes upon nucleotide fragment induction $[18,36]$. According to our results, poly(I:C) induces activation of the studied signaling pathways in a shorter time than poly $(\mathrm{dA}: \mathrm{dT})$, and a corresponding shift in cytokine expression peaks was observed. The difference in peak timing is likely due to direct activation of TLR3 signaling by poly(I:C) [37]; while it 
has been shown that poly(dA:dT) must first be transcribed to RNA before activating NF- $\mathrm{kB}$ through RIG-I dependent sensing [23] (Figure 4).

In addition to poly(I:C)- and poly(dA:dT)-induced NF-kB activation, phosphorylation of ERK1/2, STAT-1 and STAT-3 was also observed; but phosphorylation of other studied MAPKs (p38 and JNK) was not affected. In contrast, a previous study using keratinocytes reported poly(I:C) induction of p38 signaling but no induction of ERK1/2 signaling [18]. In melanocytes, another epidermal cell type, poly(dA:dT)-induced phosphorylation of p38 and JNK signaling was observed without ERK1/2 activation [24]. These differences might be due to differences in time points used: our study examined p38 phosphorylation 30 min after poly(I:C) and poly(dA:dT) transfection in HPV-KER cells, whereas the previous study examined p38 phosphorylation in NHEKs 15 min after treatment, observing a reduction after $30 \mathrm{~min}$ [18]. These results suggest that poly(I:C)- and poly(dA:dT)-induced p38 phosphorylation might be a rapid event in keratinocytes. Although we could not confirm p38 phosphorylation, inhibition of $\mathrm{p} 38$ signaling during transfection with poly(I:C) or poly $(\mathrm{dA}: \mathrm{dT})$ resulted in decreased IL- 6 and TNF- $\alpha$ expression, which is in agreement with a previous report on poly(I:C)-induced TNF- $\alpha$ expression in keratinocytes [18].

In monocytes and melanocytes, inhibition of ERK1/2 and JNK signaling pathways abolished nucleotide-induced IL-6 and TNF- $\alpha$ expression $[24,38]$. In mouse models, the disruption of ERK1/2 signaling by the inhibition of MEK1/2 functions have been shown to have anti-inflammatory effects $[39,40]$. In contrast, in our experiments the disruption of ERK1/2 signaling through inhibition of MEK1/2 kinases increased the expression of the inflammatory mediator IL- 6 . These results agree with previous in vivo findings that therapeutic inhibition of MEK1/2 in patients is often accompanied by an inflammatory skin rash [41]. These results suggest that ERK1/2 signaling-in contrast to other cell types-has a negative regulatory function in inflammatory reactions in keratinocytes. Previous reports have already demonstrated similar results: ERK1/2 signaling was shown to negatively regulate NF- $\mathrm{KB}$ activation [42], and inhibition of MEK1/2 led to increased NF-KB, STAT-1 and interferon-regulatory factor signaling in human keratinocytes [43], altough, we did not observe an increase in NF- $\mathrm{KB}$ activation upon inhibition of ERK1/2 signaling.

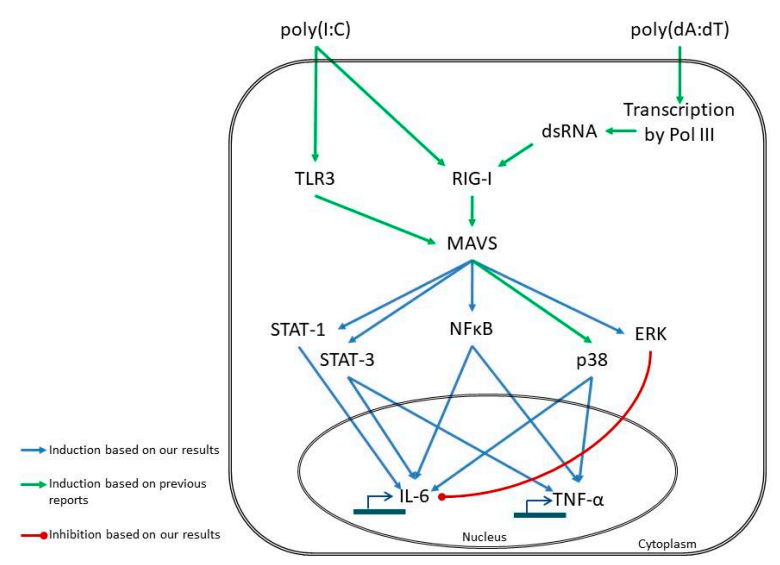

Figure 4. Proposed model of poly(I:C)- and poly(dA:dT)-induced signaling events leading to IL-6 and TNF- $\alpha$ expression in keratinocytes, based on our results and results of previous reports [21-23,44]. Our results indicate that poly(I:C) and poly(dA:dT) induce the same inflammatory pathways; however, the mode of sensing differs, leading to the observed differences in kinetic. The receptors for poly(I:C) sensing are toll-like receptor 3 (TLR3) [21] and retinoic acid induced gene I (RIG-I) [22]. In contrast, poly(dA:dT) is transcribed to double-stranded (ds) RNA by RNA polymerase III (Pol III) and is subsequently sensed by RIG-I [23]. The transcription step might be responsible for the delayed response to poly (dA:dT). The receptors activate the NF- $\mathrm{B}$, MAPK and STAT signaling routes through the adaptor molecule mitochondrial antiviral signaling protein (MAVS), and, thus, regulate the transcription of the cytokines. 
STAT signaling is known to be induced by inflammatory cytokines [45] and by poly(I:C) treatment $[18,36]$. We found that, in addition to poly(I:C), poly(dA:dT) also induced STAT-1 and STAT-3 signaling in keratinocytes, and that the induction exhibited a delay in activation after poly(dA:dT) transfection similar to those observed with other pathways. Poly(I:C)-induced STAT-1 activation has been shown to regulate TLR3 and TNF- $\alpha$ expression [18]. In our experiments, STAT-1 was found to regulate poly(I:C)- and poly(dA:dT)-induced IL- 6 expression, whereas TNF- $\alpha$ was not affected. Inhibition of STAT-3 abolished both poly(I:C)- and poly(dA:dT)-induced IL- 6 and TNF- $\alpha$ expression, showing the different regulatory functions of each STAT transcription factors.

In this study, we show the similarities as well as the differences in inflammatory signaling events of keratinocytes induced by dsRNA and dsDNA. Our data revealed that transfection with the synthetic dsRNA and dsDNA analogues poly(I:C) and poly (dA:dT) induced activation of NF- $\mathrm{kB}$ and STAT signaling, both of which were also shown to be functional in inducing cytokine expression. Moreover, we showed the negative regulatory role of ERK1/2 signaling in nucleotide-induced cytokine expression. Although dsRNA and dsDNA are recognized by different sets of receptors, they induce the same inflammatory signaling pathways in keratinocytes, albeit with different kinetics and magnitude of activation.

Studies of the last decade have highlighted disturbances in the signal transduction events in psoriasis that have led to the development of targeted therapeutics against specific signaling components. However there is still a lack of knowledge on every aspect of these mechanisms. Our results deepen the existing knowledge and contribute to the understanding of these signaling events induced in keratinocytes.

\section{Materials and Methods}

\subsection{Cell Culture}

NHEK cells, the HaCaT cell line [27] and the HPV-KER cell line established in our laboratory [28] were used for the experiments. After obtaining written informed consent from investigated individuals, skin speciments from the Plastic Surgery Unit of our Department were used to separate NHEKs, as described previously. Investigations were carried out in accordance with the rules of the Helsinki Declaration, and prior study, the study design was approved by the Human Investigation Review Board of the University of Szeged (PSO-EDAFN-002, 23 February2015, Szeged, Hungary). The epidermis was separated from the dermis with overnight incubation in Dispase (Roche Diagnostics, Manheim, Germany), and keratinocytes were obtained after maceration in $0.25 \%$ trypsin. All cell types were grown in $75 \mathrm{~cm} 2$ cell culture flasks. NHEKs and HPV-KER cells were maintained in keratinocyte serum-free medium containing epidermal growth factor and bovine pituitary factor (Gibco Keratinocyte SFM Kit; Life Technologies, Copenhagen, Denmark) and supplemented with 1\% antibiotic/antimycotic solution (PAA Laboratories GmBH, Pasching, Austria) and 1\% L-glutamine (PAA Laboratories). HaCaT cells were grown in DMEM with $4.5 \mathrm{~g} / \mathrm{L}$ glucose supplemented with $1 \%$ antibiotic/antimycotic solution, $1 \%$ L-glutamine and $10 \%$ fetal bovine serum at $37^{\circ} \mathrm{C}$ in a humidified atmosphere with $5 \% \mathrm{CO}_{2}$. The medium was changed every 2 days.

\subsection{Stimulation of the Cells}

HPV-KER cells, HaCaT cells or third passage NHEKs were seeded into 6-well plates. After $24 \mathrm{~h}$, cells were transfected with $0.666 \mu \mathrm{g} / \mathrm{mL}$ polydeoxyadenylic acid-polydeoxythymidylic acid double-stranded homopolymer (poly(dA:dT)) (InvivoGene, San Diego, CA, USA) or with $0.666 \mu \mathrm{g} / \mathrm{mL}$ polyinosinic-polycytidylic acid (poly(I:C)) (Sigma Aldrich, Saint Louis, MO, USA) using the X-tremeGene 9 transfection reagent (Roche Diagnostics). Cells were harvested at indicated time points.

For inhibition studies, cells were incubated $1 \mathrm{~h}$ prior to poly(dA:dT)/poly(I:C) transfection with

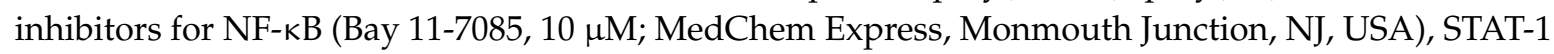


(Fludarabine, $10 \mu \mathrm{M}$; Sigma Aldrich), STAT-3 (Stattic, $5 \mu \mathrm{M}$; Sigma Aldrich), MEK1 (PD98059, $20 \mu \mathrm{M}$; Sigma Aldrich), JNK (SP600125, $10 \mu \mathrm{M}$; Tocris Bioscience, Bristol, UK) and p38 (SB203580, $10 \mu \mathrm{M}$; Tocris Bioscience).

\subsection{RNA Isolation and RT-PCR}

Cells were harvested in TRIzol ${ }^{\circledR}$ Reagent (Invitrogen Corp., Carlsbad, CA, USA) and total RNA was isolated following the manufacturer's instructions. Potential genomic DNA contamination was removed by using the Turbo DNA-free Kit (Ambion, Life Technologies) according to the manufacturer's instructions. $1 \mu \mathrm{g}$ total RNA was reverse transcribed into cDNA by the iScript cDNA Synthesis Kit (Bio-Rad Laboratories, Hercules, CA, USA). Real-time RT-PCR experiments were carried out with the Universal Probe Library system TaqMan probes (Roche Diagnostics) and qPCRBIO Probe Mix Lo-ROX (PCR Biosystem Ltd., London, UK) on a C1000 Touch Thermal Cycler (Bio-Rad Laboratories), using primers reported previously [20]. The expression of each gene was normalized to the expression of the 18S rRNA gene. Relative mRNA levels were calculated by the $\Delta \Delta C_{t}$ method.

\subsection{Detection of NF- $\kappa B$ Induction}

Luciferase assays were performed to determine the NF- $\mathrm{KB}$ activity in response to poly(dA:dT) treatment. The HPV-KER cell line was transfected with the NF- $\mathrm{kB}$ reporter construct vector $\mathrm{pNF}-\mathrm{kB}$-luc Cis-Reporter Plasmid (Stratagene, La Jolla, CA, USA) and the pGL4.75 [hRluc/CMV] plasmid (Promega, Madison, WI, USA) with the use of the X-tremeGene9 transfection reagent. The treated cells were washed twice with PBS, lysed with passive lysis buffer (Biotium, Hayward, CA, USA) and the luciferase activities in the lysates were measured using the Firefly \& Renilla Dual Luciferase Assay Kit (Biotium) and Thermo Luminoskan Ascent (Thermo Scientific, Rockford, IL, USA), according to the manufacturer's instructions. All samples were measured three times and the luciferase activity derived from the NF-kB-luc plasmid was normalized to the activity of the Renilla luciferase activity from pGL4.75 [hRluc/CMV] plasmid.

\subsection{Western Blot Analysis}

Cells were harvested at indicated time points after poly(dA:dT) or poly(I:C) transfection and lysed in lysis buffer supplemented with $0.5 \%$ SDS and $1 \%$ Halt $^{\mathrm{TM}}$ Protease and Phosphatase Inhibitor Cocktail (Thermo Scientific). Equal amounts of protein in ProTrack Loading Buffer (Lonza, Basel, Switzerland) were separated on a 7.5\% TGX Fast Cast Gel and transferred to nitrocellulose membrane $(0.45 \mu \mathrm{m}$; Bio-Rad Laboratories). After blocking the membrane in 5\% non-fat milk in Tris-Buffered Saline containing $0.2 \%$ Tween-20, primary antibodies were incubated overnight at $4{ }^{\circ} \mathrm{C}$ with constant agitation. HRP-conjugated secondary antibodies were incubated for $60 \mathrm{~min}$ at room temperature. Signal was visualized with SuperSignal ${ }^{\mathrm{TM}}$ West Pico Chemiluminescent Substrate (Thermo Scientific) on a C-Digit Blot Scanner (LI-COR Corp., Lincoln, NE, USA). Primary antibodies used were phospho-IkB $\alpha$ (Santa Cruz Biotechnology, Dallas, TX, USA), phospho-ERK1/2 (BioLegend, San Diego, CA, USA), phospho-STAT-1 (Ser727; Cell Signaling Technology, Danvers, MA, USA), phospho-STAT-3 (Ser727; Cell Signaling Technology), phospho-JNK (T183/Y185; Bio-Techne, Abingdon, UK) and phospho-p38 alpha (T180/Y182; Bio-Techne).

\subsection{Statistical Analysis}

Two-way repeated measurement analysis of variance (ANOVA) was used to compare more than two groups, and one-tailed, paired Student's $t$-test was used to compare two groups, as indicated in the figure legend. Based on at least three independent biological repeats, data are presented as mean \pm standard error. Statistical analysis was carried out using Sigma Plot Ver. 13.0, (Systat Software Inc. Erkrath, Germany) the significance level was set at $p \leq 0.05$. 
Supplementary Materials: Supplementary materials can be found at http:/ /www.mdpi.com/1422-0067/19/3/ $774 / \mathrm{s} 1$.

Acknowledgments: We would like to express our gratitude to Gergely H. Fodor for his valuable help with the statistical analysis. This work was supported by the National Research Development and Innovation Office (K111885 and GINOP-2.3.2-15-2016-00015). Judit Danis is supported by the NTP-NFTÖ-17 project by the Hungarian Ministry of Human Capacities. The founding sponsors had no role in the design of the study; in the collection, analyses, or interpretation of data; in the writing of the manuscript, and in the decision to publish the results.

Author Contributions: Judit Danis and Márta Széll conceived and designed the experiments and wrote the manuscript, Judit Danis, Luca Janovák, Barbara Gubán and Anikó Göblös performed the experiments and analyzed the data. Kornélia Szabó, Lajos Kemény and Zsuzsanna Bata-Csörgó contributed reagents and cells, helped with evaluation of the results and critically revised the manuscript. All authors have revised and approved the final version.

Conflicts of Interest: The authors declare no conflict of interest.

\section{Abbreviations}

$\begin{array}{ll}\text { IL-6 } & \text { interleukin-6 } \\ \text { TNF- } \alpha & \text { tumor necrosis factor } \alpha \\ \text { PAMP } & \text { pathogen associated molecular pattern } \\ \text { DAMP } & \text { damage associated molecular pattern } \\ \text { DNase } & \text { deoxyribonuclease } \\ \text { AIM2 } & \text { absent in melanoma 2 } \\ \text { IFN } & \text { interferon } \\ \text { TLR } & \text { toll like receptor } \\ \text { RIG-I } & \text { retinoic acid induced gene I } \\ \text { CGAS } & \text { cyclic GMP-AMP synthase } \\ \text { ds } & \text { double-stranded } \\ \text { poly }(d A: d T) & \text { polydeoxyadenylic acid-polydeoxythymidylic acid double-stranded homopolymer } \\ \text { poly(I:C) } & \text { Polyinosinic-polycytidylic acid } \\ \text { MAPK } & \text { mitogen activated protein kinase } \\ \text { JNK } & \text { c-Jun N-terminal kinase } \\ \text { ERK1/2 } & \text { extracellular signal-regulated protein kinase } 1 \text { and } 2 \\ \text { MEK1/2 } & \text { dual specificity mitogen-activated protein kinase kinase } 1 \text { and } 2 \\ \text { NF- } K B & \text { nuclear factor } \kappa \text { B } \\ \text { IKB } \alpha & \text { NF- } k B \text { inhibitor } \alpha \\ \text { STAT } & \text { signal transducer and activator of transcription } \\ \text { NHEK } & \text { normal human epidermal keratinocyte }\end{array}$

\section{References}

1. Pivarcsi, A.; Koreck, A.; Bodai, L.; Széll, M.; Szeg, C.; Belso, N.; Kenderessy-Szabó, A.; Bata-Csörgo, Z.; Dobozy, A.; Kemény, L. Differentiation-regulated expression of toll-like receptors 2 and 4 in HaCat keratinocytes. Arch. Dermatol. Res. 2004, 296, 120-124. [CrossRef] [PubMed]

2. Köllisch, G.; Kalali, B.N.; Voelcker, V.; Wallich, R.; Behrendt, H.; Ring, J.; Bauer, S.; Jakob, T.; Mempel, M.; Ollert, M. Various members of the Toll-like receptor family contribute to the innate immune response of human epidermal keratinocytes. Immunology 2005, 114, 531-541. [CrossRef] [PubMed]

3. Baker, B.S.; Ovigne, J.-M.; Powles, A.V.; Corcoran, S.; Fry, L. Normal keratinocytes express Toll-like receptors (TLRs) 1, 2 and 5: Modulation of TLR expression in chronic plaque psoriasis. Br. J. Dermatol. 2003, 148, 670-679. [CrossRef] [PubMed]

4. Mempel, M.; Voelcker, V.; Köllisch, G.; Plank, C.; Rad, R.; Gerhard, M.; Schnopp, C.; Fraunberger, P.; Walli, A.K.; Ring, J.; et al. Toll-like receptor expression in human keratinocytes: Nuclear factor $\kappa$ B controlled gene activation by Staphylococcus aureus is toll-like receptor 2 but not toll-like receptor 4 or platelet activating factor receptor dependent. J. Investig. Dermatol. 2003, 121, 1389-1396. [CrossRef] [PubMed] 
5. Luff, J.A.; Yuan, H.; Kennedy, D.; Schlegel, R.; Felsburg, P.; Moore, P.F. Keratinocyte antiviral response to poly(dA:dT) stimulation and papillomavirus infection in a canine model of X-linked severe combined immunodeficiency. PLOS ONE 2014, 9, 1-8. [CrossRef] [PubMed]

6. Almine, J.F.; O’Hare, C.A.J.; Dunphy, G.; Haga, I.R.; Naik, R.J.; Atrih, A.; Connolly, D.J.; Taylor, J.; Kelsall, I.R.; Bowie, A.G.; et al. IFI16 and cGAS cooperate in the activation of STING during DNA sensing in human keratinocytes. Nat. Commun. 2017, 8, 14392. [CrossRef] [PubMed]

7. Prens, E.P.; Kant, M.; van Dijk, G.; van der Wel, L.I.; Mourits, S.; van der Fits, L. IFN-alpha enhances poly-IC responses in human keratinocytes by inducing expression of cytosolic innate RNA receptors: Relevance for psoriasis. J. Investig. Dermatol. 2008, 128, 932-938. [CrossRef] [PubMed]

8. Tervaniemi, M.; Katayama, S.; Skoog, T.; Siitonen, H.; Vuola, J.; Nuutila, K.; Sormunen, R.; Johnsson, A.; Linnarsson, S.; Suomela, S.; et al. NOD-like receptor signaling and inflammasome-related pathways are highlighted in psoriatic epidermis. Sci. Rep. 2016, 6, 22745. [CrossRef] [PubMed]

9. Cao, T.; Shao, S.; Li, B.; Jin, L.; Lei, J.; Qiao, H.; Wang, G. Up-regulation of Interferon-inducible protein 16 contributes to psoriasis by modulating chemokine production in keratinocytes. Sci. Rep. 2016, 6, 25381. [CrossRef] [PubMed]

10. Dombrowski, Y.; Peric, M.; Koglin, S.; Kammerbauer, C.; Göss, C.; Anz, D.; Simanski, M.; Gläser, R.; Harder, J.; Hornung, V.; et al. Cytosolic DNA triggers inflammasome activation in keratinocytes in psoriatic lesions. Sci. Transl. Med. 2011, 3. [CrossRef] [PubMed]

11. Molès, J.-P.; Griez, A.; Guilhou, J.-J.; Girard, C.; Nagot, N.; Van de Perre, P.; Dujols, P. Cytosolic RNA:DNA duplexes generated by endogenous reverse transcriptase activity as autonomous inducers of skin inflammation in psoriasis. PLoS ONE 2017, 12, e0169879. [CrossRef] [PubMed]

12. Fischer, H.; Szabo, S.; Scherz, J.; Jaeger, K.; Rossiter, H.; Buchberger, M.; Ghannadan, M.; Hermann, M.; Theussl, H.-C.; Tobin, D.J.; et al. essential role of the keratinocyte-specific endonuclease DNase1L2 in the removal of nuclear DNA from hair and nails. J. Investig. Dermatol. 2011, 131, 1208-1215. [CrossRef] [PubMed]

13. Fischer, H.; Buchberger, M.; Napirei, M.; Tschachler, E.; Eckhart, L. Inactivation of DNase1L2 and DNase2 in keratinocytes suppresses DNA degradation during epidermal cornification and results in constitutive parakeratosis. Sci. Rep. 2017, 7, 6433. [CrossRef] [PubMed]

14. Ruiz-Romeu, E.; Ferran, M.; Giménez-Arnau, A.; Bugara, B.; Lipert, B.; Jura, J.; Florencia, E.F.; Prens, E.P.; Celada, A.; Pujol, R.M.; et al. MCPIP1 RNase is aberrantly distributed in psoriatic epidermis and rapidly induced by IL-17A. J. Investig. Dermatol. 2016, 136, 1599-1607. [CrossRef] [PubMed]

15. Kopfnagel, V.; Wagenknecht, S.; Harder, J.; Hofmann, K.; Kleine, M.; Buch, A.; Sodeik, B.; Werfel, T. RNase 7 strongly promotes TLR9-mediated DNA sensing by human plasmacytoid dendritic cells. J. Investig. Dermatol. 2017. [CrossRef] [PubMed]

16. Kopfnagel, V.; Wittmann, M.; Werfel, T. Human keratinocytes express AIM2 and respond to dsDNA with IL-1 $\beta$ secretion. Exp. Dermatol. 2011, 20, 1027-1029. [CrossRef] [PubMed]

17. Göblös, A.; Danis, J.; Vas, K.; Bata-Csörgő, Z.; Kemény, L.; Széll, M. Keratinocytes express functional CARD18, a negative regulator of inflammasome activation, and its altered expression in psoriasis may contribute to disease pathogenesis. Mol. Immunol. 2016, 73, 10-18. [CrossRef] [PubMed]

18. Dai, X.; Sayama, K.; Tohyama, M.; Shirakata, Y.; Yang, L.; Hirakawa, S.; Tokumaru, S.; Hashimoto, K. The NF-kB, p38 MAPK and STAT1 pathways differentially regulate the dsRNA-mediated innate immune responses of epidermal keratinocytes. Int. Immunol. 2008, 20, 901-909. [CrossRef] [PubMed]

19. Luff, J.A.; Yuan, H.; Suter, M.M.; Müller, E.J.; Schlegel, R.; Moore, P.F. Canine keratinocytes upregulate type I interferons and proinflammatory cytokines in response to poly(dA:dT) but not to canine papillomavirus. Vet. Immunol. Immunopathol. 2013, 153, 177-186. [CrossRef] [PubMed]

20. Danis, J.; Göblös, A.; Bata-Csörgő, Z.; Kemény, L.; Széll, M. PRINS non-coding RNA regulates nucleic acid-induced innate immune responses of human keratinocytes. Front. Immunol. 2017, 8, 1053. [CrossRef] [PubMed]

21. Alexopoulou, L.; Holt, A.C.; Medzhitov, R.; Flavell, R.A. Recognition of double-stranded RNA and activation of NF-kB by Toll-like receptor 3. Nature 2001, 413, 732-738. [CrossRef] [PubMed]

22. Cheng, G.; Zhong, J.; Chung, J.; Chisari, F. V Double-stranded DNA and double-stranded RNA induce a common antiviral signaling pathway in human cells. Proc. Natl. Acad. Sci. USA 2007, 104, 9035-9040. [CrossRef] [PubMed] 
23. Ablasser, A.; Bauernfeind, F.; Hartmann, G.; Latz, E.; Fitzgerald, K.A.; Hornung, V. RIG-I dependent sensing of poly $(\mathrm{dA}-\mathrm{dT})$ via the induction of an RNA polymerase III transcribed RNA intermediate. Nat. Immunol. 2009, 10, 1065-1072. [CrossRef] [PubMed]

24. Wang, S.; Liu, D.; Ning, W.; Xu, A. Cytosolic dsDNA triggers apoptosis and pro-inflammatory cytokine production in normal human melanocytes. Exp. Dermatol. 2015, 24, 298-300. [CrossRef] [PubMed]

25. Zhou, M.-W.; Jiang, R.-H.; Kim, K.-D.; Lee, J.-H.; Kim, C.-D.; Yin, W.-T.; Lee, J.-H. Rosmarinic acid inhibits poly(I:C)-induced inflammatory reaction of epidermal keratinocytes. Life Sci. 2016, 155, 189-194. [CrossRef] [PubMed]

26. Shin, J.-M.; Choi, D.-K.; Sohn, K.-C.; Kim, S.-Y.; Min Ha, J.; Ho Lee, Y.; Im, M.; Seo, Y.-J.; Deok Kim, C.; Lee, J.-H.; et al. Double-stranded RNA induces inflammation via the NF-кB pathway and inflammasome activation in the outer root sheath cells of hair follicles. Sci. Rep. 2017, 7, 44127. [CrossRef] [PubMed]

27. Boukamp, P.; Petrussevska, R.T.; Breitkreutz, D.; Hornung, J.; Markham, A.; Fusenig, N.E. Normal keratinization in a spontaneously immortalized aneuploid human keratinocyte cell line. J. Cell Biol. 1988, 106, 761-771. [CrossRef] [PubMed]

28. Tax, G.; Urbán, E.; Palotás, Z.; Puskás, R.; Kónya, Z.; Bíró, T.; Kemény, L.; Szabó, K. Propionic acid produced by Propionibacterium acnes strains contributes to their pathogenicity. Acta Derm. Venereol. 2016, 96, 43-49. [CrossRef] [PubMed]

29. Lewis, D.A.; Hengeltraub, S.F.; Gao, F.C.; Leivant, M.A.; Spandau, D.F. Aberrant NF-кB activity in HaCaT cells alters their response to UVB signaling. J. Investig. Dermatol. 2006, 126, 1885-1892. [CrossRef] [PubMed]

30. Rathinam, V.A.K.; Jiang, Z.; Waggoner, S.N.; Sharma, S.; Cole, L.E.; Waggoner, L.; Vanaja, S.K.; Monks, B.G.; Ganesan, S.; Latz, E.; et al. The AIM2 inflammasome is essential for host defense against cytosolic bacteria and DNA viruses. Nat. Immunol. 2010, 11, 395-402. [CrossRef] [PubMed]

31. Barbuto, S.; Idoyaga, J.; Villa-Perelló, M.; Longhi, M.P.; Breton, G.; Steinman, R.M.; Miur, T.W. Induction of innate and adaptive immunity by delivery of poly dA:dT to dendritic cells. Nat. Chem. Biol. 2013, 9, 250-256. [CrossRef] [PubMed]

32. Kis-Toth, K.; Szanto, A.; Thai, T.-H.; Tsokos, G.C. Cytosolic DNA-activated human dendritic cells are potent activators of the adaptive immune response. J. Immunol. 2011, 187, 1222-1234. [CrossRef] [PubMed]

33. Lande, R.; Gregorio, J.; Facchinetti, V.; Chatterjee, B.; Wang, Y.-H.; Homey, B.; Cao, W.; Wang, Y.-H.; Su, B.; Nestle, F.O.; et al. Plasmacytoid dendritic cells sense self-DNA coupled with antimicrobial peptide. Nature 2007, 449, 564-569. [CrossRef] [PubMed]

34. Oláh, A.; Ambrus, L.; Nicolussi, S.; Gertsch, J.; Tubak, V.; Kemény, L.; Soeberdt, M.; Abels, C.; Bíró, T. Inhibition of fatty acid amide hydrolase exerts cutaneous anti-inflammatory effects both in vitro and in vivo. Exp. Dermatol. 2016, 25, 328-330. [CrossRef] [PubMed]

35. Szegedi, K.; Göblös, A.; Bacsa, S.; Antal, M.; Németh, I.B.; Bata-Csörgő, Z.; Kemény, L.; Dobozy, A.; Széll, M. Expression and functional studies on the noncoding RNA, PRINS. Int. J. Mol. Sci. 2013, 14, $205-225$. [CrossRef] [PubMed]

36. Dai, X.; Sayama, K.; Yamasaki, K.; Tohyama, M.; Shirakata, Y.; Hanakawa, Y.; Tokumaru, S.; Yahata, Y.; Yang, L.; Yoshimura, A.; et al. SOCS1-negative feedback of STAT1 activation is a key pathway in the dsRNA-induced innate immune response of human keratinocytes. J. Investig. Dermatol. 2006, 126, 1574-1581. [CrossRef] [PubMed]

37. Takeuchi, O.; Hemmi, H.; Akira, S. Interferon response induced by Toll-like receptor signaling. J. Endotoxin Res. 2004, 10, 252-256. [CrossRef] [PubMed]

38. Scherle, P.A.; Jones, E.A.; Favata, M.F.; Daulerio, A.J.; Covington, M.B.; Nurnberg, S.A.; Magolda, R.L.; Trzaskos, J.M. Inhibition of MAP kinase kinase prevents cytokine and prostaglandin E2 production in lipopolysaccharide-stimulated monocytes. J. Immunol. 1998, 161, 5681-5686. [PubMed]

39. Jaffee, B.D.; Manos, E.J.; Collins, R.J.; Czerniak, P.M.; Favata, M.F.; Magolda, R.L.; Scherle, P.A.; Trzaskos, J.M. Inhibition of MAP kinase kinase (MEK) results in an anti-inflammatory response in vivo. Biochem. Biophys. Res. Commun. 2000, 268, 647-651. [CrossRef] [PubMed]

40. Duan, W.; Chan, J.H.P.; Wong, C.H.; Leung, B.P.; Wong, W.S.F. Anti-inflammatory effects of mitogen-activated protein kinase kinase inhibitor U0126 in an asthma mouse model. J. Immunol. 2004, 172, 7053-7059. [CrossRef] [PubMed]

41. Lulli, D.; Carbone, M.; Pastore, S. The MEK inhibitors trametinib and cobimetinib induce a type I interferon response in human keratinocytes. Int. J. Mol. Sci. 2017, 18, 2227. [CrossRef] [PubMed] 
42. Maeng, Y.S.; Min, J.K.; Kim, J.H.; Yamagishi, A.; Mochizuki, N.; Kwon, J.Y.; Park, Y.W.; Kim, Y.M.; Kwon, Y.G. ERK is an anti-inflammatory signal that suppresses expression of NF-KB-dependent inflammatory genes by inhibiting IKK activity in endothelial cells. Cell. Signal. 2006, 18, 994-1005. [CrossRef] [PubMed]

43. Lulli, D.; Carbone, M.L.; Pastore, S. Epidermal growth factor receptor inhibitors trigger a type I interferon response in human skin. Oncotarget 2016, 7, 47777-47793. [CrossRef] [PubMed]

44. Luecke, S.; Paludan, S.R. Molecular requirements for sensing of intracellular microbial nucleic acids by the innate immune system. Cytokine 2016, 98, 4-14. [CrossRef] [PubMed]

45. Andrés, R.M.; Hald, A.; Johansen, C.; Kragballe, K.; Iversen, L. Studies of Jak/STAT3 expression and signalling in psoriasis identifies STAT3-Ser727 phosphorylation as a modulator of transcriptional activity. Exp. Dermatol. 2013, 22, 323-328. [CrossRef] [PubMed]

(C) 2018 by the authors. Licensee MDPI, Basel, Switzerland. This article is an open access article distributed under the terms and conditions of the Creative Commons Attribution (CC BY) license (http://creativecommons.org/licenses/by/4.0/). 
II. 


\title{
PRINS Non-Coding RNA Regulates Nucleic Acid-Induced Innate Immune Responses of Human Keratinocytes
}

\author{
Judit Danis ${ }^{1,2 *}$, Anikó Göblös ${ }^{1,2}$, Zsuzsanna Bata-Csörgö ${ }^{1,2}$, Lajos Kemény ${ }^{1,2}$ and \\ Márta Széll/2,3
}

${ }^{1}$ Department of Dermatology and Allergology, University of Szeged, Szeged, Hungary, ${ }^{2}$ MTA-SZTE Dermatological Research Group, Szeged, Hungary, ${ }^{3}$ Department of Medical Genetics, University of Szeged, Szeged, Hungary

Cytosolic DNA fragments are recognized as pathogen- and danger-associated molecular patterns that induce a cascade of innate immune responses. Moreover, excessive cytosolic DNA can enhance chronic inflammation, predominantly by activating inflammasomes, and thereby contributing to the pathogenesis of chronic diseases, such as psoriasis. Psoriasis associated non-protein coding RNA induced by stress (PRINS) is

OPEN ACCESS

Edited by:

Jixin Zhong,

Case Western Reserve University,

United States

Reviewed by:

Ping Chen,

Georgetown University School of Medicine, United States

Shanzhong Gong,

University of Texas at Austin,

United States

Hui Liu,

University of California, San

Francisco, United States

${ }^{*}$ Correspondence:

Judit Danis

danis.judit@med.u-szeged.hu

Specialty section: This article was submitted to Inflammation,

a section of the journal

Frontiers in Immunology

Received: 22 June 2017 Accepted: 14 August 2017 Published: 29 August 2017

Citation: Danis J, Göblös A, Bata-Csörgó Z, Kemény L and Széll M (2017) PRINS Non-Coding RNA Regulates Nucleic Acid-Induced Innate Immune Responses of Human Keratinocytes.

Front. Immunol. 8:1053. doi: 10.3389/fimmu.2017.01053 a long non-coding RNA, which has been shown to be associated with psoriasis susceptibility and cellular stress responses; however, the precise mechanism of its action has not been determined. Here, we provide evidence that, in addition to inflammasome activation, cytosolic DNA induces intracellular inflammatory reactions while decreasing PRINS gene expression. Furthermore, PRINS overexpression can ameliorate the inflammatory-mediator production of keratinocytes induced by cytosolic DNA. Overexpression of PRINS resulted in decreased interleukin-6 (IL-6) and chemokine (C-C motif) ligand 5 (CCL-5) expression and secretion. In silico analysis predicted direct binding sites between PRINS and the mRNAs, which was confirmed by an in vitro binding assay and on cellular level. Our results indicated that PRINS binds directly to the mRNAs of IL-6 and CCL-5 at specific binding sites and eventually destabilizes these mRNAs, leading to a decrease in their expression and secretion of the corresponding proteins. These results may indicate a restrictive role for PRINS in inflammatory processes.

Keywords: PRINS, long non-coding RNA, interleukin-6, CCL-5, keratinocyte, poly(dA:dT)

\section{INTRODUCTION}

The skin provides the first line of defense against a variety of environmental, chemical, and physical stimuli and acts as an active member of the innate immune system. Double-stranded DNA (dsDNA) fragments are known to induce antiviral responses in keratinocytes $(1,2)$ as well as induce inflammasome activation and subsequent interleukin (IL)- $1 \beta$ release in these cells $(3,4)$. Moreover, keratinocytes express a wide range of pattern recognition receptors (PRR) for nucleotide fragments $(5,6)$, mainly implicated in antiviral reactions $(2,6)$. These PRRs are required for immune response in an acute infection and might also lead to the exacerbation of chronic inflammatory inherited multifactorial diseases, such as psoriasis (7). Psoriasis is caused by the interplay of professional immune cells and keratinocytes. Cytosolic nucleotide fragments are highly abundant in psoriatic skin (3), leading to chronic activation of professional immune cells (8), and are thought to be an initiator factor in the disease. In particular, cytosolic nucleotide fragments do not lead to antiviral reaction, but instead activate the AIM2 inflammasome signaling in psoriatic keratinocytes (3), leading to prolonged inflammation. 
In the last decade, genome-scale transcription studies have uncovered non-coding RNAs as previously unrecognized players in the dysregulation of inflammatory reaction in psoriatic skin $(9,10)$. The contribution of both microRNAs (miRNAs) and long non-coding RNAs (lncRNAs) to psoriasis has been extensively studied $(11,12)$. We were first to identify a lncRNA potentially contributing to disease susceptibility: PRINS, the psoriasis susceptibility-related non-coding RNA induced by stress, which is highly expressed in psoriatic non-lesional epidermis compared both to lesional or healthy epidermis (13). The expression of PRINS is modified by a diverse set of cellular stressors, including starvation, ultraviolet B (UVB) irradiation, translation inhibition (14), and hypoxia (15). Moreover, microbial stimuli decreased PRINS expression in macrophages (16) and normal human epidermal keratinocytes (NHEKs) (14), and PRINS was recently shown to interact with chemokine (C-C motif) ligand 5 (CCL-5, also known as RANTES) in kidney epithelial cells (15). CCL-5 is a chemokine attracting leukocytes to the site of inflammation. Under inflammatory conditions, keratinocytes produce large amount of CCL-5 to attract antigen-presenting cells (17) and T-cells into the epidermis (18); moreover, CCL-5 is overexpressed in atopic dermatitis and psoriatic lesions (19). Based on these findings, we aimed to investigate whether the PRINS lncRNA contributes to keratinocyte innate immune responses.

According to our results, PRINS can ameliorate dsDNAinduced keratinocyte immune responses. Bioinformatic analysis of the PRINS lncRNA sequence revealed putative interaction sites for interleukin-6 (IL-6) and CCL-5 mRNAs. Destruction of the putative interacting region resulted in the loss of the ability of PRINS to bind to the IL- 6 mRNA. In addition, our functional studies confirmed the regulatory role of the interaction between PRINS and IL-6 mRNA. Our results suggest a general antiinflammatory function for PRINS and provide insight to the role of high PRINS expression in psoriatic non-lesional skin.

\section{MATERIALS AND METHODS}

\section{Cell Culture and Inflammatory Stimuli}

Normal human epidermal keratinocytes used for the experiments were separated from skin specimens obtained from the Plastic Surgery Unit of our department. Written informed consent was obtained from all investigated individuals. The study was approved by the Human Investigation Review Board of the University of Szeged and complied with the ethical standards of research and in accordance with the Helsinki Declaration.

Epidermis was separated from the dermis by overnight incubation in Dispase (Roche Diagnostics, Manheim, Germany), and keratinocytes were obtained after maceration in $0.25 \%$ trypsin. Cells were grown in $75 \mathrm{~cm}^{2}$ cell-culture flasks and were maintained in keratinocyte serum-free medium, containing EGF and BPE (Gibco Keratinocyte SFM Kit; Life Technologies, Copenhagen, Denmark) and supplemented with 1\% antibiotic/ antimycotic solution (PAA Laboratories $\mathrm{GmBH}$, Pasching, Austria) and $1 \%$ L-glutamine (PAA Laboratories), at $37^{\circ} \mathrm{C}$ in a humidified atmosphere with $5 \% \mathrm{CO}_{2}$. The medium was changed every 2 days.
Third passage keratinocytes were seeded into 6-well plates. Cells were primed in supplement-free medium by addition of $5 \mathrm{ng} / \mathrm{ml}$ tumor necrosis factor- $\alpha$ (TNF- $\alpha$ ) and $5 \mathrm{ng} / \mathrm{ml}$ interferon- $\gamma($ IFN- $\gamma)$. After $24 \mathrm{~h}$, cells were transfected with $0.666 \mu \mathrm{g} / \mathrm{ml}$ polydeoxyadenylic acid-polydeoxythymidylic acid double-stranded homopolymer [poly(dA:dT), Sigma Aldrich, Saint Louis, MO, USA] using the X-tremeGENE 9 DNA transfection reagent (Roche Diagnostics). Cells were harvested $12 \mathrm{~h}$ after poly(dA:dT) transfection.

\section{Gene-Specific Overexpression}

For overexpressing PRINS, the AK022045 cDNA sequence [Biological Resource Center (NBRC) National Institute of Technology and Evaluation, Chiba, Japan] was cloned into a pcDNA3.1(+) vector. The empty pcDNA3.1(+) vector served as a control.

The $\triangle$ PRINS construct was created by replacing the AK022045 region (position 538-622) with the following scrambled sequence: GTGCGTGGCGGAGACGTGGTGGTAGAC C G A A T T G A G G A G G A T C C G A A G G T T A G A C G T AGGCGATCGCCGCTTCGGACGCGGTCGC. The $\triangle$ PRINS sequence was created by GeneArt gene synthesis (Thermo Scientific), and cloned into a pcDNA3.1(+) vector.

Transient transfection of NHEK cells was carried out at approximately $70 \%$ confluency in parallel to cytokine priming, using the X-tremeGENE HP DNA transfection protocol, as described by the manufacturer (Roche Diagnostics). The transfection efficiency was $85 \%$ on average, as determined by the transfection of a GFP reporter construct (Lonza, Basel, Switzerland) and analysis of GFP expression by flow cytometry. The effectiveness of overexpression was investigated with real-time RT-PCR (Figure S1 in Supplementary Material).

\section{In Silico Prediction of Interacting Sites}

Sequence complementarity between PRINS (AK022045) and the mRNA of IL-1 $\alpha$ (M28983.1), IL-1 $\beta$ (NM_000576.2), IL-6 (NM_000600.4), IL-8 (NM_000584.3), TNF- $\alpha$ (NM_000594.3), and CCL-5 (NM_002985.2) was analyzed using two algorithms: RIsearch (20), which uses a simplified nearest-neighbor energy model, and INTARNA (21-23), which calculates the free-energy values of the interaction based on predicted global and local structures of mRNAs. The regions predicted by both programs were considered as putative interaction sites.

\section{RNA Isolation and RT-PCR}

Total RNA was isolated from cells using TRIzol ${ }^{\circledR}$ Reagent (Invitrogen Corp., Carlsbad, CA, USA), following the manufacturer's instructions. Turbo DNA-free Kit (Ambion, Life Technologies) was used for the removal of contaminating DNA. cDNA was synthesized from $1 \mu \mathrm{g}$ total RNA using the iScript cDNA Synthesis Kit (Bio-Rad Laboratories, Hercules, CA, USA). Real-time RT-PCR experiments were carried out with the Universal Probe Library system (Roche Diagnostics) using a C1000 Touch Thermal Cycler (Bio-Rad Laboratories) and the primers listed in Table S1 in Supplementary Material. The expression of each gene was normalized to the 18S rRNA gene. Relative mRNA levels were calculated by the $\Delta \Delta \mathrm{Ct}$ method. 


\section{ELISA}

Cell supernatants were centrifuged $\left(5,000 \mathrm{rpm}, 4 \mathrm{~min}, 4^{\circ} \mathrm{C}\right)$ to pellet cell debris, and the amount of cytokines IL-1 $\alpha$, IL-1 $\beta$, IL-6, IL- 8 , CCL-5, and TNF- $\alpha$ was determined byELISA (IL- $1 \alpha$ DuoSet, IL-1 $\beta$ ELISA Duo Set, and TNF- $\alpha$ Duo Set, R\&D Systems, Minneapolis, MN, USA; Human IL-6 Mini TMB ELISA Development Kit, Human IL-8 TMB ELISA Development Kit, Human RANTES ATBS ELISA Development Kit, PeproTech, Rocky Hill, NJ, USA), according to the manufacturer's instructions.

\section{In Vitro Transcription and In Vitro Binding Assay}

PRINS and $\triangle$ PRINS RNA sequences were produced by in vitro transcription from pcDNA3.1(+) containing the AK022045 or $\triangle$ PRINS cDNA sequence, using Transcript Aid T7 In Vitro Transcription Kit (Thermo Scientific). Products were purified by the GeneJET RNA Purification Kit (Thermo Scientific). Quality and sequence-length analyses were carried out on reducing agarose gel-electrophoresis. The single-stranded RNA products were used in a fluorescent binding assay. The fluorescently labeled RNA sequence 5'6-carboxyfluorescein(6-FAM)/GAAGCUCUAU CUCCCCUCCAGGAGCCCAGCUAUGAACUCCUUCUCC ACAAGCGCCUUCGGUCCAGUUGCCUUCUCCCU GGGGCUGCUCCUGGUGUUGCCUGCUGCCUUCCCU GCC-3', comprising positions 91-205 of the IL-6 (NM_000600.4) mRNA sequence, was produced by Integrated DNA Technologies.

An in vitro binding assay was carried out on a Monolith NT.115 Pico MicroScale Thermophoresis instrument (NanoTemper $\mathrm{GmbH}$, Germany), in nuclease-free water, at $25^{\circ} \mathrm{C}$, with $80 \%$ Laser Power, 10\% LED Power, by 2bind $\mathrm{GmbH}$, Regensburg, Germany. Fluorescence enhancement of the 6-FAM labeled specific truncated IL-6 RNA sequence or a 6-FAM labeled unspecific DNA, as negative control, was measured after addition of PRINS or $\triangle$ PRINS. The concentration of fluorescently labeled molecules was $10 \mathrm{nM}$ constantly, while unlabeled RNA concentration ranged from $126.75 \mathrm{nM}$ to $61.9 \mathrm{pM}$. Initial fluorescence was analyzed for binding curves; the formulation used is displayed in Figure S2 in Supplementary Material.

\section{Statistical Analysis}

Experiments were carried out in triplicate with at least three biological repeats, as indicated in figure legends. For statistical analysis, one-way ANOVA was used to compare more than two groups, and one-tailed, paired $t$-test was used to compare two groups. Statistical analysis was carried out using R software, version 3.2.2., and the significance level was set at $p \leq 0.05$.

\section{RESULTS}

\section{Poly(dA:dT) Treatment of Keratinocytes Induces the Expression of Inflammatory Cytokines while Decreasing the Expression of PRINS}

To study how dsDNA influences NHEKs immune function, we analyzed the expression (Figure 1) and secretion (Figure 2) of several inflammatory cytokines and the expression of PRINS upon poly $(\mathrm{dA}: \mathrm{dT})$ exposure.

We confirmed that poly $(\mathrm{dA}: \mathrm{dT})$ significantly induced the expression and secretion of IL-1 $\beta$ in keratinocytes, as described previously (4). In addition, poly(dA:dT) induced very strong mRNA expression of IL- $1 \alpha$, IL- 6 , IL- 8 , and TNF- $\alpha$ in NHEKs (Figures 1B-F).

To gain pronounced inflammatory reaction in NHEKs, a priming step using TNF- $\alpha$ and IFN- $\gamma$ is often applied before poly $(\mathrm{dA}: \mathrm{dT})$ treatment $(3,4)$; however, the cumulative effect of this treatment on the expression of other cytokines has not been examined thoroughly. When cells were primed for $24 \mathrm{~h}$ before poly $(\mathrm{dA}: \mathrm{dT})$ treatment, IL-1 $\beta$ secretion was enhanced by the combination of TNF- $\alpha$ and IFN- $\gamma$ compared to poly $(\mathrm{dA}: \mathrm{dT})$ treatment alone. In contrast, IL-1 $\beta$ mRNA expression was not affected by priming (Figures 1E and 2D). Similarly, priming had no effect on TNF- $\alpha$ mRNA expression (Figure 1F). However, priming induced significantly higher mRNA expression of the other investigated cytokine genes (Figures 1B-D).

In a manner similar to mRNA expression, poly(dA:dT) transfection induced the secretion of the investigated cytokines, and the priming step significantly enhanced the amount of secreted IL-1 $\alpha$, IL-1 $\beta$, and IL- 8 in the keratinocyte supernatant (Figure 2).

As we and others have demonstrated altered PRINS expression upon exposure to inflammatory molecules $(14,16)$, we examined PRINS expression upon poly $(\mathrm{dA}: \mathrm{dT})$ treatment. Poly(dA:dT) alone or combined with cytokine priming decreased the expression of PRINS in NHEKs (Figure 1A). The expression of PRINS returned to the initial level after $24 \mathrm{~h}$ (data not shown), whereas the expression of inflammatory cytokines declined during this period.

\section{PRINS Overexpression Decreased IL-6 and IL-8 Levels in Keratinocytes}

The change in PRINS expression upon inflammatory stimuli suggests the possible contribution of PRINS to inflammatory responses of NHEK cells. To determine whether PRINS can regulate inflammatory cytokine expression, cells were transfected with a construct for overexpressing PRINS during the combined priming and poly $(\mathrm{dA}: \mathrm{dT})$ treatment. Expression and secretion of IL- 6 and IL- 8 was significantly decreased by PRINS overexpression (Figure 3), whereas mRNA expression and secretion of IL- $1 \alpha$, IL- $1 \beta$, and TNF- $\alpha$ were not affected (data not shown). These results suggest that PRINS does not influence inflammasome activation, but instead influences the regulation of other inflammatory processes.

\section{In Silico Analysis Revealed Putative Interacting Sites between the PRINS IncRNA and the IL-6 mRNA}

The mRNA of the chemokine CCL-5 was previously predicted to interact with PRINS; however, it was not reported whether this interaction affects the stability of the CCL- 5 mRNA (15). Therefore, we measured mRNA expression and secretion of CCL-5 during PRINS overexpression, and found that both decreased (Figure S3 in Supplementary Material) in a manner similar to the changes observed for IL-6 and IL-8. The similarity of these expression 

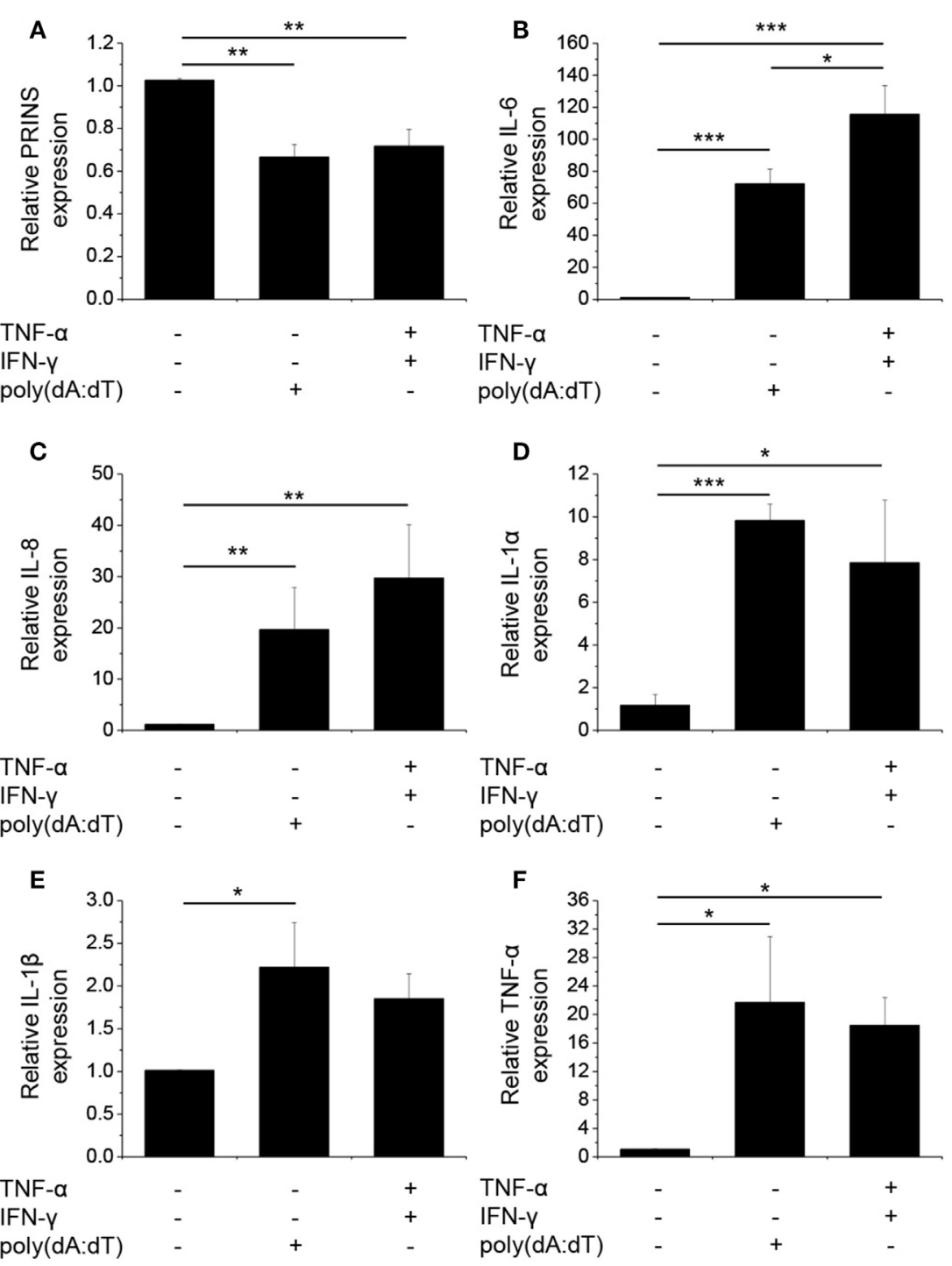

FIGURE 1 | Poly(dA:dT) treatment decreased the expression of PRINS but induced the expression and secretion of cytokines. Normal human epidermal keratinocytes were transfected with poly(dA:dT) for $12 \mathrm{~h}$ with or without priming for $24 \mathrm{~h}$ with $5 \mathrm{ng} / \mathrm{ml}$ tumor necrosis factor- $\alpha$ (TNF)- $\alpha$ and interferon- $\gamma$ (IFN- $\gamma$ ). RNA expression was detected for PRINS (A) and cytokines interleukin-6 (IL-6) (B), IL-8 (C), IL-1 $\alpha$ (D), IL-1 $\beta$ (E), TNF- $\alpha$ (F) by real-time RT-PCR. Data are presented as mean \pm SE of five independent experiments $\left({ }^{*} p \leq 0.05 ;{ }^{* *} p \leq 0.01 ;{ }^{* \star *} p \leq 0.001\right)$.

profiles led us to hypothesize similar mechanism(s) for IL-6, IL-8, and CCL-5 regulation mediated by PRINS.

To predict interactions between PRINS (AK022045) and the mRNAs of IL-6 (NM_00600.4) and IL-8 (NM_000584.3), we performed an in silico analysis using INTARNA $(22,23)$ and RIsearch (20) software. As sequence details of the CCL-5 mRNA and PRINS interaction have not been described in detail (15), we also included the CCL-5 mRNA (NM_002985.2) in the in silico analysis. As a control for the reliability of the prediction analyses, mRNA sequences of cytokines not affected by PRINS overexpression (IL$1 \alpha-M 28983.1$, IL-1 $\beta$-NM_000576.2, TNF- $\alpha-N M \_000594.3$ ) were also included. The regions predicted by both algorithms were considered putative interacting sites. Putative interaction sites were not predicted for the cytokines not affected by PRINS overexpression (IL-1 $\alpha$, IL-1 $\beta$, TNF- $\alpha$ ) in this analysis. PRINS interaction regions were only predicted for the IL- 6 and CCL- 5 mRNAs (Figures 4B,C), two mediators affected by PRINS overexpression. A distance of approximately $200 \mathrm{nt}$ separates the predicted interaction sites in the PRINS sequence, and the corresponding sites occur in the $5^{\prime}$ untranslated region (UTR) of IL- 6 and the $3^{\prime}$ UTR of CCL-5 (Figure 4A). No interaction site was predicted for IL-8.

\section{PRINS Binds to IL-6 mRNA through Direct, Sequence-Specific Interaction}

To validate the predicted interaction site, an in vitro binding experiment was carried out using the PRINS lncRNA and the IL- 6 mRNA. Binding affinity was determined using the 

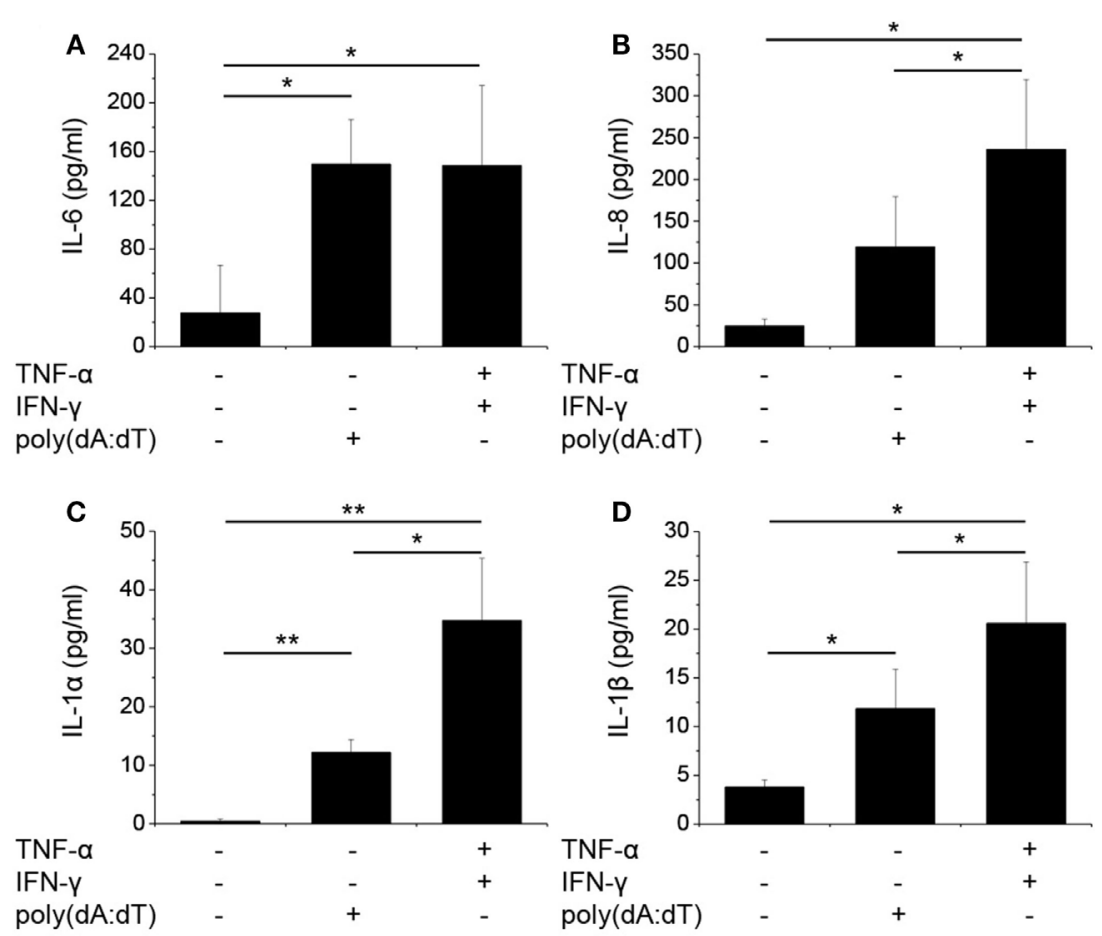

FIGURE 2 | Poly(dA:dT) treatment induced the secretion of cytokines by normal human epidermal keratinocytes (NHEKs). NHEKs were transfected with poly(dA:dT) for $12 \mathrm{~h}$ with or without priming for $24 \mathrm{~h}$ with $5 \mathrm{ng} / \mathrm{ml}$ tumor necrosis factor- $\alpha$ (TNF- $\alpha$ ) and interferon- $\gamma$ (IFN- $\gamma$ ). Secretion of cytokines interleukin-6 (IL-6) (A), IL-8 (B), IL-1 $\alpha$ (C), IL-1 $\beta$ (D) was detected by ELISA from cell supernatant. Data are presented as mean \pm SE of five independent experiments $\left({ }^{\star} p \leq 0.05\right.$; ${ }^{\star \star} p \leq 0.01$; $\left.{ }^{\star * \star} p \leq 0.001\right)$.

single-stranded PRINS RNA and a fluorescently labeled, truncated IL-6 mRNA sequence containing the predicted interacting sequence. The $\Delta$ PRINS sequence, in which the predicted interaction site to IL-6 was replaced by scrambled sequence, was used as a control. As a negative control, a fluorescently labeled DNA sequence with no similarity to either PRINS or IL-6 RNAs was used. While PRINS exhibited a very high binding affinity to the labeled IL-6 mRNA (Figure 5A, Kd = $10.3436 \mathrm{nM}$ ), specific binding for $\triangle$ PRINS and the unspecific labeled DNA could not be detected (Figure 5B). This result confirms in vitro the specificity of the regions predicted in silico (538-622 of PRINS, AK022045 and 92-204 of IL-6 mRNA, NM_000600.4).

\section{PRINS Decreases IL-6 Expression in NHEKs through Sequence-Specific Interaction}

To further validate the functionality of the in silico predicted and in vitro determined IL-6 mRNA interacting region in the PRINS sequence, we performed the overexpression experiments in NHEKs with vectors containing the wild-type PRINS or $\triangle$ PRINS (with scrambled IL-6 binding site) sequences, during the combined priming and poly(dA:dT) treatment. IL-6 expression was not affected by overexpression of $\triangle$ PRINS but was, in contrast, significantly decreased by PRINS overexpression (Figure 6A), and similar tendencies were seen in the amount of secreted IL-6 (Figure 6D). To confirm the specificity of this region in IL-6 regulation, the expression of CCL-5 was also studied. CCL- 5 expression and secretion decreased similarly both in cells overexpressing $\triangle$ PRINS and in cells overexpressing PRINS (Figures 6B,E). IL-8 expression upon PRINS or $\Delta$ PRINS overexpression showed a similar tendency to IL-6 expression, although significant differences could not be detected (Figures 6C,F). These result demonstrated that the binding site in the PRINS sequence is essential and specific for the regulation of IL-6 expression.

\section{DISCUSSION}

Due to large-scale gene-expression studies the number of annotated human non-coding RNAs has increased rapidly (24), but functional roles have been assigned only to a few of them $(25,26)$. PRINS was one of the first lncRNAs described to be dysregulated in a disease, namely in psoriasis (13). PRINS is located in an intron of the KIAA1217 gene on the sense strand (27), and, thus, it can be considered as a long intronic non-coding RNA. The expression of PRINS increases in response to various cellular stressors (14) in $\mathrm{HaCaT}$ cells, as well as to hypoxia in HK-2 cells (15) suggesting that PRINS contributes to the stress response of the cells. Recent reports on PRINS showing decreased expression upon inflammatory stimuli in both NHEKs and macrophages $(14,16)$, and the potential interaction between PRINS and the mRNA of CCL-5 (15) has led us to study its potential contribution to keratinocytes immune responses. 

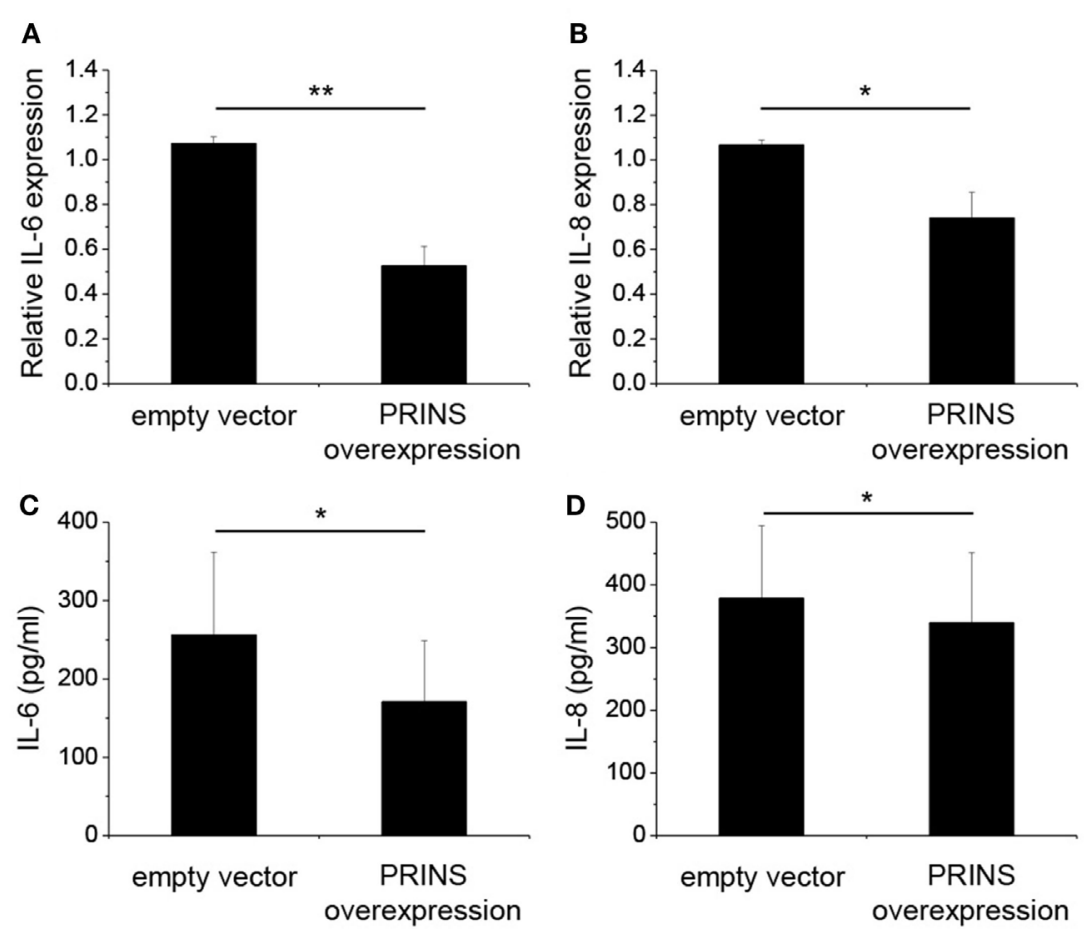

FIGURE 3 | Overexpression of PRINS regulates the expression and secretion of interleukin-6 (IL-6) and IL-8. In parallel to priming with 5 ng/ml tumor necrosis factor$\alpha$ and interferon- $\gamma$, normal human epidermal keratinocytes were transfected with a pcDNA3.1(+) vector containing the PRINS cDNA; an empty pcDNA3.1(+) vector was used as control. After $24 \mathrm{~h}$, cells were transfected with poly(dA:dT). RNA expression of cytokines IL-6 (A) and IL-8 (B) was detected by real-time RT-PCR. Secretion of cytokines IL-6 (C) and IL-8 (D), was detected by ELISA from cell supernatants. Data are presented as mean \pm SE of four independent experiments $\left({ }^{*} p \leq 0.05 ;{ }^{* *} p \leq 0.01\right)$.

To study keratinocyte immune functions, we applied a treatment with the cytosolic DNA-analog poly(dA:dT), which was reported to induce inflammasome activation in these cells $(3,28)$ and induce the expression of several cytokines through a RIG-Idependent mechanism in professional immune cells (29). Before poly(dA:dT) treatment, a priming with the cytokines TNF- $\alpha$ and IFN- $\gamma$ was applied, which were described to be key elements in keratinocyte immune responses (30) and induce a pronounced inflammasome activation (4). Our results are in agreement with recent reports describing inflammasome activation in keratinocytes $(3,4,28)$ and IL- 6 , IL- 8 , and TNF- $\alpha$ induction in canine keratinocytes (6) and human melanocytes (31) upon poly(dA:dT) exposition. Priming induced significantly enhanced mRNA expression of IL-6 and IL-8. In addition, cytokine secretion significantly increased compared to poly (dA:dT) treatment alone. In contrast to cytokine expression, poly(dA:dT) treatment decreased PRINS expression in NHEKs in line with previous reports in NHEKs and macrophages $(14,16)$.

PRINS was recently described to potentially interact with the CCL-5 mRNA (15), but its function remains to be elucidated. In this study, we demonstrate that PRINS overexpression decreases the expression of IL-6, IL-8, and CCL-5 in keratinocytes upon poly(dA:dT) treatment. In addition, decreased IL-6 expression was observed upon PRINS overexpression in UVB-treated samples as well (data not shown). Using in silico analysis, regions in the PRINS sequence were predicted to interact with CCL-5 and IL-6 mRNA. As inhibition of transcription by DNA:IncRNA triplex formation or posttranscriptional destabilization of the mRNA by mRNA-lncRNA duplex formation has been reported (25), we analyzed the sequences and found that the interacting site on IL-6 spans two exons, indicating an mRNA-lncRNA interaction. Moreover, PRINS demonstrated perinuclear localization in keratinocytes (32), making it possible to exert its effect at the posttranscriptional level. The mRNA-lncRNA interaction was validated in vitro: PRINS showed a very high binding affinity $(\mathrm{Kd}=10.3436 \mathrm{nM})$ to IL-6 mRNA, and the destruction of the predicted binding site abolished the ability of PRINS to bind to the IL- 6 mRNA. The binding site of PRINS lies within the $5^{\prime}$ UTR of the IL- 6 mRNA, which is a rare phenomenon. The majority ( $40 \%)$ of lncRNAs bind to the $3^{\prime}$ UTR of their target mRNAs, while only around $5 \%$ of lncRNAs is able to bind to the $5^{\prime}$ UTR of their target (33). The functionality of the mRNA-lncRNA interaction was also observed at the cellular level, as overexpression of $\triangle$ PRINS, in which the IL-6 interacting site is scrambled, did not decrease IL-6 levels. Thus, we demonstrated that PRINS is able to bind the IL- 6 mRNA and this specific interaction destabilizes IL-6 expression and secretion in NHEKs.

Similar to IL-6, PRINS overexpression decreased the expression of IL-8, but no interaction site could be predicted. We hypothesize that this is a secondary effect (34); however, we cannot exclude the possibility of a yet unknown interaction site between PRINS and IL-8 mRNA. 

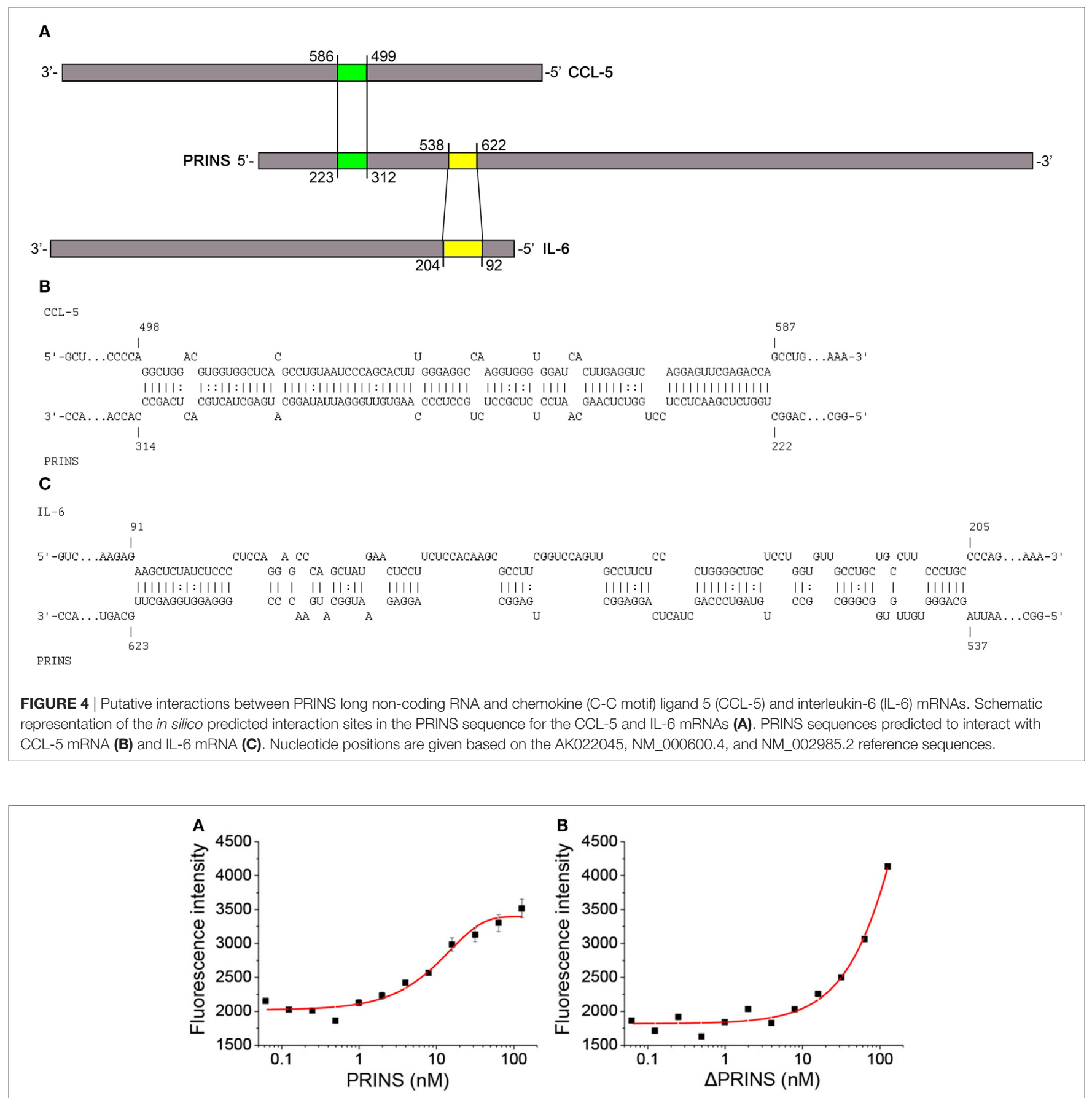

FIGURE 5 | PRINS specifically binds to interleukin-6 (IL-6) mRNA. The binding affinity of PRINS (A) and $\triangle$ PRINS (B) to IL-6 mRNA was determined by analyzing the initial fluorescence enhancement caused by specific binding. The concentration of labeled IL-6 mRNA was constant (10 nM), while the concentration of PRINS and $\triangle$ PRINS varied from $62 \mathrm{pM}$ to $127 \mathrm{nM}$.

Many lncRNAs which were reported to regulate mRNA expression were found to act as primary transcripts for miRNAs (35). We have found no evidence that PRINS is cleaved to smaller miRNA precursors, but the IL-6 binding site of PRINS is $96 \%$ similar to the miR5585, which is predicted by TargetMiner to have IL-6 mRNA as a target (36). miR5585 is located on Chromosome 7, whereas PRINS is located on Chromosome 10, so their high similarity and overlapping functions might originate from gene duplication.

Like many other non-coding RNAs, PRINS seems to have multiple cellular functions (37). It binds to nucleophosmin, a chaperon protein, and facilitates its transition from the nucleolus to the nucleoplasm upon UVB irradiation (32). Additionally, our recent results suggest that PRINS is involved with inflammation 

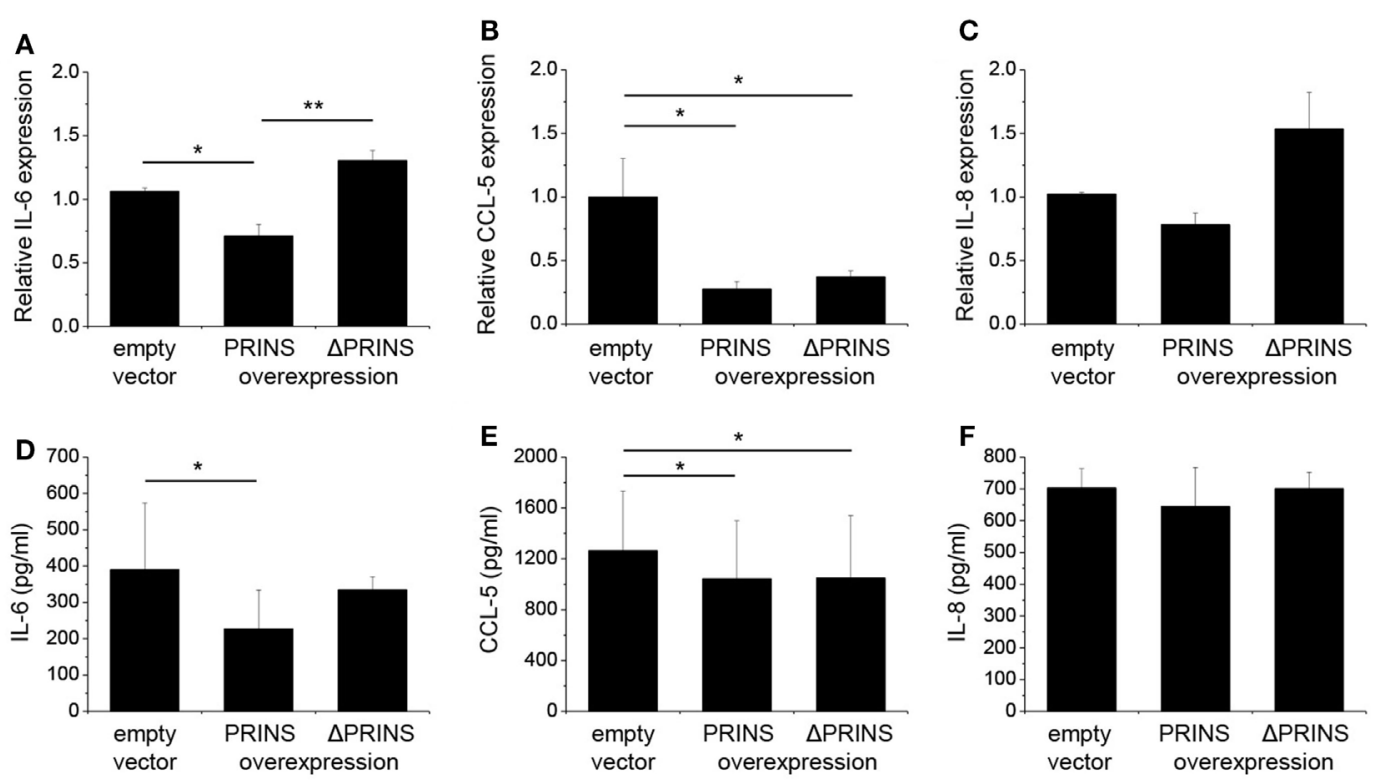

FIGURE 6 | The 538-622 nt region of PRINS is required for the regulation of interleukin-6 (IL-6) expression. In parallel to priming with 5 ng/ml tumor necrosis factor- $\alpha$ and interferon- $\gamma$, normal human epidermal keratinocytes were transfected with a pcDNA3.1(+) vector containing the PRINS cDNA or the $\Delta$ PRINS cDNA (containing a scrambled version of the IL-6 binding site at positions 538-622 nt); the empty pcDNA3.1(+) vector served as control, after 24 hours cells were transfected by poly(dA:dT). Expression of cytokines IL-6 (A), CCL-5 (B), and IL-8 (C) was detected by real-time RT-PCR. Secretion of cytokines IL-6 (D), CCL-5 (E), and IL-8 (F) was detected by ELISA from cell supernatants. Nucleotide positions based on the AK022045 reference sequence. Data are presented as mean \pm SE of three independent experiments $\left({ }^{*} p \leq 0.05 ;{ }^{* *} p \leq 0.01\right)$.

by inhibiting cytokine expression. Based on our current and previous findings (13-15), we hypothesize that elevated PRINS expression in psoriatic uninvolved epidermis may contribute to downregulation of the inflammatory functions in psoriatic keratinocytes and maintenance of normal phenotype.

Our studies were performed using a non-professional immune cell type, keratinocytes; however, the same mechanisms might be also relevant in professional immune cells. Further studies on the same PRINS-related cellular events upon additional stressors such as UVB or microbial components may widen our knowledge on the cellular functions of PRINS and, in general, about lncRNAs.

\section{AUTHOR CONTRIBUTIONS}

JD and MS designed the study, JD and AG prepared laboratory work and analyzed the data. DJ, AG, ZB-C, LK, and MS interpreted

\section{REFERENCES}

1. Luff JA, Yuan H, Kennedy D, Schlegel R, Felsburg P, Moore PF. Keratinocyte antiviral response to poly(dA:dT) stimulation and papillomavirus infection in a canine model of X-linked severe combined immunodeficiency. PLoS One (2014) 9:e102033. doi:10.1371/journal.pone.0102033

2. Suspène R, Mussil B, Laude H, Caval V, Berry N, Bouzidi MS, et al. Selfcytoplasmic DNA upregulates the mutator enzyme APOBEC3A leading to chromosomal DNA damage. Nucleic Acids Res (2017) 45:3231-41. doi:10.1093/nar/gkx001

3. Dombrowski Y, Peric M, Koglin S, Kammerbauer C, Göss C, Anz D, et al. Cytosolic DNA triggers inflammasome activation in keratinocytes in the data and drafted the manuscript. All authors approved the final version.

\section{FUNDING}

This work was supported by the National Research Development and Innovation Office [K105985 to MS, K111885 to ZB-C and GINOP-2.3.2-15-2016-00015]. JD was supported by the NTP-NFTÖ-17 project by the Hungarian Ministry of Human Capacities.

\section{SUPPLEMENTARY MATERIAL}

The Supplementary Material for this article can be found online at http://journal.frontiersin.org/article/10.3389/fimmu.2017.01053/ full\#supplementary-material.

psoriatic lesions. Sci Transl Med (2011) 3:82ra38. doi:10.1126/scitranslmed. 3002001

4. Göblös A, Danis J, Vas K, Bata-Csörgő Z, Kemény L, Széll M. Keratinocytes express functional CARD18, a negative regulator of inflammasome activation, and its altered expression in psoriasis may contribute to disease pathogenesis. Mol Immunol (2016) 73:10-8. doi:10.1016/j.molimm.2016.03.009

5. Prens EP, Kant M, van Dijk G, van der Wel LI, Mourits S, van der Fits L. IFN-alpha enhances poly-IC responses in human keratinocytes by inducing expression of cytosolic innate RNA receptors: relevance for psoriasis. J Invest Dermatol (2008) 128:932-8. doi:10.1038/sj.jid.5701087

6. Luff JA, Yuan H, Suter MM, Müller EJ, Schlegel R, Moore PF. Canine keratinocytes upregulate type I interferons and proinflammatory cytokines in response 
to poly(dA: dT) but not to canine papillomavirus. Vet Immunol Immunopathol (2013) 153:177-86. doi:10.1016/j.vetimm.2013.02.001

7. Lowes MA, Suárez-Fariñas M, Krueger JG. Immunology of psoriasis. Annu Rev Immunol (2014) 32:227-55. doi:10.1146/annurev-immunol-032713-120225

8. Lande R, Gregorio J, Facchinetti V, Chatterjee B, Wang Y-H, Homey B, et al. Plasmacytoid dendritic cells sense self-DNA coupled with antimicrobial peptide. Nature (2007) 449:564-9. doi:10.1038/nature06116

9. Tsoi LC, Iyer MK, Stuart PE, Swindell WR, Gudjonsson JE, Tejasvi T, et al. Analysis of long non-coding RNAs highlights tissue-specific expression patterns and epigenetic profiles in normal and psoriatic skin. Genome Biol (2015) 16:24. doi:10.1186/s13059-014-0570-4

10. Li B, Tsoi LC, Swindell WR, Gudjonsson JE, Tejasvi T, Johnston A, et al. Transcriptome analysis of psoriasis in a large case-control sample: RNAseq provides insights into disease mechanisms. J Invest Dermatol (2014) 134:1828-38. doi:10.1038/jid.2014.28

11. Sonkoly E, Wei T, Janson PCJ, Sääf A, Lundeberg L, Tengvall-Linder M, et al. MicroRNAs: novel regulators involved in the pathogenesis of psoriasis? PLoS One (2007) 2:1-8. doi:10.1371/journal.pone.0000610

12. Maass PG, Luft FC, Bähring S. Long non-coding RNA in health and disease. J Mol Med (2014) 92:337-46. doi:10.1007/s00109-014-1131-8

13. Sonkoly E, Bata-Csörgő Z, Pivarcsi A, Polyánka H, Kenderessy-Szabó A, Molnár $G$, et al. Identification and characterization of a novel, psoriasis susceptibility-related noncoding RNA gene, PRINS. J Biol Chem (2005) 280:24159-67. doi:10.1074/jbc.M501704200

14. Bari L, Bacsa S, Sonkoly E, Bata-Csörgő Z, Kemény L, Dobozy A, et al. Comparison of stress-induced PRINS gene expression in normal human keratinocytes and HaCaT cells. Arch Dermatol Res (2011) 303:745-52. doi:10.1007/ s00403-011-1162-8

15. Yu T-M, Palanisamy K, Sun K-T, Day Y-J, Shu K-H, Wang I-K, et al. RANTES mediates kidney ischemia reperfusion injury through a possible role of HIF$1 \alpha$ and LncRNA PRINS. Sci Rep (2016) 6:18424. doi:10.1038/srep18424

16. Pawar K, Hanisch C, Palma Vera SE, Einspanier R, Sharbati S. Down regulated lncRNA MEG3 eliminates mycobacteria in macrophages via autophagy. Sci Rep (2016) 6:19416. doi:10.1038/srep19416

17. Ouwehand K, Spiekstra SW, Waaijman T, Breetveld M, Scheper RJ, de Gruijl TD, et al. CCL5 and CCL20 mediate immigration of Langerhans cells into the epidermis of full thickness human skin equivalents. Eur J Cell Biol (2012) 91:765-73. doi:10.1016/j.ejcb.2012.06.004

18. de Groot M, Teunissen MBM, Ortonne JP, Lambert JR, Naeyaert JM, Picavet DI, et al. Expression of the chemokine receptor CCR5 in psoriasis and results of a randomized placebo controlled trial with a CCR5 inhibitor. Arch Dermatol Res (2007) 299:305-13. doi:10.1007/s00403-007-0764-7

19. Giustizieri ML, Mascia F, Frezzolini A, De Pità O, Chinni LM, Giannetti A, et al. Keratinocytes from patients with atopic dermatitis and psoriasis show a distinct chemokine production profile in response to $\mathrm{T}$ cellderived cytokines. J Allergy Clin Immunol (2001) 107:871-7. doi:10.1067/ mai.2001.114707

20. Wenzel A, Akbasli E, Gorodkin J. RIsearch: fast RNA-RNA interaction search using a simplified nearest-neighbor energy model. Bioinformatics (2012) 28:2738-46. doi:10.1093/bioinformatics/bts519

21. Smith C, Heyne S, Richter AS, Will S, Backofen R. Freiburg RNA tools: a web server integrating INTARNA, EXPARNA and LOCARNA. Nucleic Acids Res (2010) 38:W373-7. doi:10.1093/nar/gkq316

22. Busch A, Richter AS, Backofen R. IntaRNA: efficient prediction of bacterial sRNA targets incorporating target site accessibility and seed regions. Bioinformatics (2008) 24:2849-56. doi:10.1093/bioinformatics/btn544
23. Wright PR, Georg J, Mann M, Sorescu DA, Richter AS, Lott S, et al. CopraRNA and IntaRNA: predicting small RNA targets, networks and interaction domains. Nucleic Acids Res (2014) 42:W119-23. doi:10.1093/nar/gku359

24. Derrien T, Johnson R, Bussotti G, Tanzer A, Djebali S, Tilgner H, et al. The GENCODE v7 catalog of human long noncoding RNAs: analysis of their gene structure, evolution, and expression. Genome Res (2012) 22:1775-89. doi:10.1101/gr.132159.111

25. Kung JTY, Colognori D, Lee JT. Long noncoding RNAs: past, present, and future. Genetics (2013) 193:651-69. doi:10.1534/genetics.112.146704

26. Heward JA, Lindsay MA. Long non-coding RNAs in the regulation of the immune response. Trends Immunol (2014) 35:408-19. doi:10.1016/j. it.2014.07.005

27. Széll M, Danis J, Bata-Csörgő Z, Kemény L. PRINS, a primate-specific long non-coding RNA, plays a role in the keratinocyte stress response and psoriasis pathogenesis. Pflügers (2016) 468:935-43. doi:10.1007/s00424-016-1803-Z

28. Kopfnagel V, Wittmann M, Werfel T. Human keratinocytes express AIM2 and respond to dsDNA with IL-1 $\beta$ secretion. Exp Dermatol (2011) 20:1027-9. doi:10.1111/j.1600-0625.2011.01382.x

29. Ablasser A, Bauernfeind F, Hartmann G, Latz E, Fitzgerald KA, Hornung V. RIG-I dependent sensing of poly(dA-dT) via the induction of an RNA polymerase III transcribed RNA intermediate. Nat Immunol (2009) 10:1065-72. doi:10.1038/ni.1779

30. Szabó K, Bata-Csörgő Z, Dallos A, Bebes A, Francziszti L, Dobozy A, et al. Regulatory networks contributing to psoriasis susceptibility. Acta Derm Venereol (2014) 94:380-5. doi:10.2340/00015555-1708

31. Wang $\mathrm{S}$, Liu $\mathrm{D}$, Ning $\mathrm{W}, \mathrm{Xu} \mathrm{A}$. Cytosolic dsDNA triggers apoptosis and pro-inflammatory cytokine production in normal human melanocytes. Exp Dermatol (2015) 24:298-300. doi:10.1111/exd.12621

32. Szegedi K, Göblös A, Bacsa S, Antal M, Németh IB, Bata-Csörgő Z, et al. Expression and functional studies on the noncoding RNA, PRINS. Int J Mol Sci (2013) 14:205-25. doi:10.3390/ijms14010205

33. Szcześniak MW, Makałowska I. IncRNA-RNA interactions across the human transcriptome. PLoS One (2016) 11:e0150353. doi:10.1371/journal. pone. 0150353

34. Scheller J, Chalaris A, Schmidt-Arras D, Rose-John S. The pro- and anti-inflammatory properties of the cytokine interleukin-6. Biochim Biophys Acta (2011) 1813:878-88. doi:10.1016/j.bbamcr.2011.01.034

35. Gutschner T, Diederichs S. The hallmarks of cancer: a long non-coding RNA point of view. RNA Biol (2012) 9:703-19. doi:10.4161/rna.20481

36. Bandyopadhyay S, Mitra R. TargetMiner: microRNA target prediction with systematic identification of tissue-specific negative examples. Bioinformatics (2009) 25:2625-31. doi:10.1093/bioinformatics/btp503

37. Kapusta A, Feschotte C. Volatile evolution of long noncoding RNA repertoires: mechanisms and biological implications. Trends Genet (2014) 30:439-52. doi:10.1016/j.tig.2014.08.004

Conflict of Interest Statement: The authors declare that the research was conducted in the absence of any commercial or financial relationships that could be construed as a potential conflict of interest.

Copyright ( 2017 Danis, Göblös, Bata-Csörgö, Kemény and Széll. This is an openaccess article distributed under the terms of the Creative Commons Attribution License (CC BY). The use, distribution or reproduction in other forums is permitted, provided the original author(s) or licensor are credited and that the original publication in this journal is cited, in accordance with accepted academic practice. No use, distribution or reproduction is permitted which does not comply with these terms. 
III. 


\title{
PRINS, a primate-specific long non-coding RNA, plays a role in the keratinocyte stress response and psoriasis pathogenesis
}

\author{
Márta Széll $^{1,2}$ - Judit Danis ${ }^{3} \cdot$ Zsuzsanna Bata-Csörgö $^{2,3} \cdot$ Lajos Kemény $^{2,3}$
}

Received: 30 November 2015 / Accepted: 23 February 2016/Published online: 3 March 2016

(C) The Author(s) 2016. This article is published with open access at Springerlink.com

\begin{abstract}
In the last few years with the recent emergence of high-throughput technologies, thousands of long non-coding RNAs (lncRNAs) have been identified in the human genome. However, assigning functional annotation and determining cellular contexts for these RNAs are still in its infancy. As information gained about lncRNA structure, interacting partners, and roles in human diseases may be helpful in the characterization of novel lncRNAs, we review our knowledge on a selected group of IncRNAs that were identified serendipitously years ago by large-scale gene expression methods used to study human diseases. In particular, we focus on the Psoriasis-susceptibility-Related RNA Gene Induced by Stress (PRINS) lncRNA, first identified by our research group as a transcript highest expressed in psoriatic nonlesional epidermis. Results gathered for PRINS in the last 10 years indicate that it is conserved in primates and plays a role in keratinocyte stress response. Elevated levels of PRINS expression in psoriatic non-lesional keratinocytes alter the stress response of non-lesional epidermis and contribute to disease pathogenesis. Finally, we propose a categorization for the PRINS lncRNA based on a recently elaborated system for lncRNA classification.
\end{abstract}

Márta Széll

szell.marta@med.u-szeged.hu

1 Department of Medical Genetics, Faculty of Medicine, University of Szeged, SzegedSomogyi B. u. 4, 6720, Hungary

2 MTA-SZTE Dermatological Research Group, SzegedKorányi fasor 6, 6720, Hungary

3 Department of Dermatology and Allergology, Faculty of Medicine, University of Szeged, SzegedKorányi fasor 6, 6720, Hungary
Keywords Psoriasis $\cdot$ lncRNA $\cdot$ Keratinocyte stress response $\cdot$ PRINS $\cdot$ Primate specific

\section{Introduction}

One of the biggest surprises at the completion of the Human Genome Project [24] was the discovery of the low proteincoding capacity of the completed sequence: only approximately $2 \%$ of our genome encodes proteins, corresponding to roughly 20,000 genes. Is it a matter of wastefulness that "Mother Nature" maintains at least 234 genes (more than $1 \%$ of protein encoding genes) [41] to keep our genome in a good shape when only $2 \%$ of it has any meaning? Now, it is clear that this repair machinery is not working leanly, as approximately $80 \%$ of our DNA content is functional and most of it is transcribed into RNA [20, 22]. Understanding this only opened new questions: what is the function of this large amount of RNA? Will this understanding bring us closer to resolving questions about cell physiology? Moreover, will it bring new understanding of the still unknown mechanisms of genetically determined diseases that afflict us? Thanks to recently developed molecular biology tools, such as tiling array technologies [46] and RNA-Seq [13] as well as bioinformatics tools [8], we know that tens of thousands of functional RNA molecules are transcribed from our genome with varying length, genomic content, and functions. Concomitant with the growing number of characterized RNA molecules, the need for effective classification has increased. Although many attempts have been made to define subclasses of RNA function and various classification criteria have been proposed by multiple authors [62], RNA size has remained the primary aspect amenable for classification. From the start of the classification attempts, it was suspected that microRNAs (miRNAs, approximately 22 nucleotides in length) comprised 
a distinct class of molecules within non-coding RNAs. Now, it is clear that their function, as well as their size, distinguishes miRNA. To date (http://www.mirbase.org/cgi-bin/mirna summary.pl?org=hsa), 1881 distinct human miRNAs have been identified, and since 2001, extensive research has uncovered the function of many miRNAs in physiologically normal and disease conditions. miRNAs are known to be involved in the regulation of all aspects of intracellular events and the mechanism by which they act has been clarified [23].

The function of another distinct group, the long non-coding RNAs (lncRNA, $>200$ nucleotides), is not as well known. Thousands of lncRNAs have been identified in the recent years [74], and it is generally accepted that this group of RNAs has much more diverse functions than miRNAs.

Already at the beginning of the molecular biology revolution, it was relatively easy to identify protein-coding genes within human sequences by identifying open reading frames (ORF). No such sequence analysis tools are available for identifying non-coding genes. Since the 1990s, when the importance of IncRNAs was uncovered, many attempts have been made to develop computational approaches for identifying lncRNAs within the human genome $[25,75]$. Through the efforts of the GENCODE Project, a good estimate for the frequency, the structure, the evolution, and the expression of lncRNAs is available [17]. An analysis of lncRNA annotation by Darrien et al. (2012) concluded that the human genome includes approximately 14,000 lncRNA genes, a number that are much higher than those estimated for miRNA genes and relatively close to the number of protein-coding genes. Although much information has been gathered about the functions of proteins and miRNAs in health and in disease, we are still at the beginning of our journey in exploring the functions of IncRNAs.

\section{The great past and bright future of IncRNAs unexpectedly identified by large-scale gene expression experiments in human diseases}

In order to understand the functions of thousands of lncRNAs, we must characterize them one by one, understand their molecular and cellular contexts, and discover their contribution to human diseases. Before the "big boom" of omics research, sporadic reports of the identification and functional characterization of lncRNAs were available. Interestingly, most of these early reports came from attempts to identify differentially expressed transcripts in human diseases using relatively old-fashioned methods of large-scale gene expression, such as complementary DNA (cDNA) $\lambda$ phage library screening [16], cDNA subtractive hybridization [33], and differential display [61]. These studies identified the first lncRNAs, such as BC200, MALAT-1, PCGEM, and DD3. In subsequent systematic studies, much information has been gathered on structures, interaction partners, subcellular localizations, and functions of these lncRNAs. Moreover, data clearly indicated that these gene products might serve as novel diagnostic tools and therapeutic targets for treating human diseases. Clearly, lncRNA research is not just an "l'art pour l'art" activity of biomedical specialists but is expected to have clinical utility.

Two important lncRNAs early identified were $\mathrm{BC} 1$, a neuron-specific rodent lncRNA [16], and its human orthologue, BC200 [70]. The in-depth study of these two orthologues revealed interesting data on their functions, long before the upheaval brought by the advent of systematic largescale bioinformatics and next-generation techniques. These IncRNAs are expressed in neurons, specifically in the postsynaptic area of dendrites. Both gene products are part of a cytoplasmic ribonucleoprotein complex and bind to the poly(A)-binding protein (PABP) [43, 48]. PABP plays an important role in translation regulation in eukaryotic cells, along with translation factors, such as eIF4F, eRF3, and Paip proteins $[36,57]$. Furthermore, it has been also reported that $\mathrm{BC} 1$ and $\mathrm{BC} 200$ bind the fragile $\mathrm{X}$ mental retardation protein, the product of the FMRP disease-causing gene [79]. Dysfunction(s) of $\mathrm{BC} 1 / \mathrm{BC} 200-\mathrm{FMRP}$ binding leads to abnormal translation in the post-synaptic area and contributes to the phenotype seen in fragile X mental retardation syndrome [80]. BC1 and BC200 were the first lncRNAs to be used in knock-out experiments: BCI knock-out mice exhibited behavioral changes and shorter life spans compared to controls [45]. BC200 was also shown to have a role in aging and Alzheimer's disease: Mus et al. (2007) [50] have demonstrated that normal aging is associated with decreased BC200 expression in the brain, while BC200 expression was significantly upregulated in the brains of Alzheimer's patients, where abnormal localization to the perykarial region was observed. Under normal conditions, BC200 is expressed exclusively in neurons; however, BC200 was found to be expressed in human neoplasms [10]. Recently, De Leener et al. [15] proposed BC200 as a potential biomarker for diagnosing early-stage breast cancer.

BC200 is not the only early-identified lncRNA that holds promise as a diagnostic marker in human cancer. The prostatespecific PCGEM1 and DD3 lncRNAs were identified by differential display as early as 2000 [61]. PCGEM1 was found to have ethnic-specific expression, being much higher in the prostate epithelial cells of African-American prostate cancer patients compared to Caucasian patients. Moreover, PCGEM was found to be upregulated in normal prostates of individuals with relatives who had been diagnosed with prostate cancer. The pathogenic role of PCGEM1 in prostate cancer was further indicated by its ectopic expression in $\mathrm{LNCaP}$ and NIH3T3 cells, which resulted in hyperproliferation [53]. Some years later, PCGEM1 was patented as a promising biomarker for prostate cancer [32]. In a recent paper, it was suggested that PCGEM may serve as a reliable biomarker for the 
assessment of drug efficacy during prostate cancer treatment [29]. While PCGEM is expressed both in healthy and in diseased prostates, the DD3 lncRNA, identified in the same differential display experiment [61], exhibits strictly specific expression for prostate cancer, providing the possibility of developing a highly specific diagnostic tool for the disease. Based on this observation, Tinzl et al. (2004) [71] developed a nucleic acid-based diagnostic tool that can be used to detect DD3 lncRNA from urine with high specificity and sensitivity. The product, Progensa, has been on the market since 2011 [21]. In a recent advance, Ding et al. [19] developed an oncolytic viral vector, Ad.DD3.E1A.E1B( $\Delta 55)$-(PTEN), under the control of the prostate-specific DD3 promoter and proved its apoptotic effect in prostate cancer cell lines.

MALAT-1 lncRNA was first identified in a cDNA subtractive hybridization experiment from metastasizing lung adenocarcinoma in 2000 [33]. MALAT-1 is possibly the most extensively studied of the early-identified lncRNAs, as it is expressed in a wide range of tissue types and its overexpression has been detected in many human malignancies. Extensive studies have also shed light on the cellular function of MALAT-1: Hutchinson et al. (2007) [31] reported that MALAT-1 co-localizes with SC35 splicing domains, suggesting that MALAT-1 may be a component of the splicing machinery. Cis and trans regulatory factors for the localization of the MALAT-1 lncRNA to nuclear speckles have been identified [47]. Functional studies performed on cell lines from different types of human malignancies revealed that MALAT- 1 is indeed key for the maintenance of hyperproliferation and metastasizing potential $[26,34,56,69,76,77,81,83]$. In addition to being a promising biomarker for the diagnosis of a wide range of human malignancies, MALAT-1 proved to be a putative target for siRNA-mediated therapy, as recently demonstrated by Ren et al. [54].

Taken together, the above examples of lncRNAs demonstrate well that several gene products incidentally identified by large-scale gene expression studies have been scientifically and medically interesting, and their study has not only lead to a better understanding of human pathologies but has uncovered potential diagnostic tools and therapeutic targets. Next, we discuss the example of an IncRNA identified by differential display in a study of psoriasis. We describe its role in keratinocyte physiology and psoriasis pathogenesis.

\section{Identification of PRINS, an IncRNA involved in psoriasis pathogenesis}

Psoriasis, affecting approximately $2-4 \%$ of the population, is a classic multifactorial skin disease. The interplay of multigenic susceptibility as well as environmental and lifestyle factors leads to the development of symptoms, characterized by epidermal hyperproliferation and inflammation [18]. Intensive research of the last few decades revealed that abnormally functioning keratinocytes and skin-infiltrating professional immune cells are responsible for the disease phenotype [4-6]. As yet, it is still unknown whether abnormal keratinocyte functions of normal-appearing epidermis or aberrant lymphocyte activation is the primary trigger for development of the disease. Accumulating evidence suggests that altered skin tissue homeostasis, especially keratinocyte-specific alterations of the normal-appearing skin of psoriatic patients, is key in the initiation of the disease phenotype. The "immune era" of psoriasis research unquestionably brought breakthroughs for new, targeted therapies of the disease [28]. Nonetheless, to identify novel targets for intervention and possibly for prevention, we must understand the role of aberrant keratinocyte function in the course of the disease.

To this end, the aim of our workgroup is to identify and characterize abnormal molecular patterns in non-lesional psoriatic keratinocytes contributing to the initiation of the disease phenotype and factors that make these keratinocytes prone to respond with hyperproliferation to cytokines produced by skin-infiltrating lymphocytes. We previously performed a differential display experiment to compare gene expression in non-lesional psoriatic epidermis and control healthy epidermis. In 2000, several differentially expressed protein-coding transcripts in the psoriatic non-lesional epidermis were identified, and of these, we focused on the expression of EDA+ fibronectin. We were first to demonstrate that, upon cytokine induction, keratinocytes of the non-lesional epidermis are able to produce this form of cellular fibronectin and, thus, maintain an autocrine loop resulting in keratinocytes hyperproliferation [66]. This finding confirmed our a priori hypothesis that not only professional immune cells, but also keratinocyte-derived factors contribute to disease susceptibility.

In addition to protein-coding transcripts differentially expressed in psoriatic non-lesional epidermis, we also identified a transcript that was unlikely to encode a protein but, nevertheless, exhibited $100 \%$ sequence identity to the $3^{\prime}$ end of a cDNA (GenBank accession number AK022045) previously identified in a cDNA library derived from a 10-weekold human embryo. In parallel with sequence similarity searches, in vitro experiments were performed to determine the expression pattern of the identified transcript during proliferation and differentiation of keratinocytes. The highest expression of the non-coding RNA was found in serum-starved, contact-inhibited keratinocytes as well as in these cells immediately after serum re-addition; however, when the cells began to proliferate, the expression of the AK022045 transcript dropped dramatically. With this compelling result, we decided to turn our focus to the in-depth characterization of this transcript, and since then, we have been engaged in parallel but manifold interconnected characterization of its role in psoriasis and in keratinocyte stress response. 
Extensive sequence similarity searches and the determination of the $5^{\prime}$ end of the transcript allowed us to draw a putative structure for the newly identified gene. The full-length transcript is $3.6 \mathrm{~kb}$, and a putative TFIIB transcription factor binding site was identified in the genomic sequence proximal to the putative transcription start site. The transcript contains two exons, both harboring Alu elements, and shows a high degree of similarity to a heat shock element in a small non-coding RNA, G8. Based on these findings, we supposed that this transcript is an lncRNA and named it Psoriasissusceptibility-Related RNA Gene Induced by Stress (PRINS). The full-length sequence is available to the scientific community (http://www.ncbi.nlm.nih.gov/gene/?term= PRINS[sym]) [58].

By using quantitative real-time PCR (Q-RT-PCR) [58] and in situ hybridization (ISH) methods [65], PRINS expression was determined in human tissue types. These two experimental approaches revealed that PRINS expression varied in different human tissue types: the highest level of expression was observed in the veins, high levels were found in tissues derived from female and male gonads and lung, moderate expression was detected in tissue types derived from the gastrointestinal tract, and no apparent expression was present in the brain. Both ISH and Q-RT-PCR revealed a relatively high level of basal PRINS expression in healthy epidermis.

The contribution of PRINS to the pathogenesis of psoriasis susceptibility was further indicated in experiments of organotypic skin cultures. Organotypic skin cultures from healthy volunteers and from the non-lesional skin of psoriatic patients were co-incubated with a T cell lymphokine mix previously shown to induce the proliferation of non-lesional psoriatic epidermal keratinocytes but not keratinocytes derived from normal healthy epidermis $[5,6]$. PRINS expression differed in the two systems: while the treatment decreased PRINS expression in the non-lesional psoriatic epidermis, it was unchanged in the normal healthy epidermis. This result suggested that PRINS may contribute to psoriasis susceptibility as a modifier gene and may be part of the inherently altered molecular network of non-lesional epidermal keratinocytes contributing to disease pathogenesis [58].

To identify PRINS interacting partners and targets, in vitro binding assays [65] and cDNA microarray experiments [64] were performed. In the latter, PRINS expression was silenced in keratinocytes and the genes with altered expressions were studied in detail. G1P3, one of the identified genes to be under the control of PRINS, had been previously shown to play a pathogenic role in human malignancies with anti-apoptotic effects, and it is regulated by interferon- $\alpha[11,67]$. These two features of G1P3 are also important in psoriasis pathogenesis $[40,52]$. We found that the mRNA expression of PRINSregulated G1P3 was upregulated 400-fold in lesional and 9fold in non-lesional psoriatic epidermis, compared to healthy epidermis. In vitro experiments revealed that the down- regulation of G1P3 inhibited the spontaneous apoptosis of keratinocytes, indicating that its high expression might contribute to the altered apoptotic features of psoriatic keratinocytes and, thus, to disease pathogenesis. Taken together, these results indicate that the deregulation of the PRINS IncRNA contributes to psoriasis pathogenesis at least partially by altering the expression of G1P3 and leading to decreased sensitivity of keratinocytes toward spontaneous apoptosis [64]. In another set of experiments, an in vitro binding assay identified the nucleophosmin (NPM) protein as a direct interacting partner of the PRINS IncRNA. To determine whether this interaction had any relevance to psoriasis pathogenesis, the expression of NPM was studied in both healthy and psoriatic non-lesional epidermises. No apparent difference was found in the level or pattern of expression. Our finding was in agreement with a previous study examining nuclear staining for NPM in epithelial cells [7]. Additional evidence that NPM and the PRINS lncRNA might be direct interacting partners came from staining patterns in cultured keratinocytes: ISH staining of PRINS and immunohistochemical (IH) staining of NPM showed for both a predominant nuclear localization. In psoriatic lesional epidermis, however, the staining pattern of NPM was dramatically changed in the different layers of the epidermis: the highest level of NPM expression was found in basal and immediate suprabasal keratinocytes. Moreover, keratinocytes showing the highest level of NPM expression exhibited a marked cytoplasmic immunopositivity, revealing that, in keratinocytes of lesional psoriatic epidermis, both the level and the intracellular pattern of NPM expression were changed [65].

Thus, altered expression of proteins that are either interacting partners of PRINS or are under the control of PRINS indicates that, indeed, this lncRNA plays an important role in psoriasis and that, by altering normal keratinocyte function(s), it contributes to disease pathogenesis.

\section{The role of PRINS in keratinocyte stress response}

The first outstanding finding about the possible cellular functions of PRINS was the contrast between the high expression found in serum-starved, contact-inhibited keratinocytes and the very low levels of expression in highly proliferating keratinocytes [58], suggesting that PRINS may have a key role in the keratinocyte stress response. To test this, the survival of keratinocytes was studied during down-regulation of PRINS. No effects of PRINS down-regulation were found on the survival of keratinocytes under favorable culturing conditions; however, when serum was withdrawn from the PRINS down-regulated keratinocytes, the survival rate decreased significantly. This result confirmed that elevated PRINS expression in stressed keratinocytes is not an epiphenomenon but that, indeed, this lncRNA contributes to the cellular stress 
response. Further in vitro experiments revealed that other stress factors, including microbial components (viral and bacterial), translation inhibition with cyclohexamide, and UV-B irradiation, are able to induce high-level PRINS expression in keratinocytes. The UV-B results were especially intriguing, since the PRINS interaction partner NPM has a welldocumented role in cellular UV-B response: the predominantly nucleolar localization of NPM is changed upon UV-B irradiation in fibroblasts, and in cancer cells [44, 78], translocation to the nucleoplasm and, to some extent, to the cytoplasm occurs. In vitro experiments were performed to determine whether the same phenomenon occurs in epidermal keratinocytes and whether PRINS has any role in it. PRINS expression was down-regulated in UV-B-irradiated keratinocytes, and intracellular re-distribution of NPM occurred subsequently. Thus, NPM was localized to the nucleus in keratinocytes in which PRINS was down-regulated, indicating that PRINS physically interacted with NPM as well as functionally regulated NPM in this cellular stress response [65]. Taken together, our in vitro results suggested that PRINS IncRNA contributes to both stress responses and apoptosis signaling in keratinocytes, and relevantly, its role in psoriasis pathogenesis involves altering these pathways.

Nuclear factor kappa B (NF-kB) signaling is known to be altered in psoriatic keratinocytes [73], and this may be a link between $\mathrm{T}$ cell-mediated and keratinocyte-mediated processes in disease pathogenesis. To determine whether PRINS has a role in NF- $\mathrm{KB}$ signaling, PRINS expression was altered in keratinocytes and the activity of the NF- $\mathrm{KB}$ pathway was examined after lipopolysaccharide (LPS) induction and priming with psoriasis-related cytokines and detected using a luciferase-based approach. LPS induction of the NF-KB pathway is well known [49], and it has been shown that LPS can upregulate the expression of PRINS in keratinocytes. Neither the down-regulation [3] nor the robust upregulation [14] of PRINS had an effect on NF-kB activity, indicating that PRINS is not involved in this signaling pathway in keratinocytes, although other influences were not excluded.

We are currently working on identifying the signaling pathways in keratinocytes by which PRINS affects cell functions and contributes to disease pathogenesis in psoriasis.

\section{Classification of PRINS, a novel non-coding RNA conserved in primates}

In the 1990s and early 2000s - when lncRNAs were identified accidently rather than by systematic search - the need to classify non-coding RNAs was not particularly compelling. Although the reports of novel lncRNAs caught the interest of the scientific community at scientific meetings, the general response was to consider them too eccentric to be taken seriously. However, this attitude has dramatically changed in the last few years as a result of two developments: on one hand, a large body information about IncRNAs has accumulated from large-scale gene expression studies in the last 15-20 years [35], and on the other hand, thousands of novel human IncRNA genes have been identified using high-throughput methods in the last few years [27]. Systematic annotation of these newly identified lncRNA transcripts was necessary to aid researchers in their search of the understanding the functions of lncRNAs.

In the last few years, several attempts have been made to address this need, resulting in a rather complicated system for categorizing aspects [62] as well as an "easier-to-follow" system for categorizing lncRNAs [38]. The varying-and we believe - still evolving taxonomy of lncRNA reflects the novelty of the field.

To provide a guide to the IncRNA classification suggested by Kapusta et al. [38], we use this system to apply an initial classification for the PRINS IncRNA.

According to the Kapusta classification, the first aspect to consider when categorizing an IncRNA is its genomic context. The first report of PRINS IncRNA [58] provided its location to be on the short arm of human chromosome 10 (map position 10p12.31) and indicated that it is composed of two exons and an intron of approximately $7 \mathrm{~kb}$ in length. The entire PRINS IncRNA resides in an intron of the recently annotated KIAA1217 gene, also known as SKT, which is involved in early stages of embryogenesis [63]. Proximal to KIAA1217 is the OUT deubiquitinase 1 gene, whereas distal to KIAA1217 is the Rho GTPase-activating protein 21 . Interestingly, the miR603 miRNA is located in a KIAA1217 intron, $3^{\prime}$ of the PRINS coding region.

The second aspect to consider when categorizing an lncRNA is its chromatin context. A transcription start site was identified $6 \mathrm{~kb}$ proximal to the putative $5^{\prime}$ end of the PRINS gene using the ENCODE database. This region is marked by a high density of binding sites for several transcription factors, including GATA2, Fos, HDAC2 and STAT3, and histone modification sites associated with active transcription, such as mono- and tri-methylation of lysine 4 of histone $\mathrm{H} 3$ (H3K4me1/3) and acetylation of lysine 9 and 27 (H3K9Ac, $\mathrm{H} 3 \mathrm{~K} 27 \mathrm{Ac}$ ), suggesting that a strongly regulated active promoter might be associated with the lncRNA. The region adjacent to the 3' end of the PRINS IncRNA gene also contains histone modification sights, which, due to the close 3' proximity to the PRINS lncRNA gene, might be an enhancer element. Of all cells examined to date, the highest signals were found in normal human keratinocytes, indicating that the PRINS IncRNA is indeed expressed in keratinocytes and its expression is regulated by epigenetic factors.

The third and possibly most informative aspect to consider is the subcellular localization of the lncRNA. From our experimental results, we found that the PRINS IncRNA is mainly localized in the nucleolus of normal human cultured 
keratinocytes, although moderate perinuclear and cytoplasmic expression was also detected. This is in good agreement with reports that non-coding RNAs localize mainly to the nucleus [37], which suggests a role in the temporal-spatial regulation of nuclear organization and/or regulation of gene expression. The intracellular localization of the NPM protein, which was identified to be physically and functionally interacting with PRINS, is indicative of a nucleolar/nuclear role for PRINS. As early as 1984 [60], NPM was reported to be localized in the nucleolus and shown to shuttle between the nucleolus and the cytoplasm [9]. As both NPM [2] and PRINS [68] demonstrate strict regulation during cell growth and during cellular stress response and, additionally, have functionally overlapping features during these processes [65], we postulate that, indeed, these two molecules interact in these processes.

Since sequence conservation of lncRNAs is rare, it is assumed that their biological activities are dependent on structure. The putative secondary structure of the PRINS lncRNA was determined from the primary sequence by computational prediction (Fig. 1a). In addition to strong structural features, the PRINS sequence might also determine its cellular localization, as it includes the AGCCC pentamer with the sequence restrictions at positions -8 ( $\mathrm{T}$ or $\mathrm{A})$ and $-3(\mathrm{G}$ or $\mathrm{C})$ of a motif which was reported to be crucial for nuclear localization of IncRNAs [82]. Our ISH results are in good agreement with this sequence-based analysis, as the highest level of PRINS expression was detected in the nucleolus of keratinocytes, with moderate staining in the nucleoplasm and the cytoplasm.

Intriguingly, the PRINS IncRNA sequence contains three Alu elements. It is well established that transposable elements (TEs) have been very important in the evolution of IncRNAs [39]. According to some estimates, approximately two thirds of functioning human lncRNAs contain at least one TEderived element, which are seldom found in protein-coding genes. These elements very often make up a relatively large portion of the lncRNA genes [42]. This is also true for the PRINS IncRNA, which contains three Alu elements comprising approximately one third of its sequence (Fig. 1b). The possible contribution of TE elements to lncRNA evolution and function is extensively reviewed by Kapusta et al. [38].
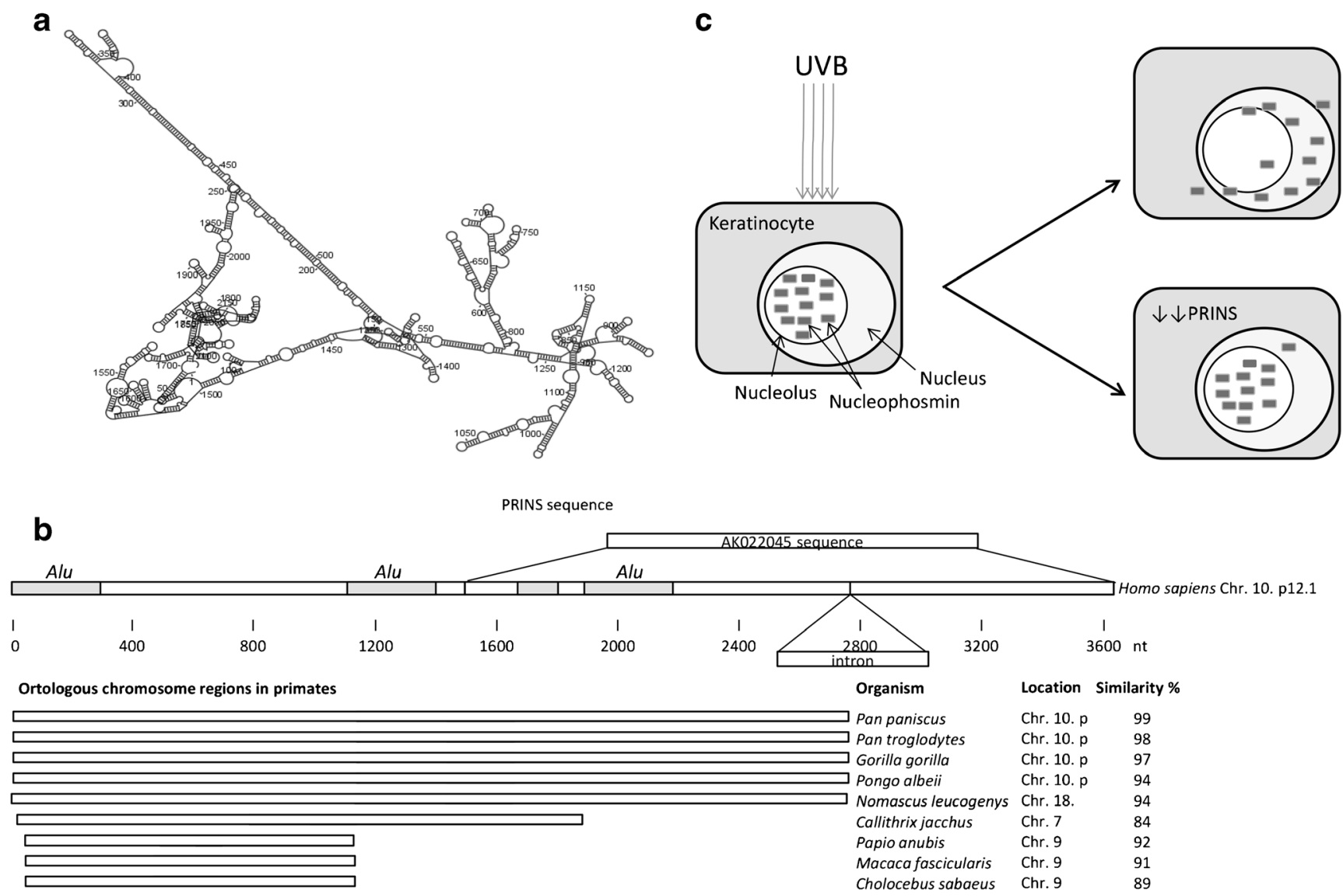

Fig. 1 Major characteristics of the PRINS lncRNA. a Putative secondary structure of the PRINS IncRNA. b Similarity search identified three Alu elements within the PRINS lncRNA sequence. The PRINS gene is localized on the p12.1 arm of human Chr. 10, which is highly conserved in human and four other primate species. Although partial sequence similarity was found, it is largely due to the conservation of
Alu elements. In other primate species, the PRINS sequence was distributed on other chromosomes. c UVB irradiation induces the shuttling of nucleophosmin (NPM) from the nucleolus to the nucleoplasm. Silencing of the PRINS lncRNA, which physically interacts with NPM, results in the retention in the nucleolus 
It has been estimated that only $21 \%$ of known lncRNAs occurring in primates have orthologues in other orders and only $3 \%$ of the primate lncRNAs have an orthologue in tetrapods [51]. The results obtained with the PRINS IncRNA sequence agree well with these estimates, in that it could be found only in the genomes of primates with variations in the extent of similarity (Fig. 1b). PRINS and the orthologues with the highest similarity among primate species reside on the short arm of chromosome 10. Taken together, these data suggest that the PRINS IncRNA gene is most probably a primatespecific sequence and transposition was the major mechanism of its origin.

As many lncRNAs serve as sources for miRNAs [55], it was interesting to examine the PRINS lncRNA for miRNA pre-sequences. However, no pre-miRNA sequences were identified using the ever-growing mirbase database (http:// www.mirbase.org/). It is interesting to note, however, that the intron in which the PRINS IncRNA is located harbors a miRNA. Analysis of miRNA harboring lncRNAs has shown it to be an evolutionary conserved group [12]. Thus, as PRINS is a primate-specific lncRNA, it is not surprising that it does not harbor any miRNA sequences.

The final criterion for classifying lncRNAs is the most challenging: function. However, this aspect is the most likely to advance the understanding of the role of lncRNAs in health and disease. Because the highest PRINS expression was observed in the nucleolus of normal human keratinocytes and the sequence contains a nuclear-specific motif, it is reasonable to assume its functions are in the nucleolus or nuclei. Our in vitro binding assays identified NPM as the most prominent interaction partner of PRINS, and the highest NPM expression was found in the nucleolus [60]. These results together with the results from the PRINS IHS and binding assay support the hypothesis that PRINS is a physical partner of NPM in the nucleolus and the complex formed by their binding contributes to the cellular stress response (Fig. 1c). Whether PRINS is interacting with proteins other than NPM and how it functions in concert with other keratinocyte-expressed lncRNAs [30] and/or miRNAs [59] are still challenging questions to answer. Moreover, the data cited above have been obtained from experiments performed in normal human keratinocytes and keratinocyte cell lines, leaving open the question whether PRINS is expressed with the same intracellular pattern and functions the same way in other cell types.

Together, the results from our experiments indicate that the evolutionarily young, primate-specific PRINS is one of the lncRNAs that is differentially expressed in psoriasis [72], that it plays a role in keratinocyte stress response, and that its elevated expression in psoriatic non-lesional epidermis contributes to the altered stress response of psoriatic keratinocytes and, thus, to disease pathogenesis. Psoriasis is a humanspecific multifactorial skin disease, which has not yet been identified in other primates. It remains to be determined whether any association exists between the primate/human lncRNAs and the special susceptibility to certain multifactorial diseases that exist only in humans.

\section{Conclusions}

There is no doubt that one of the greatest (and previously unforeseen) achievements of genome programs was the discovery of novel layers of cell regulation represented by lncRNAs. The importance of these transcripts is underscored by the fact that they are almost equal in number with proteincoding genes in the human genome [17]. We are still far from being able to comprehensively place these novel regulatory molecules into regulatory networks, similarly to what are currently known of protein-protein and proteinDNA interactions based on experimental data. A tremendous amount of experimental work, spanning decades, was necessary to gain sufficient information about individual proteins and DNA elements to describe these regulatory networks. Although highly developed in silico methods may speed this process for regulatory RNAs - including lncRNAs - it is reasonable to assume that, unless newly identified lncRNAs are experimentally characterized, it will not be possible to identify their cellular contexts. Classification of lncRNAs is crucial for their annotation, and information already available for the well-known, serendipitously identified lncRNAs is likely to have great importance in this work. According to some estimates, there are approximately 130 human IncRNAs extensively characterized to date [1] and they may serve well in the development of classification and annotation of thousands of identified but not yet characterized lncRNAs. In addition to understanding the cellular functions of these molecules, their contribution to human diseases will have to be elucidated, promising insights into the missing heritable and yet unrevealed mechanisms of human diseases.

Acknowledgments This study was financed by the National Research, Development and Innovation (NKFI) Fund, grant numbers OTKA K105985 and OTKA 5K321.

\section{Compliance with ethical standards}

Conflict of interest The authors declare that they have no conflict of interest.

Open Access This article is distributed under the terms of the Creative Commons Attribution 4.0 International License (http:// creativecommons.org/licenses/by/4.0/), which permits unrestricted use, distribution, and reproduction in any medium, provided you give appropriate credit to the original author(s) and the source, provide a link to the Creative Commons license, and indicate if changes were made. 


\section{References}

1. Amaral PP, Clark MB, Gascoigne DK, Dinger ME, Mattick JS (2011) lncRNAdb: a reference database for long noncoding RNAs. Nucleic Acids Res 39:D146-D151

2. Amin MA, Matsunaga S, Uchiyama S, Fukui K (2008) Depletion of nucleophosmin leads to distortion of nucleolar and nuclear structures in HeLa cells. Biochem J 415:345-351

3. Bari L, Bacsa S, Sonkoly E, Bata-Csorgo Z, Kemeny L et al (2011) Comparison of stress-induced PRINS gene expression in normal human keratinocytes and $\mathrm{HaCaT}$ cells. Arch Dermatol Res 303: 745-752

4. Bata-Csorgo Z, Szell M (2012) The psoriatic keratinocytes. Expert Rev Dermatol 7:473-481

5. Bata-Csorgo Z, Hammerberg C, Voorhees JJ, Cooper KD (1995) Kinetics and regulation of human keratinocyte stem cell growth in short-term primary ex vivo culture. Cooperative growth factors from psoriatic lesional $\mathrm{T}$ lymphocytes stimulate proliferation among psoriatic uninvolved, but not normal, stem keratinocytes. J Clin Invest 95:317-327

6. Bata-Csorgo Z, Cooper KD, Ting KM, Voorhees JJ, Hammerberg C (1998) Fibronectin and alpha5 integrin regulate keratinocyte cell cycling. A mechanism for increased fibronectin potentiation of $\mathrm{T}$ cell lymphokine-driven keratinocyte hyperproliferation in psoriasis. J Clin Investig 101:1509-1518

7. Beylot-Barry M, Lamant L, Vergier B, de Muret A, Fraitag S et al (1996) Detection of $\mathrm{t}(2 ; 5)(\mathrm{p} 23 ; \mathrm{q} 35)$ translocation by reverse transcriptase polymerase chain reaction and in situ hybridization in CD30-positive primary cutaneous lymphoma and lymphomatoid papulosis. Am J Pathol 149:483-492

8. Boley N, Stoiber MH, Booth BW, Wan KH, Hoskins RA et al (2014) Genome-guided transcript assembly by integrative analysis of RNA sequence data. Nat Biotechnol 32:341-346

9. Borer RA, Lehner CF, Eppenberger HM, Nigg EA (1989) Major nucleolar proteins shuttle between nucleus and cytoplasm. Cell 56: 379-390

10. Chen W, Bocker W, Brosius J, Tiedge H (1997) Expression of neural BC200 RNA in human tumours. J Pathol 183:345-351

11. Cheriyath V, Glaser KB, Waring JF, Baz R, Hussein MA et al (2007) G1P3, an IFN-induced survival factor, antagonizes TRAIL-induced apoptosis in human myeloma cells. J Clin Invest 117:3107-3117

12. Chodroff RA, Goodstadt L, Sirey TM, Oliver PL, Davies KE et al (2010) Long noncoding RNA genes: conservation of sequence and brain expression among diverse amniotes. Genome Biol 11:R72

13. Costa V, Aprile M, Esposito R, Ciccodicola A (2013) RNA-Seq and human complex diseases: recent accomplishments and future perspectives. Eur J Hum Genet 21:134-142

14. Danis J, Göblös A, Bata-Csörgő ZS, Kemény L, Széll M (2015) PRINS, the psoriasis susceptibility related non-coding RNA is involved in stress response of cells, but not in inflammasome activation. Immunol Szle 8(3):12

15. De Leeneer K, Claes K (2015) Non coding RNA molecules as potential biomarkers in breast cancer. Adv Exp Med Biol 867: 263-275

16. DeChiara TM, Brosius J (1987) Neural BC1 RNA: cDNA clones reveal nonrepetitive sequence content. Proc Natl Acad Sci U S A 84:2624-2628

17. Derrien T, Johnson R, Bussotti G, Tanzer A, Djebali S et al (2012) The GENCODE v7 catalog of human long noncoding RNAs: analysis of their gene structure, evolution, and expression. Genome Res 22:1775-1789

18. Di Meglio P, Villanova F, Nestle FO (2014) Psoriasis. Cold Spring Harb Perspect Med 4
19. Ding M, Cao X, Xu HN, Fan JK, Huang HL et al (2012) Prostate cancer-specific and potent antitumor effect of a DD3-controlled oncolytic virus harboring the PTEN gene. PLoS ONE 7, e35153

20. Djebali S, Davis CA, Merkel A, Dobin A, Lassmann T et al (2012) Landscape of transcription in human cells. Nature 489:101-108

21. Durand X, Moutereau S, Xylinas E, de la Taille A (2011) Progensa PCA3 test for prostate cancer. Expert Rev Mol Diagn 11:137-144

22. ENCODE Project Consortium (2012) An integrated encyclopedia of DNA elements in the human genome. Nature 489:57-74

23. Good L (2003) Translation repression by antisense sequences. Cell Mol Life Sci 60:854-861

24. Green ED, WATSON JD, Collins FS (2015) Human Genome Project: twenty-five years of big biology. Nature 526:29-31

25. Griffiths-Jones S, Moxon S, Marshall M, Khanna A, Eddy SR et al (2005) Rfam: annotating non-coding RNAs in complete genomes. Nucleic Acids Res 33:D121-D124

26. Guerrieri F (2015) Long non-coding RNAs era in liver cancer. World J Hepatol 7:1971-1973

27. Guo X, Gao L, Wang Y, Chiu DK, Wang T et al (2015) Advances in long noncoding RNAs: identification, structure prediction and function annotation. Brief Funct Genomics

28. Harden JL, Krueger JG, Bowcock AM (2015) The immunogenetics of psoriasis: a comprehensive review. J Autoimmun 64:66-73

29. Hirsch GE, Parisi MM, Martins LA, Andrade CM, Barbe-Tuana FM et al (2015) gamma-Oryzanol reduces caveolin-1 and PCGEM1 expression, markers of aggressiveness in prostate cancer cell lines. Prostate 75:783-797

30. Hombach S, Kretz M (2013) The non-coding skin: exploring the roles of long non-coding RNAs in epidermal homeostasis and disease. Bioessays 35:1093-1100

31. Hutchinson JN, Ensminger AW, Clemson CM, Lynch CR, Lawrence JB et al (2007) A screen for nuclear transcripts identifies two linked noncoding RNAs associated with SC35 splicing domains. BMC Genomics 8:39

32. Ifere GO, Ananaba GA (2009) Prostate cancer gene expression marker 1 (PCGEM1): a patented prostate- specific non-coding gene and regulator of prostate cancer progression. Recent Pat DNA Gene Seq 3:151-163

33. Ji P, Diederichs S, Wang W, Boing S, Metzger R et al (2003) MALAT-1, a novel noncoding RNA, and thymosin beta4 predict metastasis and survival in early-stage non-small cell lung cancer. Oncogene 22:8031-8041

34. Jiao F, Hu H, Yuan C, Wang L, Jiang W et al (2014) Elevated expression level of long noncoding RNA MALAT-1 facilitates cell growth, migration and invasion in pancreatic cancer. Oncol Rep 32: 2485-2492

35. Johnsson P, Lipovich L, Grander D, Morris KV (2014) Evolutionary conservation of long non-coding RNAs; sequence, structure, function. Biochim Biophys Acta 1840:1063-1071

36. Kahvejian A, Svitkin YV, Sukarieh R, M'Boutchou MN, Sonenberg N (2005) Mammalian poly(A)-binding protein is a eukaryotic translation initiation factor, which acts via multiple mechanisms. Genes Dev 19:104-113

37. Kapranov P, Cheng J, Dike S, Nix DA, Duttagupta R et al (2007) RNA maps reveal new RNA classes and a possible function for pervasive transcription. Science 316:1484-1488

38. Kapusta A, Feschotte C (2014) Volatile evolution of long noncoding RNA repertoires: mechanisms and biological implications. Trends Genet 30:439-452

39. Kapusta A, Kronenberg Z, Lynch VJ, Zhuo X, Ramsay L et al (2013) Transposable elements are major contributors to the origin, diversification, and regulation of vertebrate long noncoding RNAs. PLoS Genet 9, e1003470

40. Kastelan M, Prpic-Massari L, Brajac I (2009) Apoptosis in psoriasis. Acta Dermatovenerol Croat 17:182-186 
41. Kauffmann A, Rosselli F, Lazar V, Winnepenninckx V, Mansuet-Lupo A et al (2008) High expression of DNA repair pathways is associated with metastasis in melanoma patients. Oncogene 27:565-573

42. Kelley D, Rinn J (2012) Transposable elements reveal a stem cellspecific class of long noncoding RNAs. Genome Biol 13:R107

43. Khanam T, Muddashetty RS, Kahvejian A, Sonenberg N, Brosius J (2006) Poly(A)-binding protein binds to A-rich sequences via RNA-binding domains $1+2$ and 3+4. RNA Biol 3:170-177

44. Lee E, Koo J, Berger T (2005) UVB phototherapy and skin cancer risk: a review of the literature. Int J Dermatol 44:355-360

45. Lewejohann L, Skryabin BV, Sachser N, Prehn C, Heiduschka P et al (2004) Role of a neuronal small non-messenger RNA: behavioural alterations in BC1 RNA-deleted mice. Behav Brain Res 154: 273-289

46. Liu XS (2007) Getting started in tiling microarray analysis. PLoS Comput Biol 3:1842-1844

47. Miyagawa R, Tano K, Mizuno R, Nakamura Y, Ijiri K et al (2012) Identification of cis- and trans-acting factors involved in the localization of MALAT-1 noncoding RNA to nuclear speckles. RNA 18: 738-751

48. Muddashetty R, Khanam T, Kondrashov A, Bundman M, Iacoangeli A et al (2002) Poly(A)-binding protein is associated with neuronal $\mathrm{BC} 1$ and $\mathrm{BC} 200$ ribonucleoprotein particles. J Mol Biol 321:433-445

49. Muller JM, Ziegler-Heitbrock HW, Baeuerle PA (1993) Nuclear factor kappa B, a mediator of lipopolysaccharide effects. Immunobiology 187:233-256

50. Mus E, Hof PR, Tiedge H (2007) Dendritic BC200 RNA in aging and in Alzheimer's disease. Proc Natl Acad Sci U S A 104:10679-10684

51. Necsulea A, Soumillon M, Warnefors M, Liechti A, Daish T et al (2014) The evolution of IncRNA repertoires and expression patterns in tetrapods. Nature 505:635-640

52. Nestle FO, Conrad C, Tun-Kyi A, Homey B, Gombert M et al (2005) Plasmacytoid predendritic cells initiate psoriasis through interferon-alpha production. J Exp Med 202:135-143

53. Petrovics G, Zhang W, Makarem M, Street JP, Connelly R et al (2004) Elevated expression of PCGEM1, a prostate-specific gene with cell growth-promoting function, is associated with high-risk prostate cancer patients. Oncogene 23:605-611

54. Ren S, Liu Y, Xu W, Sun Y, Lu J et al (2013) Long noncoding RNA MALAT-1 is a new potential therapeutic target for castration resistant prostate cancer. J Urol 190:2278-2287

55. Rother S, Meister G (2011) Small RNAs derived from longer noncoding RNAs. Biochimie 93:1905-1915

56. Schmidt LH, Spieker T, Koschmieder S, Schaffers S, Humberg J et al (2011) The long noncoding MALAT-1 RNA indicates a poor prognosis in non-small cell lung cancer and induces migration and tumor growth. J Thorac Oncol 6:1984-1992

57. Sonenberg N, Dever TE (2003) Eukaryotic translation initiation factors and regulators. Curr Opin Struct Biol 13:56-63

58. Sonkoly E, Bata-Csorgo Z, Pivarcsi A, Polyanka H, KenderessySzabo A et al (2005) Identification and characterization of a novel, psoriasis susceptibility-related noncoding RNA gene, PRINS. J Biol Chem 280:24159-24167

59. Sonkoly E, Stahle M, Pivarcsi A (2008) MicroRNAs: novel regulators in skin inflammation. Clin Exp Dermatol 33:312-315

60. Spector DL, Ochs RL, Busch H (1984) Silver staining, immunofluorescence, and immunoelectron microscopic localization of nucleolar phosphoproteins B23 and C23. Chromosoma 90:139-148

61. Srikantan V, Zou Z, Petrovics G, Xu L, Augustus M et al (2000) PCGEM1, a prostate-specific gene, is overexpressed in prostate cancer. Proc Natl Acad Sci U S A 97:12216-12221

62. St Laurent G, Wahlestedt C, Kapranov P (2015) The landscape of long noncoding RNA classification. Trends Genet 31:239-251

63. Suda H, Lee KJ, Semba K, Kyushima F, Ando T et al (2011) The Skt gene, required for anorectal development, is a candidate for a molecular marker of the cloacal plate. Pediatr Surg Int 27: 269-273

64. Szegedi K, Sonkoly E, Nagy N, Nemeth IB, Bata-Csorgo Z et al (2010) The anti-apoptotic protein G1P3 is overexpressed in psoriasis and regulated by the non-coding RNA, PRINS. Exp Dermatol 19:269-278

65. Szegedi K, Goblos A, Bacsa S, Antal M, Nemeth IB et al (2012) Expression and functional studies on the noncoding RNA, PRINS. Int J Mol Sci 14:205-225

66. Szell M, Bata-Csorgo Z, Koreck A, Pivarcsi A, Polyanka H et al (2004) Proliferating keratinocytes are putative sources of the psoriasis susceptibility-related EDA (extra domain A of fibronectin) oncofetal fibronectin. J Investig Dermatol 123:537-546

67. Tahara E Jr, Tahara H, Kanno M, Naka K, Takeda Y et al (2005) G1P3, an interferon inducible gene 6-16, is expressed in gastric cancers and inhibits mitochondrial-mediated apoptosis in gastric cancer cell line TMK-1 cell. Cancer Immunol Immunother 54:729-740

68. Temesvári E (1996) Kontakt ekzema. Háziorvos Továbbképző Szemle 1:394-396

69. Tian Y, Zhang X, Hao Y, Fang Z, He Y (2014) Potential roles of abnormally expressed long noncoding RNA UCA1 and Malat-1 in metastasis of melanoma. Melanoma Res 24:335-341

70. Tiedge H, Chen W, Brosius J (1993) Primary structure, neuralspecific expression, and dendritic location of human BC200 RNA. J Neurosci 13:2382-2390

71. Tinzl M, Marberger M, Horvath S, Chypre C (2004) DD3PCA3 RNA analysis in urine - a new perspective for detecting prostate cancer. Eur Urol 46:182-186

72. Tsoi LC, Iyer MK, Stuart PE, Swindell WR, Gudjonsson JE et al (2015) Analysis of long non-coding RNAs highlights tissuespecific expression patterns and epigenetic profiles in normal and psoriatic skin. Genome Biol 16:24

73. Tsuruta D (2009) NF-kappaB links keratinocytes and lymphocytes in the pathogenesis of psoriasis. Recent Patents Inflamm Allergy Drug Discov 3:40-48

74. Volders P, Verheggen K, Menschaert G, Vandepoele K, Martens L et al (2015) An update on LNCipedia: a database for annotated human lncRNA sequences. Nucleic Acids Res 43:4363-4364

75. Washietl S, Pedersen JS, Korbel JO, Stocsits C, Gruber AR et al (2007) Structured RNAs in the ENCODE selected regions of the human genome. Genome Res 17:852-864

76. Xu C, Yang M, Tian J, Wang X, Li Z (2011) MALAT-1: a long noncoding RNA and its important 3 ' end functional motif in colorectal cancer metastasis. Int J Oncol 39:169-175

77. Ying L, Chen Q, Wang Y, Zhou Z, Huang Yet al (2012) Upregulated MALAT-1 contributes to bladder cancer cell migration by inducing epithelial-to-mesenchymal transition. Mol Biosyst 8:2289-2294

78. Yogev O, Saadon K, Anzi S, Inoue K, Shaulian E (2008) DNA damage-dependent translocation of B23 and p19 ARF is regulated by the Jun N-terminal kinase pathway. Cancer Res 68:1398-1406

79. Zalfa F, Giorgi M, Primerano B, Moro A, di Penta A et al (2003) The fragile $\mathrm{X}$ syndrome protein FMRP associates with $\mathrm{BC} 1 \mathrm{RNA}$ and regulates the translation of specific mRNAs at synapses. Cell 112:317-327

80. Zalfa F, Eleuteri B, Dickson KS, Mercaldo V, De Rubeis S et al (2007) A new function for the fragile $X$ mental retardation protein in regulation of PSD-95 mRNA stability. Nat Neurosci 10:578-587

81. Zhang ZJ, Tong YQ, Wang JJ, Yang C, Zhou GH et al (2011) Spaceflight alters the gene expression profile of cervical cancer cells. Chin J Cancer 30:842-852

82. Zhang B, Gunawardane L, Niazi F, Jahanbani F, Chen $X$ et al (2014) A novel RNA motif mediates the strict nuclear localization of a long noncoding RNA. Mol Cell Biol 34:2318-2329

83. Zhou S, Wang J, Zhang Z (2014) An emerging understanding of long noncoding RNAs in kidney cancer. J Cancer Res Clin Oncol 140:1989-1995 